University of South Florida

DIGITAL COMMONS

@ UNIVERSITY OF SOUTH FLORIDA
Digital Commons @ University of

South Florida

$12-1-2010$

\title{
Assessing Air Quality Impacts of Managed Lanes
}

CUTR

Follow this and additional works at: https://digitalcommons.usf.edu/cutr_nctr

\section{Recommended Citation}

"Assessing Air Quality Impacts of Managed Lanes," National Center for Transit Research (NCTR) Report No. CUTR-NCTR-RR-2009-06, Center for Urban Transportation Research, University of South Florida, 2010. DOI: https://doi.org/10.5038/CUTR-NCTR-RR-2009-06

Available at: https://scholarcommons.usf.edu/cutr_nctr/134

This Technical Report is brought to you for free and open access by the National Center for Transit Research (NCTR) Archive (2000-2020) at Digital Commons @ University of South Florida. It has been accepted for inclusion in Research Reports by an authorized administrator of Digital Commons @ University of South Florida. For more information, please contact digitalcommons@usf.edu. 
Prepared by

National Center for Transit Research

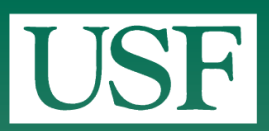

UNIVERSITY OF

SOUTH FLORIDA

\section{Assessing Air Quality Impacts of Managed Lanes}

December 2010

Final Report

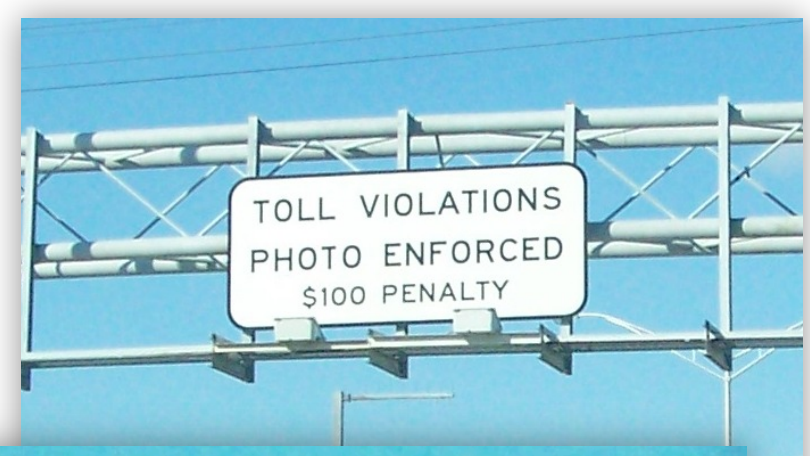

Funded by

Florida Department of Transportation

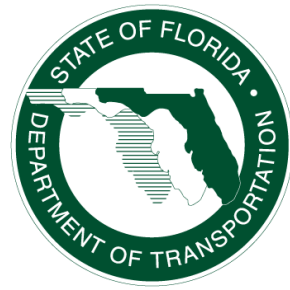




\section{DISCLAIMER}

The opinions, findings, and conclusions expressed in this publication are those of the authors and not necessarily those of the State of Florida Department of Transportation. 


\title{
Assessing Air Quality Impacts of Managed Lanes
}

Final Report

Prepared for

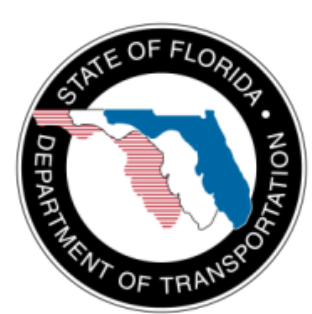

State of Florida Department of Transportation

Public Transit Office

605 Suwannee Street, MS 30

Tallahassee, Florida 32399-0450

Project Manager: Amy Datz

\author{
Prepared by \\ Amy L. Stuart, Ph.D. \\ Pei-Sung Lin, Ph.D., P.E., PTOE \\ Changyoung Lee, Ph.D., PTP \\ Haofei $Y u$ \\ Hongyun Chen
}

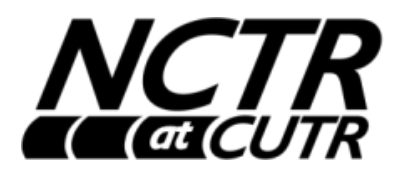

National Center for Transit Research

Center for Urban Transportation Research (CUTR)

University of South Florida

4202 East Fowler Avenue, CUT100

Tampa, Florida 33620-5375

December 2010

BDK85 TWO \#977-11 


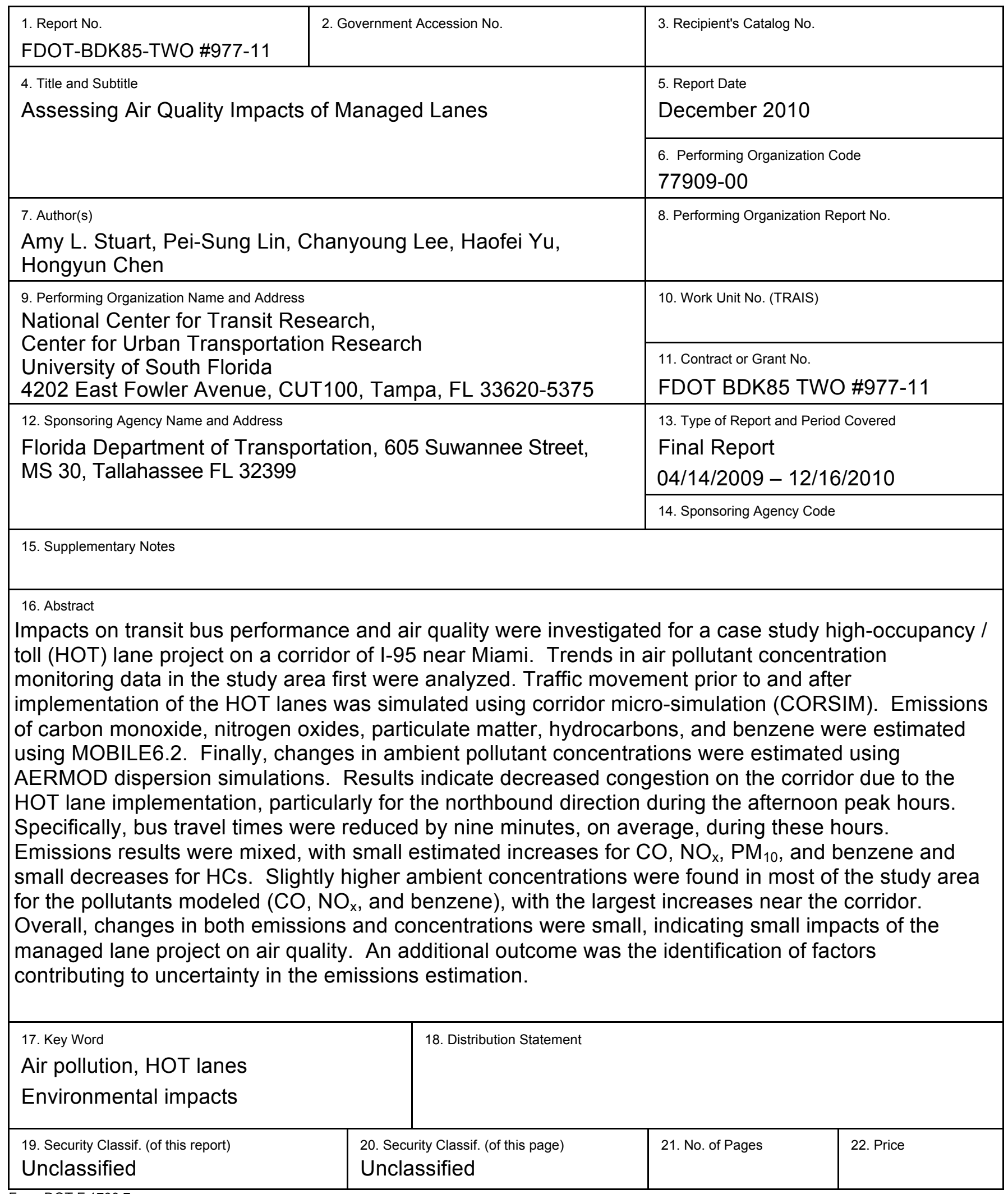

Form DOT F 1700.7 


\section{EXECUTIVE SUMMARY}

Managed lanes are currently of significant interest for transportation management in the U.S. Resultant reductions in congestion are expected to have potential benefits for transit service use. Additionally, since transportation systems contribute substantially to air pollution, information on the impacts of managed lanes on air quality and methods to assess those impacts are needed.

In this study, impacts on transit bus performance and air quality were investigated for a case study managed lane project. The case study project is the l-95 Express project managed by the Florida Department of Transportation through the Miami Urban Partnership Agreement. It involves conversion of a single high-occupancy vehicle (HOV) lane into two high-occupancy / toll (HOT) lanes along a corridor of I-95 between Miami and Fort Lauderdale.

Objectives of this project were to:

1. assess air quality and temporal trends in air quality prior to the managed lane project,

2. determine emissions changes due to the managed lane project for select pollutants, and

3. determine modeled air pollutant concentrations due to the managed lane project.

Several methods were used to accomplish these objectives. First, trends in ambient concentrations in the study area of select air pollutants that are substantially associated with vehicle emissions were investigated through analysis of available monitoring data from monitoring reports and the U.S. Environmental Protection Agency air quality database. Traffic movement on the case study corridor prior to and after implementation of the HOT lane project was simulated in order to study impacts on corridor performance and to determine changes due to the managed lane project on traffic parameters that affect emissions. An established corridor micro-simulation modeling package (CORSIM) was used. Impacts on transit buses were a specific focus. Resultant traffic data were combined with MOBILE6.2 emissions factor estimation to calculate changes in emissions of five select pollutants emitted from vehicles: carbon monoxide $(\mathrm{CO})$, nitrogen oxides $\left(\mathrm{NO}_{\mathrm{x}}\right)$, coarse particulate matter $\left(\mathrm{PM}_{10}\right)$, hydrocarbons (HCs), and benzene. Changes in ambient concentrations of select pollutants due to the corridor project were estimated using AERMOD dispersion modeling. Finally, factors affecting emissions changes were investigated.

Results indicate the following:

- Of the pollutants whose monitoring data were studied, only ozone and $\mathrm{PM}_{2.5}$ had measured levels near to or slightly exceeding the regulatory standard levels between the years 2000 to 2009 at some sites in Broward County. Concentrations of pollutants with substantial primary emissions $\left(\mathrm{CO}\right.$, nitrogen dioxide $\left[\mathrm{NO}_{2}\right]$, and $\left.\mathrm{PM}_{10}\right)$ were observed to be highest at some 
monitoring sites close to I-95. Overall, the data indicate reductions over the decade in CO and $\mathrm{NO}_{2}$ concentrations, with no clear apparent trend in ozone or particulate matter concentrations. For the toxic pollutants studied (benzene, 1,3-butadiene, and acetaldehyde), data are sparse, but lower concentrations of the former two were observed in 2009 relative to 2000 .

- Improvements were found in the simulated speed performance of the corridor due to the HOT lane implementation, particularly for the northbound direction during the afternoon peak hours. Bus travel times, specifically, were reduced by nine minutes, on average, during these hours.

- Emissions results were mixed. Compared with the baseline (pre-implementation) scenario, small increases in $\mathrm{CO}, \mathrm{NOx}, \mathrm{PM}_{10}$, and benzene emissions were estimated to occur for the post-implementation scenario studied. Conversely, small decreases in $\mathrm{HC}$ emissions were estimated. Emissions from buses, specifically, were estimated to decrease as a result of HOT lane implementation for all pollutants studied.

- Simulated changes in ambient concentrations of select pollutants (CO, NOx, and benzene) due to corridor emissions indicate slightly higher concentrations throughout much of the study area for the post-implementation scenario compared with the baseline scenario. Decreases at some locations near the northern end of the corridor also were found, due to changes in the spatial distribution of emissions. Estimated differences were largest near the corridor, which could be important to populations living nearby.

- Overall, estimated changes in both emissions and concentrations were small, indicating only small expected impacts of the HOT lane project on air quality.

An analysis of the factors influencing the emissions changes suggests substantial uncertainty in the emissions changes resulting from HOT lane implementation. First, changes in volumes on the corridor were found to impact the emissions result. Volumes were estimated to increase slightly; however, the actual impact on volumes could not be captured because total volumes entering the corridor are inputs to the corridor simulation model. It is expected that changes in input volumes will depend on the comparative performance of the surrounding transportation network, which is not represented here. Second, the impact of speed on emissions factors was analyzed. For the range of speed improvements realized through the HOT lane implementation, the MOBILE6.2 emissions factors did not change substantially for the pollutants studied. Conversely, the CORSIM emissions factors did (using the default tables). Use of the CORSIM factors would result in emissions improvements for $\mathrm{CO}$ and $\mathrm{NO}_{\mathrm{x}}$. These issues suggest uncertainty in the emissions and air quality changes expected from the HOT lane implementation. Overall, further work is needed to improve 1) estimation of network level 
impacts of managed lane projects on vehicle volume redistribution, 2) emissions factor estimator model representation of speed effects, and 3) tools for effectively translating between transportation and air pollution models. Finally, it is important to note that air quality impacts of managed lanes projects likely depend on the conditions of the case studied. Generalizable conclusions will require more analyses for other case studies. 


\section{TABLE OF CONTENTS}

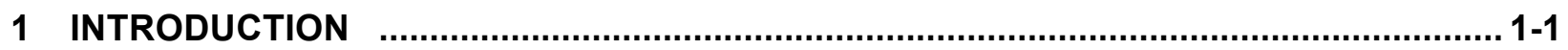

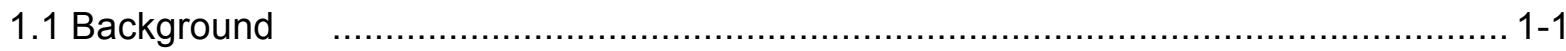

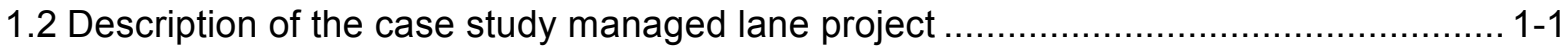

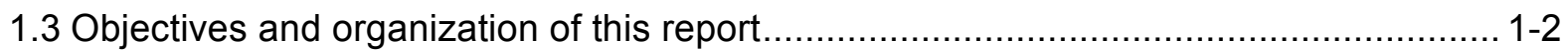

2 BASELINE AIR QUALITY (OBJECTIVE 1): METHODS AND FINDINGS ....................... 2-1

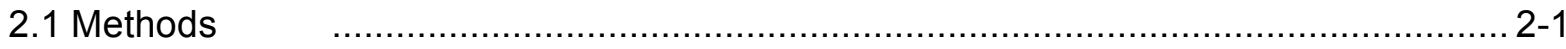

2.2 Results: Measured air pollutant concentrations and trends ................................. 2-2

2.2.1 Criteria air pollutants and the Air Quality Index ................................... 2-2

2.2.1.1 Carbon monoxide .................................................................... 2-2

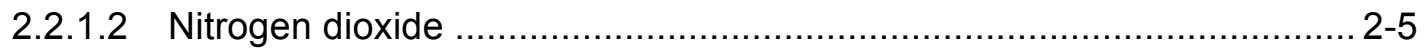

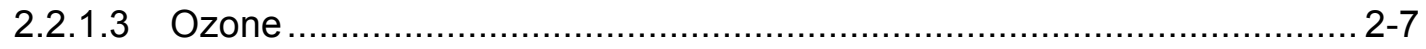

2.2.1.4 Particulate matter ...................................................................... 2-9

2.2.1.5 Air Quality Index .................................................................. 2-13

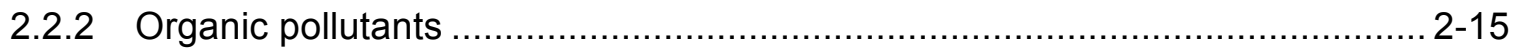

2.2.2.1 Volatile organic compounds .................................................... 2-15

2.2.2.2 Select mobile source air toxics ............................................... 2-15

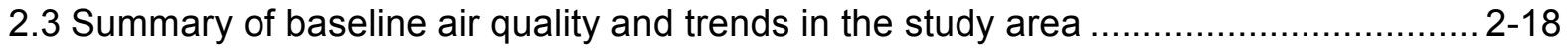

3 MOBILE SOURCE EMISSIONS (OBJECTIVE 2): METHODS AND FINDINGS.............. 3-1

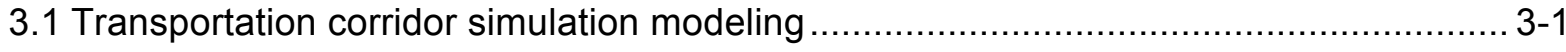

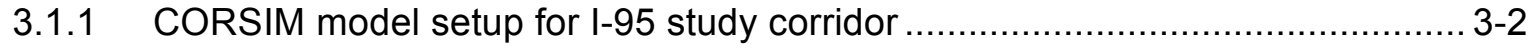

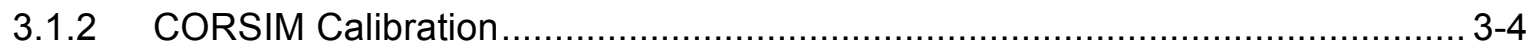

3.1.3 Discussion of mode share impacts of managed lane implementation .............. 3-5

3.1.4 CORSIM Results: Managed lane performance ................................... 3-7

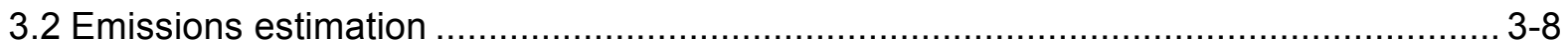

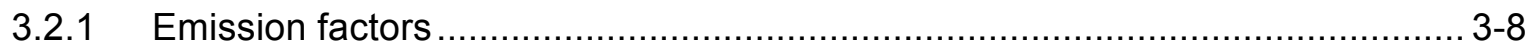

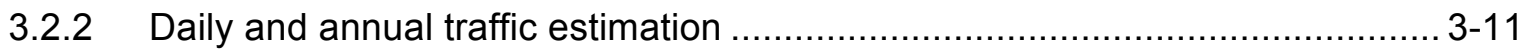


3.2.3 Emissions

3.2.4 Discussion of factors influencing emissions changes ............................. 3-14

3.2.5 Discussion of emissions uncertainties ............................................... 3-15

3.3 Summary of emissions calculations and results .............................................. 3-17

4 AIR QUALITY EFFECTS (OBJECTIVE 3): METHODS AND FINDINGS......................... 4-1

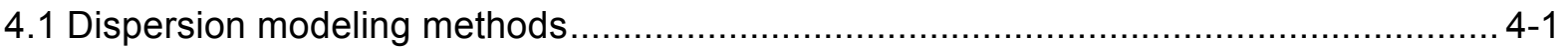

4.1.1 Review and selection of dispersion models ......................................... $4-1$

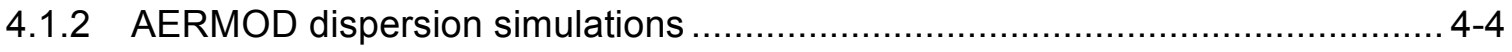

4.2 Results: Estimated pollutant concentrations ...................................................... 4-6

4.3 Summary and discussion of air quality results .................................................. 4-12

5 INTEGRATED DISCUSSION AND SUMMARY ..................................................... 5-1

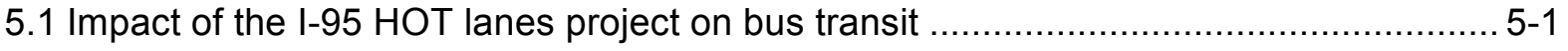

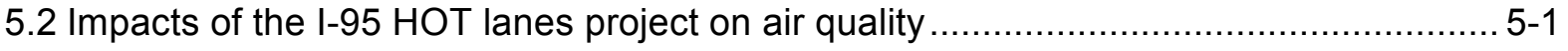

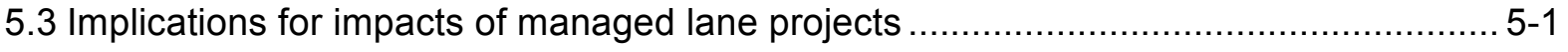

5.4 Issues with combining transportation modeling and air pollution methods ................. 5-2

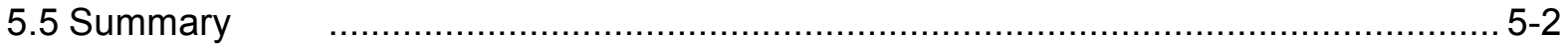

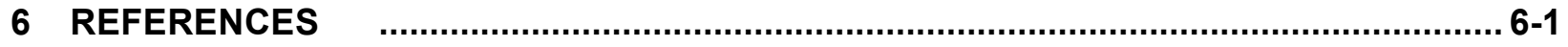

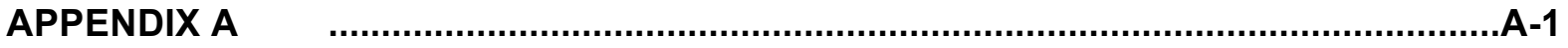




\section{LIST OF TABLES}

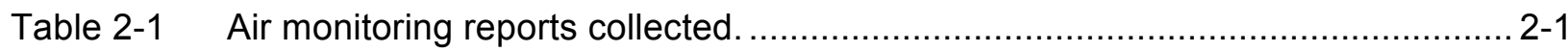

Table 2-2 Air monitoring sites in Broward and Miami-Dade counties ................................ 2-3

Table 2-3 Particulate matter monitoring sites in the study area and monitoring method.... 2-11

Table 2-4 Explanation of the PM monitoring method ................................................ 2-12

Table 2-5 Air quality Index levels and their interpretation .......................................... 2-14

Table 2-6 List of VOC monitoring sites and available data period ................................ 2-15

Table 2-7 Monitoring sites for the focus pollutants .............................................. 2-16

Table 3-1 Findings of changes of mode-share due to current HOT implementation ............ 3-6

Table 3-2 Mapping of vehicle class categories between CORSIM and MOBILE6.2 .......... 3-9

Table 3-3 MOBILE6.2 vehicle classes and distribution percentages ............................... 3-10

Table 3-4 All-vehicle annual average emissions factors for the before scenario............... 3-12

Table 3-5 All-vehicle annual average emission factors for the after scenario GPLs ......... 3-12

Table 3-6 All-vehicle annual average emission factors for the after scenario HOT lanes .. 3-12

Table 3-7 Annual average emissions factors for buses for the before scenario............... 3-12

Table 3-8 Annual average emissions factors for buses for the after scenario HOT lanes.. 3-12

Table 3-9 Estimated 2009 annual emissions ....................................................... 3-14

Table 3-10 Percentage change in 2009 annual emissions due to implementation. ............ 3-15

Table 4-1 Surface characteristics parameters ......................................................... 4-5

Table 4-2 Range in modeled concentrations before HOT implementation........................ 4-7

Table 4-3 Range in modeled concentrations after HOT implementation .......................... 4-7

Table 4-4 Comparison between the modeled and measured CO concentrations............... 4-9

Table 4-5 Domain average differences in modeled pollutant concentrations ................... 4-10 


\section{LIST OF FIGURES}

Figure 1-1 Three phases of managed lane project. .................................................. 1-2

Figure 2-1 Carbon monoxide monitoring sites .......................................................... 2-4

Figure 2-2 Measured carbon monoxide concentrations............................................... 2-5

Figure 2-3 NO2 monitoring sites ............................................................................ 2-6

Figure 2-4 Measured nitrogen dioxide concentrations .............................................. 2-7

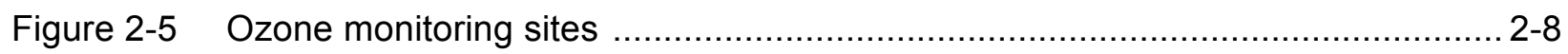

Figure 2-6 Measured $\mathrm{O} 3$ concentrations .................................................................. 2

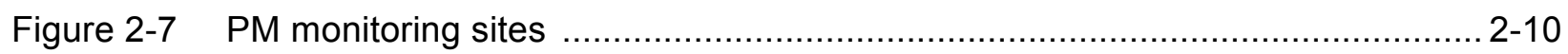

Figure 2-8 Measured PM10 concentrations ............................................................. 2-12

Figure 2-9 Measured PM2.5 concentrations ............................................................ 2-13

Figure 2-10 Annual distributions of the daily Air Quality Index ...................................... 2-14

Figure 2-11 Measured benzene concentrations ................................................... 2-17

Figure 2-12 Measured acetaldehyde concentrations ............................................... 2-17

Figure 2-13 Measured 1,3-butadiene concentrations .............................................. 2-18

Figure 3-1 I-95 study corridor and the corresponding CORSIM network .......................... 3-2

Figure 3-2 Bus volumes for northbound and southbound lanes during each time period...... 3-3

Figure 3-3 Phase 1A-NB 1-95 volume validation sites ............................................. 3-5

Figure 3-4 Average speeds for afternoon peak hours for northbound lanes ..................... 3-7

Figure 3-5 Time savings for the northbound and southbound lanes.............................. 3-8

Figure 3-6 Diurnal and monthly traffic count distributions ...................................... 3-11

Figure 3-7 Comparison of diurnal and monthly traffic count distributions ...................... 3-13

Figure 3-8 Relative emissions before and after HOT lane implementation ....................... 3-14

Figure 3-9 Relative emission factors for all vehicles from CORSIM and MOBILE6.2 ......... 3-16

Figure 4-1 Section of I-95 modeled....................................................................... 4

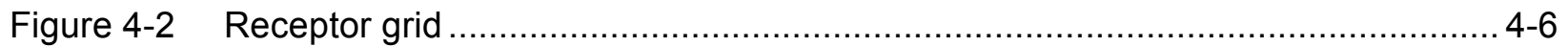

Figure 4-3 Modeled pollutant concentrations prior to implementation of HOT lanes ............ 4-8

Figure 4-4 Domain average concentrations for the baseline scenario............................ 4-9

Figure 4-5 Change in carbon monoxide concentrations due to HOT implementation ......... 4-10

Figure 4-6 Change in nitrogen oxides concentrations due to HOT implementation ............ 4-11

Figure 4-7 Change in benzene concentrations due to HOT implementation ..................... 4-11 


\section{INTRODUCTION}

\subsection{Background}

The concept of managed lanes in transportation management is currently of significant interest around the U.S. due to its potential to mitigate traffic congestion and generate revenue. The concept uses variable pricing of tolls to ensure desired operating speeds of vehicles using managed lane facilities. The resultant reduction of congestion is particularly important to the efficiency, visibility, and use of transit services. Public buses, carpools, and vanpools, which are allowed use of managed lanes for waived or reduced fees, can then experience largely unimpeded flow. Increased use of transit options is expected to result from successful implementation of managed lane concepts. Therefore, the National Center for Transit Research (NCTR) at the University of South Florida's Center for Urban Transportation Research has targeted analysis of the design and performance of managed lane projects as a focus of study.

The Florida Department of Transportation (FDOT) recently implemented a managed lane project in south Florida through the Miami Urban Partnership Agreement. This agreement includes 21 miles of managed high occupancy/toll (HOT) lanes on the I-95 corridor between Miami and Fort Lauderdale. The federal government also is providing millions of dollars for new buses and bus rapid transit (BRT) service on the l-95 corridor. As the current express buses on I-95 can be substantially slowed in congestion, the HOT managed lane project is expected to enhance the speed of the BRT service network and lead to increased use of transit on the corridor.

In addition, transportation systems currently are a significant source of air pollutant emissions throughout the U.S. (US Environmental Protection Agency 2001). Transportation infrastructure and management projects must now often consider the air quality impacts (National Research Council 2004). However, there is significant controversy over the impacts of transportation infrastructure and management projects on emissions and resultant air quality impacts (Transportation Research Board 1995; Replogle 1995; Dowling et al. 2005). Hence, it is important to evaluate the potential benefits and costs of transportation projects on air quality. The I-95 managed lane project provides an opportunity to evaluate these impacts and develop methods for assessment applicable to future projects.

\subsection{Description of the case study managed lane project}

The managed lane project, also known as the "95 Express," is part of the Interstate 95 (I-95) management program managed by FDOT. The project involves converting the single high- 
occupancy vehicle (HOV) lane between Miami and Fort Lauderdale into two HOT lanes. The number of the general-purpose lanes will remain the same. Vehicles have the option to choose between general-purpose lanes or pay a toll charge to use the HOT lanes. Certain types of high occupancy vehicles (registered vanpools, carpools with three or more people, and transit buses in Broward and Miami-Dade counties) are allowed to use the HOT lanes free of charge. Hybrid vehicles and motorcycles are also free of the toll charge. The project is aimed at reducing the congestion on I-95 and encouraging carpool and transit use (FDOT 2009).

The project consists of three phases, as shown in Figure 1.1. Phase $1 \mathrm{~A}$ involves the implementation of HOT lanes for northbound I-95 between SR-112 and north of the Golden Glades Interchange in Miami-Dade County. In Phase 1B, the HOT lanes were implemented on the southbound lanes of the same section of I-95. Phase 2 will extend the HOT lanes further north into Broward County. In this report, impacts of Phase $1 \mathrm{~A}$ and $1 \mathrm{~B}$ are studied.

\subsection{Objectives and organization of this report}

The overall goals of this research were to contribute to the understanding of potential impacts of managed lane transportation projects on air quality and on bus transit and to improve methods for determination of impacts. Objective 1 was to assess baseline air quality and temporal trends using available air quality monitoring data. Objective 2 was to

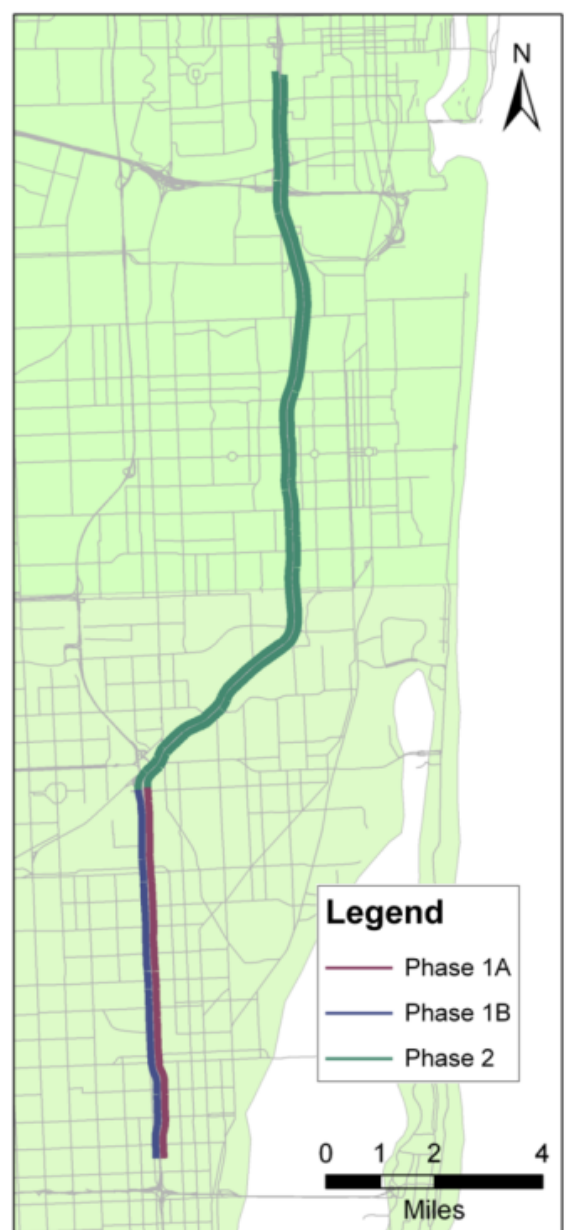

Figure 1-1. Three phases of managed lane project. determine the change in emissions of select pollutants from the case-study corridor due to the implementation of the HOT lane project. Objective 3 was to assess impacts on air pollutant concentrations due to the implementation of the HOT lane project. A specific sub-focus within these objectives, particularly Objective 2, was to assess impacts of the HOT lane project on transit bus service performance and resultant emissions. This report is organized around these objectives. Chapters 2 through 4 provide methods, results, and discussion for each objective, respectively. Chapter 5 provides a final integration and discussion of the results from all objectives. 


\section{BASELINE AIR QUALITY (OBJECTIVE 1): METHODS AND FINDINGS}

To characterize the impacts of the I-95 case study project on air quality, metrics of baseline air quality in the surrounding Miami-Date and Broward counties prior to the implementation of the managed lane project are needed. Trends in measured concentrations of several air pollutants for these counties are discussed.

\subsection{Methods}

Several pollutants were selected as the focus for this work. Specific pollutants were selected based on the criteria that mobile sources contribute substantially to their emissions or ambient concentrations. Pollutants selected for study were ozone $\left(\mathrm{O}_{3}\right)$, nitrogen dioxide $\left(\mathrm{NO}_{2}\right)$, carbon monoxide (CO), particulate matter (PM), volatile organic compounds (VOCs), benzene, acetaldehyde, and 1,3-butadiene. As a measure of combined criteria pollutant air quality, data on the Air Quality Index also were studied.

To determine baseline air quality in the study area, air quality information was compiled from two types of data sources - local and state air monitoring reports and federal air quality system data. First, available air monitoring reports of Broward and Miami-Dade counties as well as the State of Florida Department of Environmental Protection were collected and the data were compiled, beginning with the year 2000. The agencies, report type, and temporal data availability are shown in Table 2-1. The reports differ in the detail of air quality information reported. The state-level and the Miami-Dade County reports each contain summarized monitoring data for all criteria pollutants at monitoring sites throughout the respective jurisdictions. However, the Broward County report provides only trends of ozone and particulate matter with no detailed data.

Table 2-1. Air monitoring reports collected, including publishing agencies and annual temporal availability since 2000

\begin{tabular}{|c|c|c|}
\hline Agency & Report & Availability \\
\hline Florida Department of Environmental Protection & $\begin{array}{c}\text { Annual Air Monitoring Report } \\
\text { Quick Look Report }\end{array}$ & $\begin{array}{c}2000-2006 \\
2000-2009\end{array}$ \\
\hline $\begin{array}{c}\text { Broward County Environmental Protection and } \\
\text { Growth Management Department }\end{array}$ & $\begin{array}{c}\text { Environmental Benchmarks } \\
\text { Report }\end{array}$ & $2000-2008$ \\
\hline $\begin{array}{c}\text { Miami-Dade County Department of Environmental } \\
\text { Resources Management }\end{array}$ & Ambient Air Monitoring Report & $2002-2007$ \\
\hline
\end{tabular}

Second, raw and summarized monitoring data for January 2000 through June 2009 were collected from the U.S. Environmental Protection Agency (USEPA) AirData Summary Report database and the USEPA Air Quality System database. Table 2-2 provides a list of air 
monitoring sites located in Broward and Miami-Dade counties, pollutants monitored at each site, and years for which data are available. Trends in measured pollutant values at each site as well as calculated county averages are provided in Section 2.2. Site locations also were mapped, and distances to the I-95 corridor were measured using ArcGIS. The shortest distance of each monitoring site to I-95 is listed in Table 2-2.

\subsection{Results: Measured air pollutant concentrations and trends}

\subsubsection{Criteria air pollutants and the Air Quality Index}

For this project, a few criteria pollutants associated with vehicular emissions were selected for study: carbon monoxide $(\mathrm{CO})$, nitrogen dioxide $\left(\mathrm{NO}_{2}\right)$, ozone $\left(\mathrm{O}_{3}\right)$, particulate matter less than $2.5 \mu \mathrm{m}$ in diameter $\left(\mathrm{PM}_{2.5}\right)$, and particulate matter less than $10 \mu \mathrm{m}$ in diameter $\left(\mathrm{PM}_{10}\right)$. Criteria air pollutants are a set of common air pollutants that can be present at levels harmful to human health and welfare and are regulated by National Ambient Air Quality Standards (NAAQS). The standards are threshold levels in air that are considered protective of health and welfare. Hence, measured concentrations are expected to be lower than these levels. The Air Quality Index, which combines concentration data from several criteria pollutants into an overall metric, also was studied.

\subsubsection{Carbon monoxide}

$\mathrm{CO}$ is a colorless gas. Health effects occur due to reduction of the oxygen-carrying capacity of the blood upon inhalation. Persons with cardiovascular disease are most susceptible. The current NAAQS levels for carbon monoxide are 35 ppmv (parts per million by volume) ${ }^{1}$ for the one-hour average and 9 ppmv for the eight-hour average. ${ }^{2}$ Carbon monoxide is emitted directly during fuel combustion, leading to high concentrations near roadways and roadway intersections.

Figure 2-1 provides maps of the CO monitoring sites in Broward and Miami-Dade counties. All $\mathrm{CO}$ monitoring sites in both counties use a Thermo Electron/Thermo Environmental Instruments Model 48 series Gas Filter Correlation Ambient CO Analyzer to monitor CO concentration continuously. Hourly $\mathrm{CO}$ concentration data are reported. There are five monitoring sites located in Broward County and four sites in Miami-Dade County. Of these, the S. Univ. Rd and N. State Rd sites in Broward County stopped monitoring CO in 2006 and 2004, respectively.

\footnotetext{
${ }_{2}^{1}$ ppmv is a unit of measurement that quantifies the number of molecules of the pollutant per million air molecules.

2 To meet the NAAQS, these levels may not be exceeded more than once per year.
} 
Table 2-2. Air monitoring sites in Broward and Miami-Dade counties, including pollutants monitored, and distance to I-95

For each pollutant measured at a given site, years for which data are available also are provided. Other refers to VOCs and select air toxics discussed in Section 2.2.

\begin{tabular}{|c|c|c|c|c|c|c|c|c|c|c|}
\hline County & Site ID No. & Address & Abbreviation & Distance to $1-95$ & CO & $\mathrm{NO}_{2}$ & $\mathrm{O}_{3}$ & $P M_{10}$ & $P M_{2.5}$ & Other \\
\hline Broward & $12-011-0010$ & Lincoln Park Elementary School (NW corner) & Lincoln Park & $0.1 \mathrm{mi}$ & $00-09$ & & & $00-09$ & & \\
\hline Broward & 12-011-0011 & 1800 SW 4th Ave, Fort Lauderdale & SW 4th Ave & $1.4 \mathrm{mi}$ & & & & $00-07$ & & \\
\hline Broward & $12-011-0031$ & 12600 West Sample Rd & W Sample & $9.9 \mathrm{mi}$ & & 00-09 & $00-09$ & & & \\
\hline Broward & $12-011-0033$ & 3211 College Ave, Vista View Park & Vista & $10.6 \mathrm{mi}$ & & & 09 & & 09 & \\
\hline Broward & 12-011-1002 & 3205 SW 70th Ave & SW 70th Ave & $4.3 \mathrm{mi}$ & & & & $00-09$ & $00-09$ & $00-09$ \\
\hline Broward & $12-011-1201$ & 2900 S. University Dr & S Univ & $5.1 \mathrm{mi}$ & $00-06$ & & & & & \\
\hline Broward & $12-011-2003$ & 1951 NE 48th St & NE 48th St & $1.6 \mathrm{mi}$ & & & $00-09$ & & & \\
\hline Broward & 12-011-2004 & 851 SW 3 Ave, Pompano Beach & SW 3 Ave & $0.5 \mathrm{mi}$ & $00-09$ & & & $00-09$ & $00-09$ & $00-08$ \\
\hline Broward & $12-011-3002$ & 2701 Plunkett St, Hollywood & Plunkett St & $0.4 \mathrm{mi}$ & $00-09$ & & & $00-09$ & $00-09$ & $00-08$ \\
\hline Broward & 12-011-5001 & 3701 North State Rd 207 & N State Rd & $2.6 \mathrm{mi}$ & $00-04$ & & & & & \\
\hline Broward & 12-011-5002 & 11251 Taft S,t Pembroke Pines & Taft St & $8.2 \mathrm{mi}$ & & & & $00-02$ & & \\
\hline Broward & $12-011-5005$ & 4010 Winston Park Blvd & Winston & $3.3 \mathrm{mi}$ & & & & $00-09$ & & $00,02-09$ \\
\hline Broward & $12-011-6002$ & 1200 NW 72 Ave, Plantation & NW 72 Ave & $4.6 \mathrm{mi}$ & & & & $00-01$ & & \\
\hline Broward & $12-011-7002$ & $301 \mathrm{NE}$ 12th St & NE 12th St & $0.9 \mathrm{mi}$ & & & & 00 & & \\
\hline Broward & $12-011-8002$ & 7000 N Ocean Dr & Ocean $\mathrm{Dr}$ & $3.5 \mathrm{mi}$ & & $00-09$ & $00-09$ & & & \\
\hline Miami-Dade & $12-086-0020$ & 7100 NW 36th St & NW 36th St & $6.0 \mathrm{mi}$ & & & & $00-03$ & & $02-05$ \\
\hline Miami-Dade & $12-086-0021$ & Krome Ave, Thompson Park & Krome Ave & $14.8 \mathrm{mi}$ & & & $00-03$ & & & \\
\hline Miami-Dade & $12-086-0027$ & Rosenstiel School & Rosenstiel & $2.9 \mathrm{mi}$ & & $00-09$ & $00-09$ & & & \\
\hline Miami-Dade & $12-086-0029$ & 19590 Old Cutler Rd-Perdue Medical Center & Perdue Med & $13.5 \mathrm{mi}$ & & & $00-09$ & & & $02-05$ \\
\hline Miami-Dade & $12-086-0030$ & Everglades NP & Everglades & $38.8 \mathrm{mi}$ & & & $00-04$ & & & \\
\hline Miami-Dade & 12-086-0031 & 16000 South Dixie Hwy & S Dixie Hw & $12.1 \mathrm{mi}$ & $00-09$ & & & & & \\
\hline Miami-Dade & $12-086-0033$ & 7700 NW 186 St (Palm Springs Fire Station) & PF & $7.3 \mathrm{mi}$ & & & & & 05-09 & \\
\hline Miami-Dade & $12-086-0034$ & NW corner of intersection of SW $88 \mathrm{St} \& \mathrm{~N}$ Kendall Dr & SW $88 \mathrm{St}$ & $12.7 \mathrm{mi}$ & 05-09 & & & & & \\
\hline Miami-Dade & $12-086-1016$ & NW 20 St and 12 Ave (Miami Fire Station) & MF & $0.1 \mathrm{mi}$ & & & & $00-09$ & $00-09$ & \\
\hline Miami-Dade & 12-086-1019 & 2201 SW 4 St & SW 4 St & $2.1 \mathrm{mi}$ & $00-09$ & & & & & \\
\hline Miami-Dade & $12-086-3001$ & 6400 NW 27th Ave & NW 27th Ave & $2.3 \mathrm{mi}$ & & & & $00-03$ & & \\
\hline Miami-Dade & $12-086-4002$ & Metro Annex 864 NW 3rd S & Annex & $0.3 \mathrm{mi}$ & $00-09$ & 00-09 & & & & $02-03$ \\
\hline Miami-Dade & $12-086-6001$ & 325 NW 2nd St (Homestead Fire Station) & $\mathrm{HF}$ & $25.6 \mathrm{mil}$ & & & & $00-03$ & $00-09$ & \\
\hline
\end{tabular}



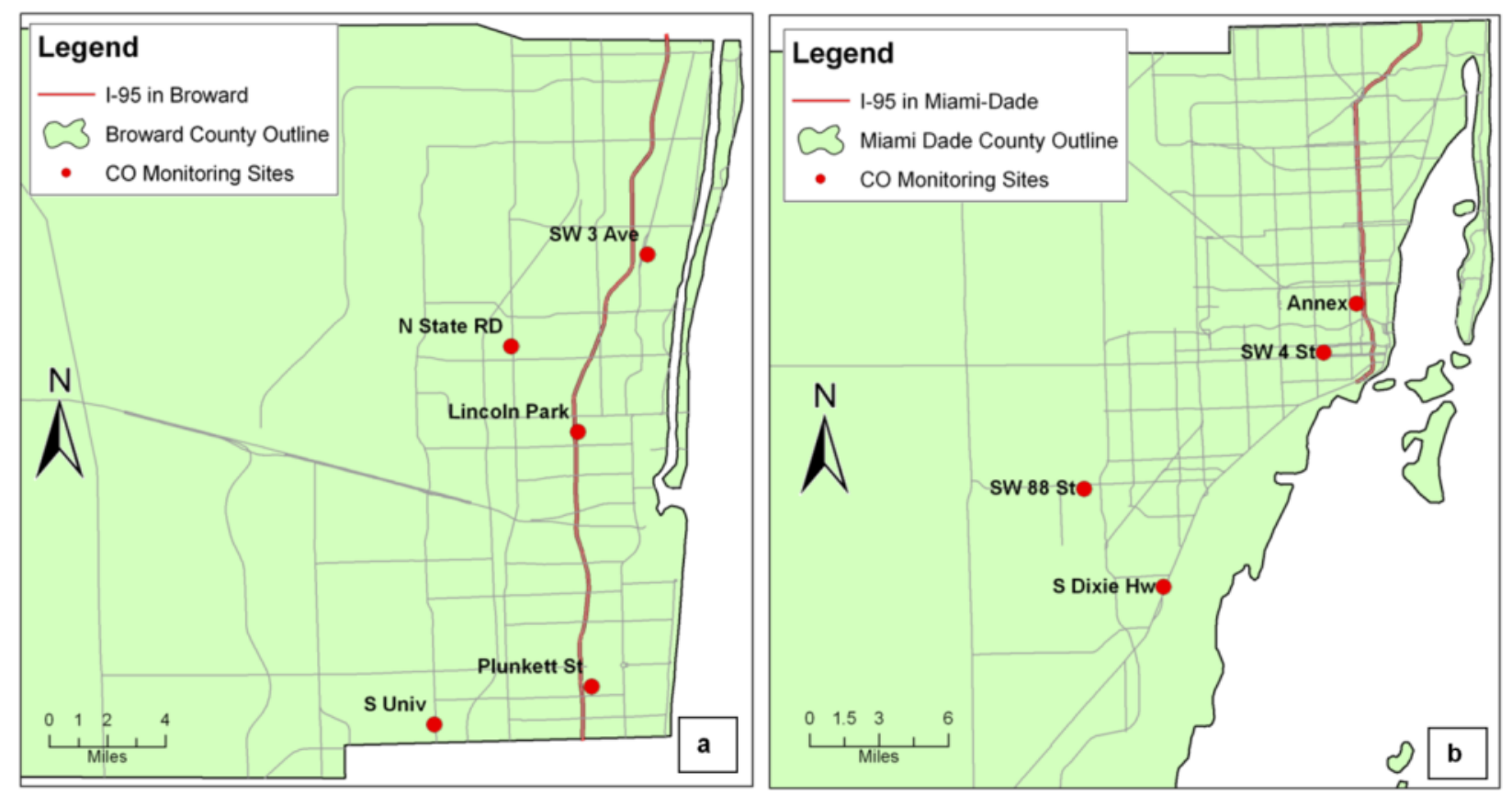

Figure 2-1. Carbon monoxide monitoring sites in (a) Broward and (b) Miami-Dade counties. Abbreviated site names are provided in Table 2-2.

The SW 88 St site in Miami-Dade County started monitoring CO in 2005. As shown in Figure 21, three sites in Broward County (SW 3 Ave, Lincoln Park, and Plunkett St) and one site in Miami-Dade County (Annex) are located in close proximity to I-95. Due to their proximity, these sites are expected to provide good metrics of the effects of the project on carbon monoxide levels.

Multi-year trends in the highest hourly average and highest eight-hour average CO concentrations for both counties are shown in Figure 2-2. As shown in the figure, all of the monitored CO concentrations are substantially below the NAAQS. Measured CO concentrations are similar in both counties, with slightly higher values overall in Miami-Dade County. In Broward County, the one-hour average values range from 1.4 ppmv at the SW 3 Ave site in 2009 to 7.5 ppmv at the Lincoln Park site in 2000. In Miami-Dade County, they range from 1.7 ppmv (S Dixie Hw, 2009) to 11.9 ppmv (Annex, 2004). The monitored eight-hour average CO concentrations range from 0.8 ppmv (SW 3 Ave site, 2009) to 5.7 ppmv (Lincoln Park, 2002) in Broward County and from 1.2 ppmv (S Dixie Hw site, 2007-2008) to 6.4 ppmv (Annex, 2004) in Miami-Dade County. The highest one-hour CO concentration showed an apparent declining trend. The county average highest one-hour $\mathrm{CO}$ concentration in Broward County dropped from 5.14 ppmv in 2000 to 2.1 ppmv in 2009. Miami-Dade County had a higher decrease, dropping from 6.23 ppmv in 2000 to 2.45 ppmv in 2009. The largest decrease was observed in the SW 3 Ave site in Broward County, for which the concentration dropped from 4.5 
ppmv in 2000 to 1.4 ppmv in 2009. The highest eight-hour CO concentration in both counties also showed a declining trend, with more fluctuations. In Broward County, the county average highest eight-hour CO concentration showed a 57 percent decrease, from 3.34 ppmv in 2000 to 1.43 ppmv in 2009. A similar trend is observed for Miami-Dade County, with a 53 percent decrease from 3.86 ppmv in 2000 to 1.83 ppmv in 2009. The largest decrease of the highest eight-hour CO concentration was 63 percent, which was observed at the SW 4 St site in MiamiDade County.
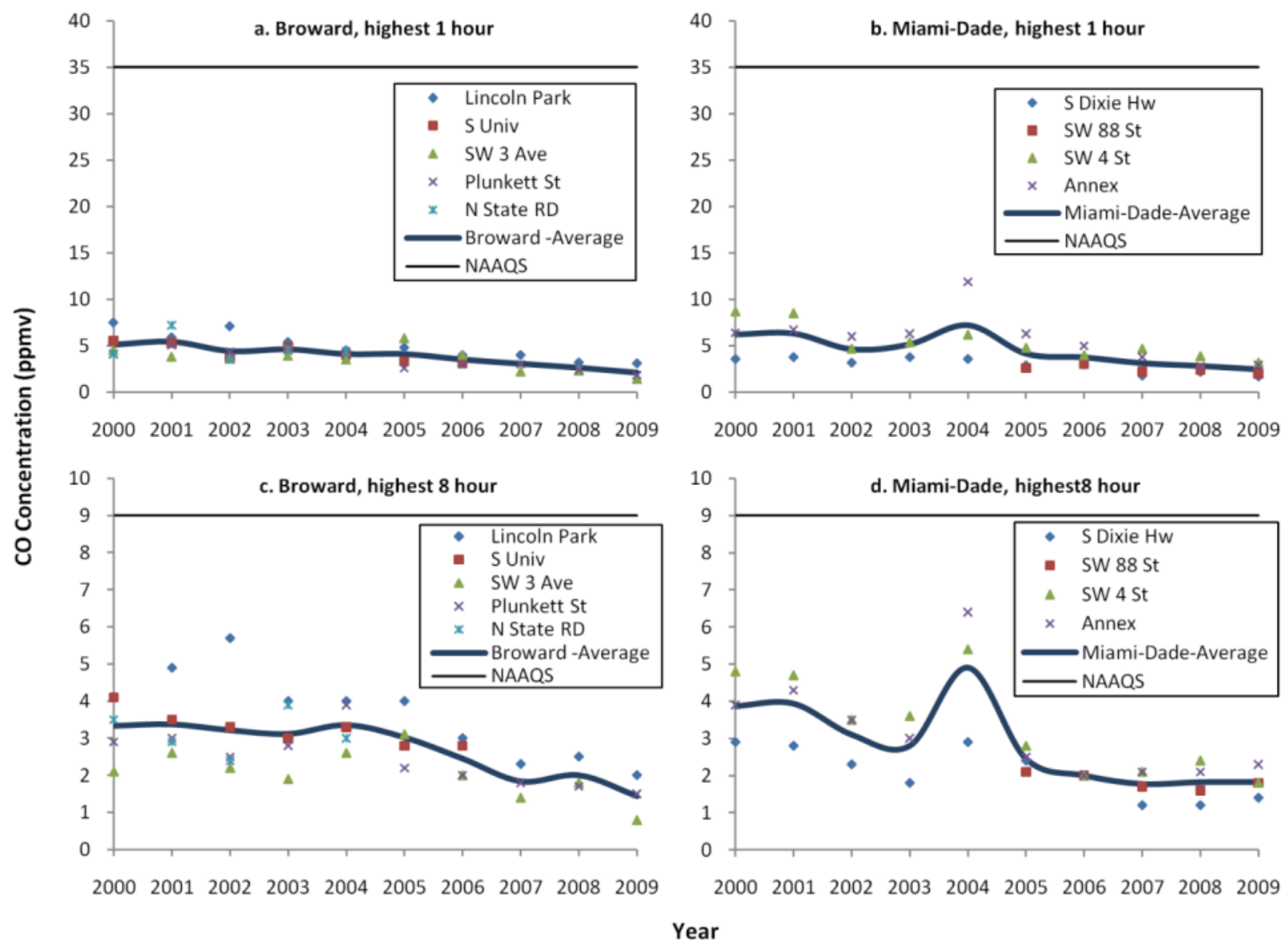

Figure 2-2. Multi-year trends of measured carbon monoxide concentrations in (a, c) Broward and $(b, d)$ Miami-Dade counties. The highest one-hour average values are provided in subplots $a$ and $b$, while subplots $\mathrm{c}$ and $\mathrm{d}$ provide the highest eight-hour average values. Calculated county average values are shown with solid lines.

\subsubsection{Nitrogen dioxide}

$\mathrm{NO}_{2}$ is a light brown gas. It may increase airway responsiveness and trigger acute respiratory symptoms in susceptible groups. $\mathrm{NO}_{2}$ also contributes to the formation in the atmosphere of near-surface ozone, another criteria pollutant (Denison et al. 2000). The current National Ambient Air Quality Standard (NAAQS) levels for $\mathrm{NO}_{2}$ are 0.053 ppmv for the annual (arithmetic) average and 100 ppbv (parts per billion by volume) for the maximum one-hour 
average. ${ }^{3} \mathrm{NO}_{2}$ is formed primarily from nitrogen oxide (NO) emitted during combustion.

Formation occurs relatively quickly, leading to peak concentration within a short distance of roadways.

Figure 2-3 shows a map of the $\mathrm{NO}_{2}$ monitoring sites in both counties. There are two sites in each county. Thermo Environmental Instruments, Inc., Model 42 series Chemiluminescence $\mathrm{NO}-\mathrm{NO}_{2}-\mathrm{NO}_{x}$ Analyzers are used at all $\mathrm{NO}_{2}$ monitoring sites to collect hourly ambient $\mathrm{NO}_{2}$ concentrations. One of the sites (Annex) in Miami-Dade County is located near to I-95, with the others farther away. Sites in closer proximity to the roadway are likely to provide better metrics of the effects of roadway projects such as this one on $\mathrm{NO}_{2}$ concentrations.
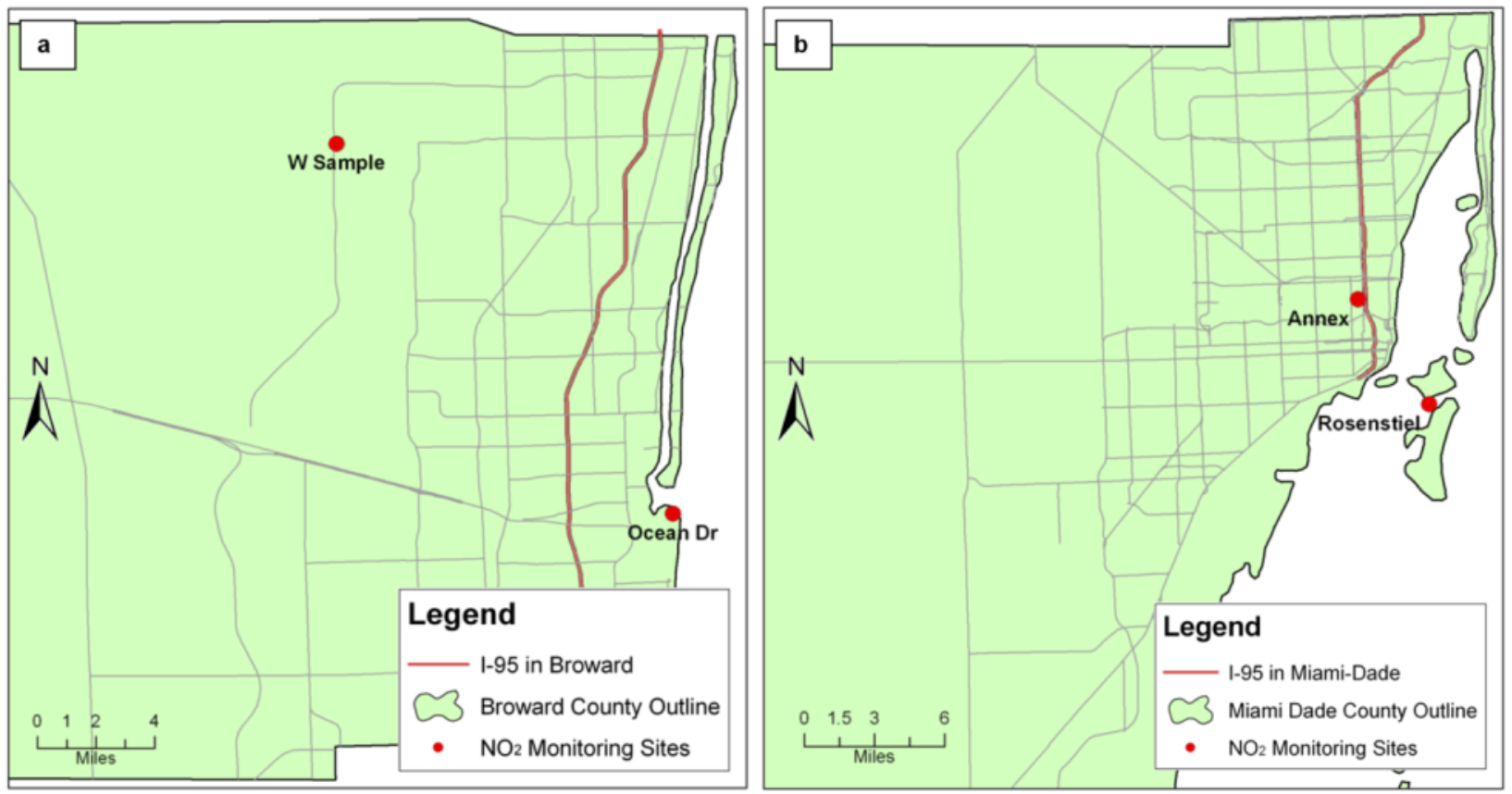

Figure 2-3. $\mathrm{NO}_{2}$ monitoring sites in (a) Broward and (b) Miami-Dade counties. Abbreviated site names are provided in Table 2.2.

Trends in annual average and one-hour maximum $\mathrm{NO}_{2}$ concentrations for each county are shown in Figure 2-4. All values are below the NAAQS levels. The annual $\mathrm{NO}_{2}$ concentration in Broward County ranges from 0.005 ppmv (W. Sample, 2008) to $0.01 \mathrm{ppmv}$ (Ocean Dr, 2000) and ranges from 0.004 ppmv (Rosenstiel, 2008) to 0.016 ppmv (Annex, 2001) in Miami-Dade County. Annual average values are somewhat consistent from 2000 with a slightly declining trend. In Broward County, the county averaged annual $\mathrm{NO}_{2}$ concentration was $0.0097 \mathrm{ppmv}$ in

\footnotetext{
${ }^{3}$ The three-year average of the 98th percentile of daily maximum one-hour average must not exceed this value.
} 
2000 , and decreased to $0.0061 \mathrm{ppmv}$ in 2009. The county averaged $\mathrm{NO}_{2}$ concentration in Miami-Dade County dropped from 0.011 ppmv in 2000 to 0.0067 ppmv in 2009.

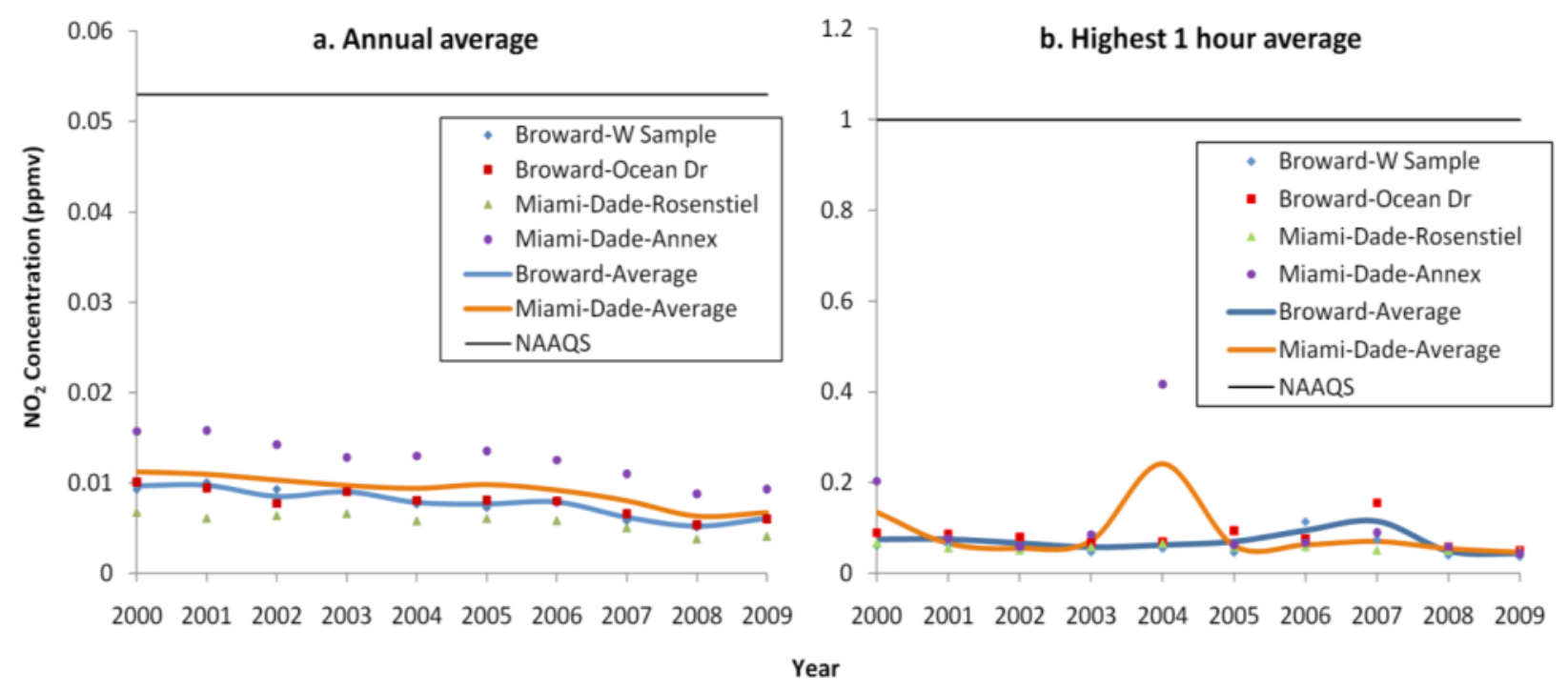

Figure 2-4. Multi-year trends of measured (a) annual average and (b) highest one-hour average $\mathrm{NO}_{2}$ concentrations in Broward and Miami-Dade counties. Calculated averages of all monitor values for each county are shown as solid lines. Note that a few data values were missing in the USEPA database; values from the State report were used in these cases.

The highest measured one-hour average $\mathrm{NO}_{2}$ concentration was 0.16 ppmv (Ocean Dr, 2007) in Broward County and 0.42 ppmv (Annex, 2004) in Miami-Dade County, while the lowest measured one-hour average $\mathrm{NO}_{2}$ concentration was 0.037 ppmv (W Sample, 2009) in Broward County and 0.043 ppmv (Annex, 2009) in Miami-Dade County. Substantial fluctuations are seen over the years studied, particularly at the Annex monitoring site. Spikes in concentration are seen at this site in both 2000 and 2004. It is notable that the Annex site in Miami-Dade County is in close proximity to I-95. It also has considerably higher annual average $\mathrm{NO}_{2}$ concentrations than the other monitoring sites and high fluctuations in the one-hour values.

\subsubsection{Ozone}

Ground-level ozone is the main component of urban smog and is associated with respiratory health impacts. Repeated exposure to $\mathrm{O}_{3}$ may also damage the lungs and permanently scar lung tissue. The current National Ambient Air Quality Standard (NAAQS) level for ozone is 75 ppbv for the fourth-highest eight-hour average. ${ }^{4}$ However, this standard is currently under reconsideration. There are also continuing obligations under a historical one-hour standard of

\footnotetext{
${ }^{4}$ The three-year average of the fourth-highest daily maximum eight-hour average at any monitor cannot exceed this value.
} 
0.12 ppmv that was officially revoked April 25, 2009. Ozone $\left(\mathrm{O}_{3}\right)$ is a secondary pollutant, formed in the atmosphere through reaction of nitrogen oxides and volatile organic compounds in the presence of sunlight. Concentrations do not typically peak in close proximity to sources in an urban area but are expected to exhibit high levels downwind over a broader area.

Figure 2-5 shows a map of the ozone monitoring sites active sometime during the period of study. Miami-Dade County has two $\mathrm{O}_{3}$ monitoring sites still in operation (Rosenstiel and Perdue Med sites). The Krome Ave and Everglades sites stopped monitoring for ozone in 2003 and 2004, respectively. In Broward County, the Vista site was newly established in 2009. Sites located within five miles of I-95 are the NE 48th St site (1.7 miles) and Ocean Dr site (3.5 miles) in Broward County and Rosenstiel site (2.9 miles) in Miami-Dade County. All monitoring sites except for the Everglades site use Thermo Electron/Thermo Environmental Instruments 49 series Photometric Ambient $\mathrm{O}_{3}$ Analyzer (Method 047) for ozone monitoring. The Everglades site uses a Monitor Labs/Lear Siegler Model 8810 Photometric Ozone Analyzer. Hourly ozone concentration data are reported.
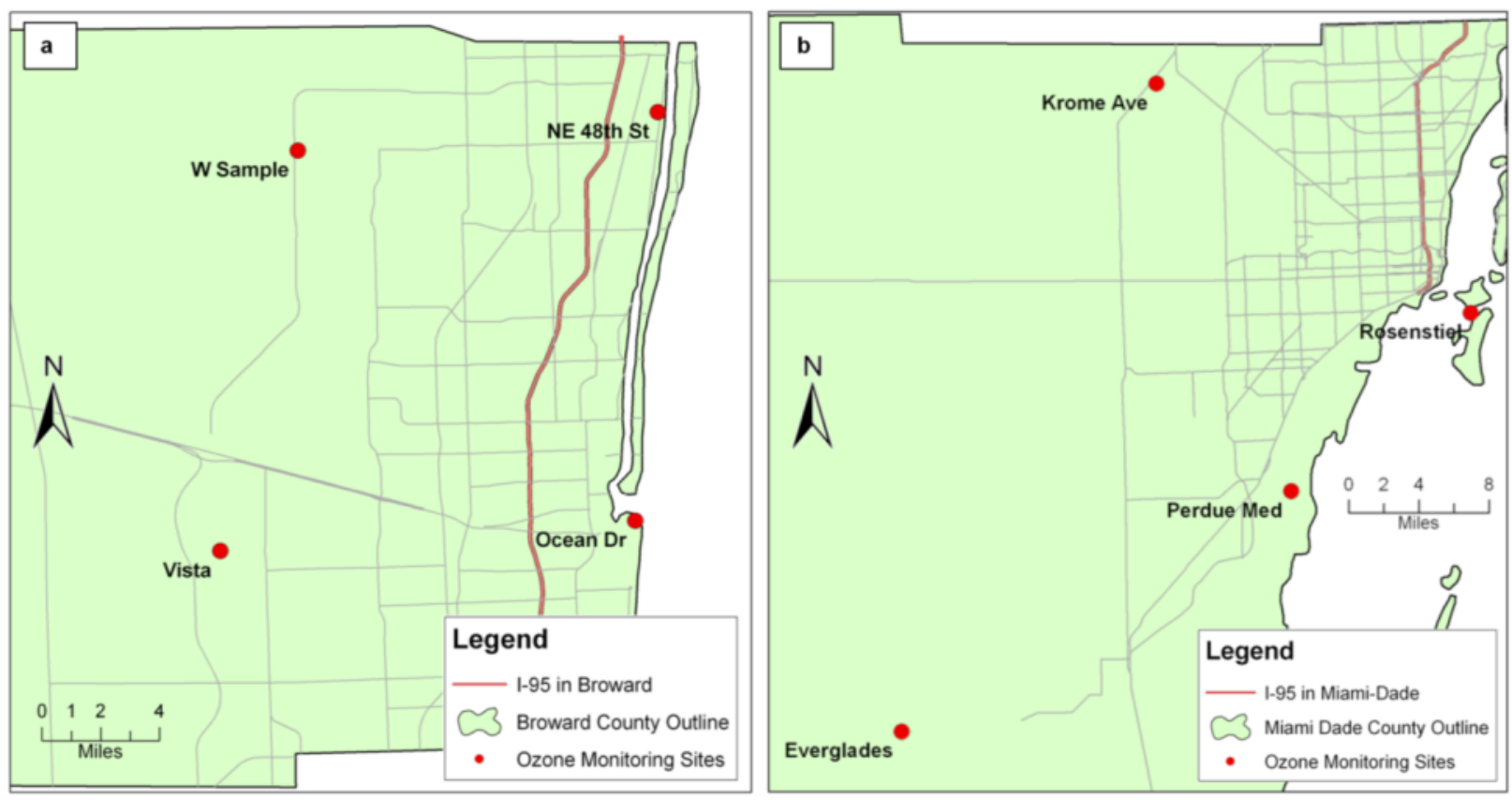

Figure 2-5. Ozone monitoring sites in (a) Broward and (b) Miami-Dade counties. Coordinate values for the Vista site were obtained from FDEP (2009).

Multi-year trends in measured concentrations of ozone are shown in Figure 2-6. In Broward County, the fourth highest eight-hour ozone concentration ranged from $0.055 \mathrm{ppmv}$ (Vista, 2009) to 0.077 ppmv (Ocean Dr, 2006). The fourth-highest eight-hour ozone concentration in 
Miami-Dade County ranged from 0.06 ppmv (Everglades, 2002) to 0.084 ppmv (Krome Ave, 2001). Some of these values are higher than the NAAQS level. The highest one-hour ozone concentration ranged from $0.071 \mathrm{ppmv}$ (W Sample, 2004 and 2007) to $0.11 \mathrm{ppmv}$ (Ocean Dr, 2001, 2006 and 2008). In Miami-Dade County, it ranged from 0.069 ppmv (Everglades, 2002) to 0.119 ppmv (Rosenstiel and Perdue Med, 2001). This latter value is very close to the onehour NAAQS level (now revoked). Substantial fluctuations also are observed in the data with no apparent multi-year trends, although calculated county average concentrations in 2009 were lower than those in 2000 for all metrics studied except the highest one-hour average.
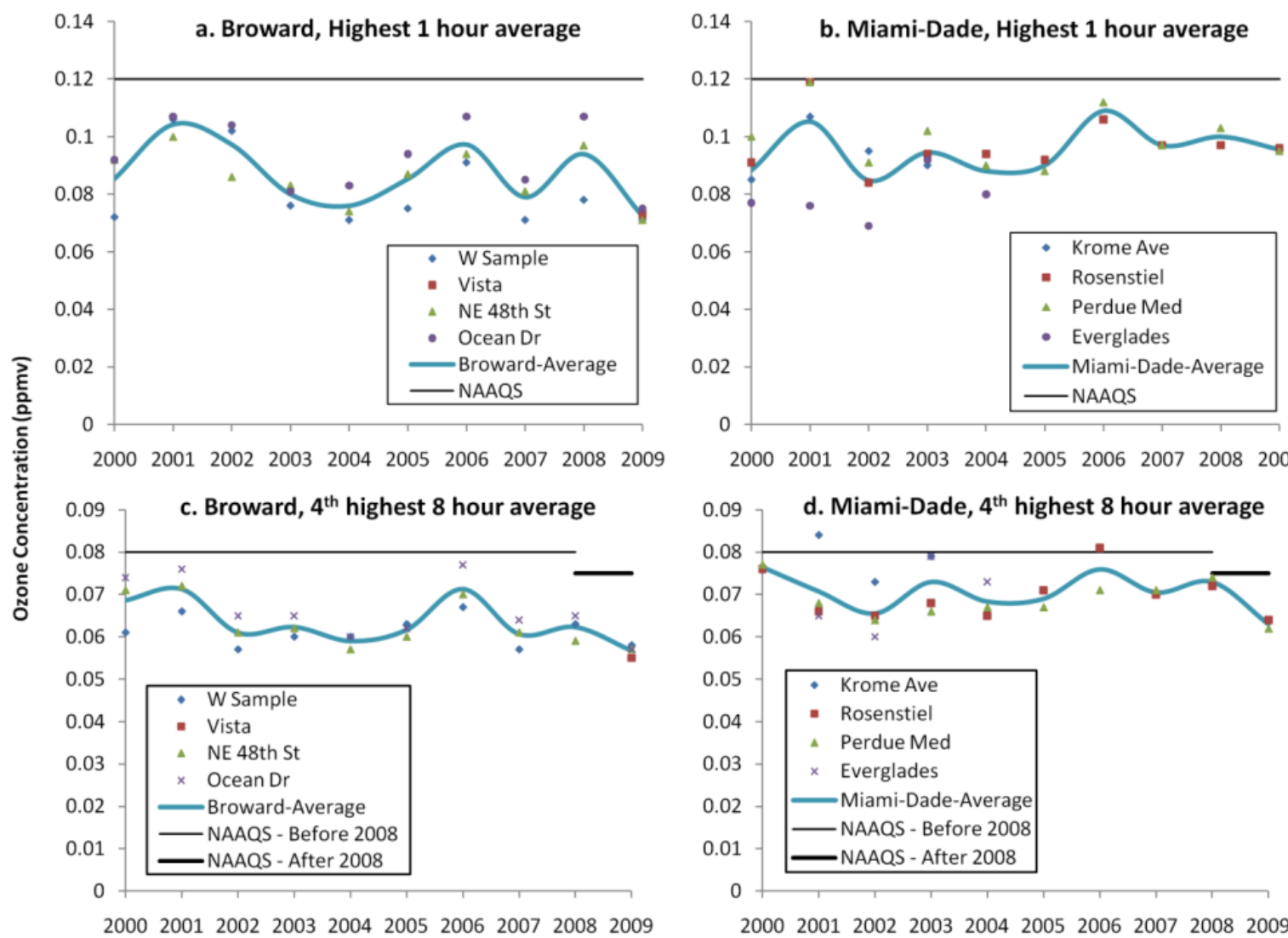

2000200120022003200420052006200720082009

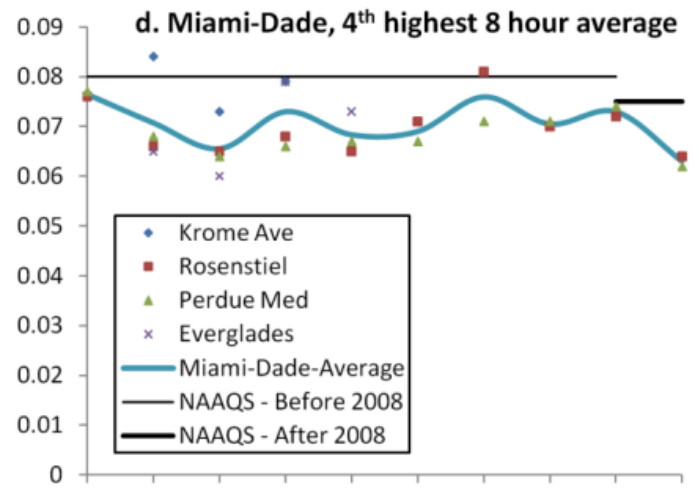

2000200120022003200420052006200720082009

Year

Figure 2-6. Multi-year trends in $\mathrm{O}_{3}$ concentrations in (a, c) Broward and (b, d) Miami-Dade counties. Calculated county average values are shown with solid lines. Differences in some data values reported in collected sources were found.

\subsubsection{Particulate matter}

PM consists of very small solid particles or liquid droplets that are suspended in the air.

Constituent particles vary greatly in diameter, shape and composition. USEPA categorizes and regulates particulate matter by size due to evidence for increased health effects for small-size particles. Health outcomes include premature death, hospital and emergency room visits, and increased respiratory and cardiovascular symptoms. The regulated size ranges are $\mathrm{PM}_{10}$ and 
$\mathrm{PM}_{2.5}$; the subscript refers to the aerodynamic diameter in micrometers of the largest particles in the category; $\mathrm{PM}_{10}$ refers to particles with diameters less than $10 \mu \mathrm{m}$. Particulate matter is both emitted directly from sources and formed in the atmosphere. Concentrations can be higher near sources such as roadways (particularly for $\mathrm{PM}_{10}$ ), but also typically exhibit widespread highs downwind of sources (particularly for $\mathrm{PM}_{2.5}$ ).

Figure 2-7 provides a map of PM monitoring sites in the study area during the period studied (2000-2009). In Broward County, 10 monitoring sites have been used, but only six (Lincoln Park, SW $70^{\text {th }}$, SW $3^{\text {rd }}$ Ave, Plunkett St, Winston, Vistas) were active in 2009. Miami-Dade County has had five sites, with three active in 2009 (PF, MF, and HF). See Table 2-2 for a listing of the period of active monitoring for each site.
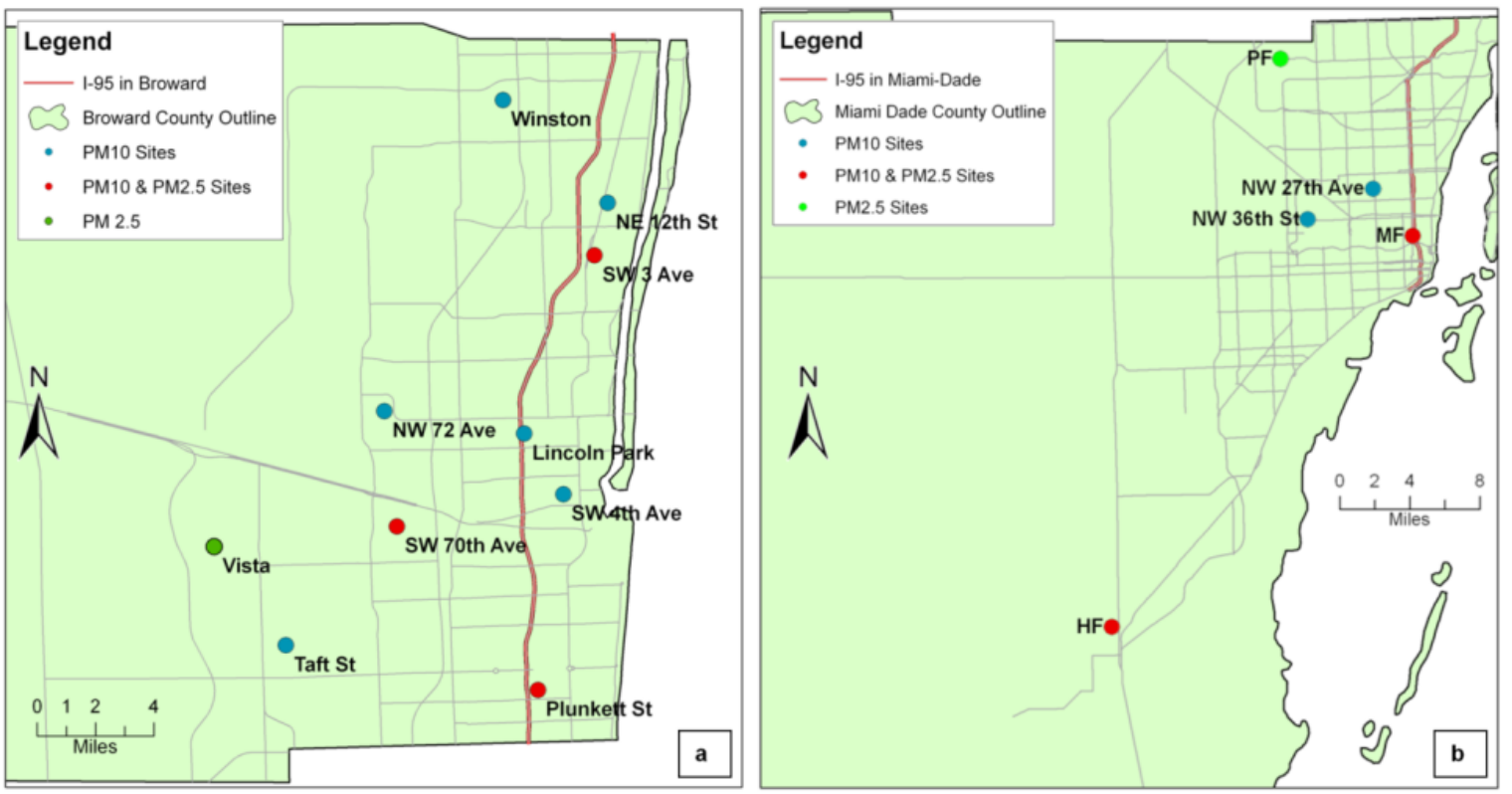

Figure 2-7. PM monitoring sites in (a) Broward and(b) Miami-Dade counties active sometime during $2000-2009$.

Several different methods have been used for PM monitoring in the study area, as shown in Table 2-3 and Table 2-4. This includes federal reference manual filter methods (e.g., methods 062 and 063 form $\mathrm{PM}_{10}$ and method 118 for $\mathrm{PM}_{2.5}$ ), co-located monitors used for quality assurance, and continuous methods used for obtaining time-resolved data (method 079 for $\mathrm{PM}_{10}$ and method 702 for $\mathrm{PM}_{2.5}$ ). To determine $\mathrm{PM}_{2.5}$ composition, each county also has one speciation sampler (method 810). Reported data from all methods were used in the analyses below. 


\subsubsection{1 $\underline{P M}_{10}$}

As the current NAAQS level for $\mathrm{PM}_{10}$ is based on a 24-hour average concentration, Figure 2-8 provides the multi-year trends in the highest 24-hour average concentrations at monitoring sites in both counties. Values range from 19 to $122 \mu \mathrm{g} / \mathrm{m}^{3}$ in Broward County; the lowest value was observed at Lincoln Park and Winston in 2009, and the highest values were observed at Plunkett St in 2007. In Miami-Dade County, values ranged from 31 to $64.5 \mu \mathrm{g} / \mathrm{m}^{3}$; the lowest value was observed at MF in 2008, and the highest values were observed at MF and NW 27th Ave in 2009 and 2003, respectively. No values exceed the current NAAQS standard of 150 $\mu \mathrm{g} / \mathrm{m}^{3}{ }^{5}$ Although substantial fluctuations exist, no clear multi-year trend is apparent. A peak in $\mathrm{PM}_{10}$ concentrations was observed from $2005-2008$ at Plunkett St and SW $3^{\text {rd }}$ Ave in Broward County, which are near the I-95 roadway.

Table 2-3. Particulate matter monitoring sites in the study area and monitoring method

\begin{tabular}{|c|c|c|c|c|}
\hline County & Site ID & Abbreviation & Monitoring Method & Type \\
\hline Broward & $12-011-0010$ & Lincoln Park & 062 & Manual \\
\hline Broward & $12-011-0011$ & SW 4th Ave & 062 & Manual \\
\hline \multirow[t]{2}{*}{ Broward } & \multirow{2}{*}{$12-011-1002$} & \multirow{2}{*}{ SW 70th Ave } & $\mathrm{N} / \mathrm{A}$ & Manual-2 \\
\hline & & & 062 & Manual \\
\hline \multirow{2}{*}{ Broward } & \multirow{2}{*}{$12-011-2004$} & \multirow{2}{*}{ SW 3 Ave } & 062 & Manual \\
\hline & & & 079 & Continuous \\
\hline \multirow{2}{*}{ Broward } & \multirow{2}{*}{$12-011-3002$} & \multirow{2}{*}{ Plunkett St } & 062 & Manual \\
\hline & & & 079 & Continuous \\
\hline Broward & $12-011-5002$ & Taft St & 062 & Manual \\
\hline Broward & $12-011-5005$ & Winston & 062 & Manual \\
\hline Broward & $12-011-6002$ & NW 72 Ave & 062 & Manual \\
\hline Broward & $12-011-7002$ & NE 12th St & 062 & Manual \\
\hline Miami-Dade & $12-086-0020$ & NW 36th St & 063 & Manual \\
\hline \multirow{2}{*}{ Miami-Dade } & \multirow{2}{*}{$12-086-1016$} & \multirow{2}{*}{ MF } & 063 & Manual-2 \\
\hline & & & 063 & Manual \\
\hline Miami-Dade & $12-086-3001$ & NW 27th Ave & 063 & Manual \\
\hline Miami-Dade & $12-086-6001$ & $\mathrm{HF}$ & 063 & Manual \\
\hline Broward & $12-011-0033$ & Vista & 702 & Continuous \\
\hline \multirow{4}{*}{ Broward } & \multirow{4}{*}{$12-011-1002$} & \multirow{4}{*}{ SW 70th Ave } & 118 & Manual-2 \\
\hline & & & 118 & Manual \\
\hline & & & 810 & Speciation \\
\hline & & & 702 & Continuous \\
\hline Broward & $12-011-2004$ & SW 3 Ave & 118 & Manual \\
\hline Broward & $12-011-3002$ & Plunkett St & 118 & Manual \\
\hline Miami-Dade & $12-086-0033$ & $\mathrm{PF}$ & 118 & Manual \\
\hline \multirow{4}{*}{ Miami-Dade } & \multirow{4}{*}{$12-086-1016$} & \multirow{4}{*}{ MF } & 118 & Manual-2 \\
\hline & & & 118 & Manual \\
\hline & & & 702 & Continuous \\
\hline & & & 810 & Speciation \\
\hline \multirow{2}{*}{ Miami-Dade } & \multirow{2}{*}{$12-086-6001$} & \multirow{2}{*}{$\mathrm{HF}$} & 118 & Manual \\
\hline & & & 702 & Continuous \\
\hline
\end{tabular}

\footnotetext{
${ }^{5}$ This threshold may not be exceeded more than once per year on average over three years.
} 
Table 2-4. Explanation of PM monitoring method

\begin{tabular}{|c|c|c|c|}
\hline$P M$ & Code & Category & Explanation \\
\hline \multirow{3}{*}{$\mathrm{PM}_{10}$} & 062 & Reference & $\begin{array}{l}\text { Wedding \& Associates/Thermo Environmental Instruments, } \\
\text { Inc. Model } 600 \mathrm{PM}_{10} \text { Critical Flow High-Volume Sampler }\end{array}$ \\
\hline & 063 & Reference & $\begin{array}{l}\text { Sierra-Andersen/General Metal Works Model } 1200 \text { PM}_{10} \\
\text { High-Volume Air Sampler System }\end{array}$ \\
\hline & 079 & Equivalent & $\begin{array}{l}\text { Thermo Scientific TEOM } \AA \text { 1400AB PM } 10 \text { Ambient Particulate } \\
\text { Monitor or Rupprecht \& Patashnick TEOM } ® \text { Series } 1400 \text { and } \\
\text { Series } 1400 \text { a } \mathrm{PM}_{10} \text { Monitors }\end{array}$ \\
\hline \multirow{3}{*}{$\mathrm{PM}_{2.5}$} & 118 & Reference & $\begin{array}{l}\text { Rupprecht \& Patashnick Partisol®-Plus Model } 2025 \\
\text { Sequential Air Sampler or Thermo Scientific Partisol-Plus } \\
2025 \text { Sequential Air Sampler }\end{array}$ \\
\hline & 702 & Non-Reference & $\begin{array}{l}\text { TEOM Gravimetric } \mathrm{PM}_{2.5} \text { Sharp Cut Cyclone (SCC) monitor } \\
\text { with correction factor }\end{array}$ \\
\hline & 810 & Non-Reference & Met-One speciation samplers (SASS) with Teflon filters \\
\hline
\end{tabular}
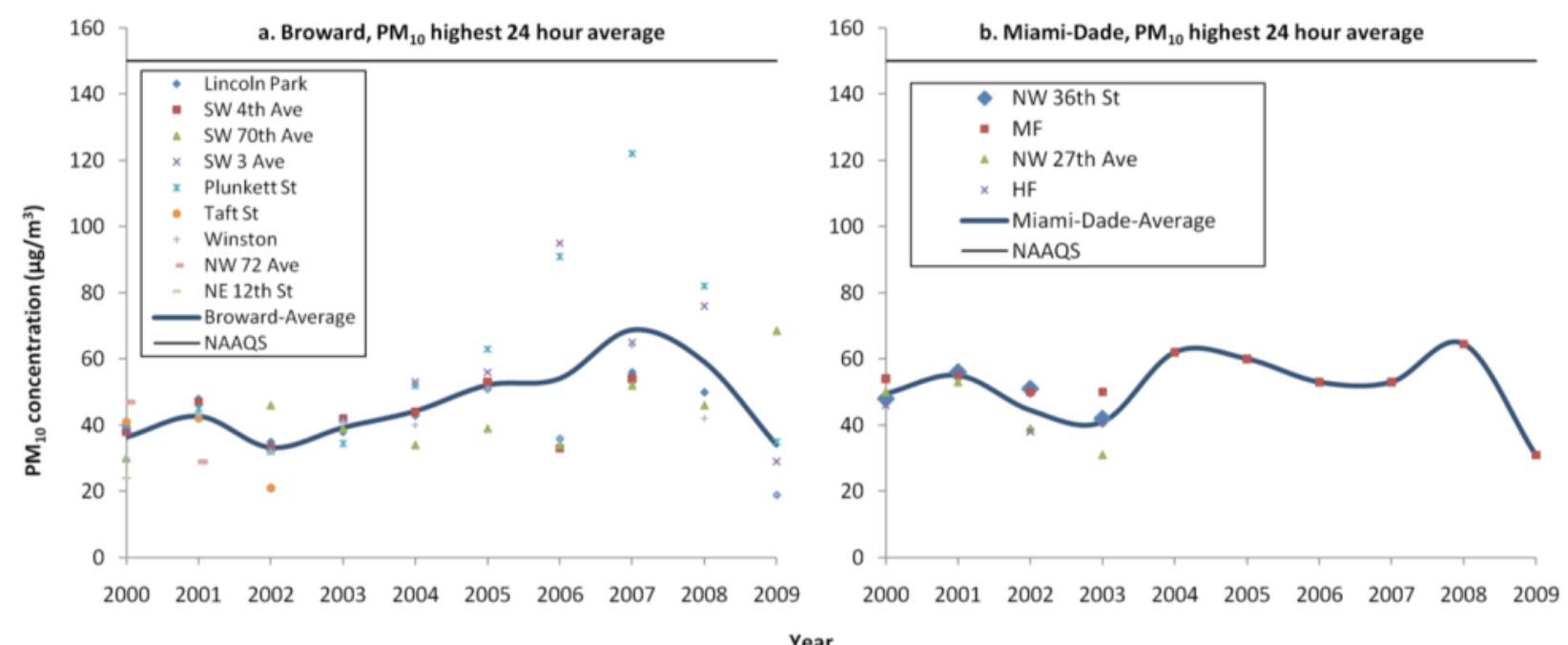

Figure 2-8. Maximum 24-hour average $\mathrm{PM}_{10}$ concentrations in (a) Broward and (b) Miami-Dade counties. Values at individual monitoring sites are averages of values from multiple monitors at each site. County averaged data are shown in solid lines.

\subsubsection{2 $\underline{\mathrm{PM}_{2.5}}$}

Measured $\mathrm{PM}_{2.5}$ concentrations are shown in Figure 2-9. The current NAAQS levels are 15 $\mu \mathrm{g} / \mathrm{m}^{3}$ for the annual average concentration ${ }^{6}$ and $35 \mu \mathrm{g} / \mathrm{m}^{3}$ for the $98^{\text {th }}$ percentile of the 24-hour average. ${ }^{7}$ Annual mean measured values ranged from $6.5 \mu \mathrm{g} / \mathrm{m}^{3}$ (Plunkett St, 2009) to 10.5 $\mu \mathrm{g} / \mathrm{m}^{3}$ (SW 70th Ave, 2007) in Broward County and from $6.1 \mu \mathrm{g} / \mathrm{m}^{3}$ (PF, 2009) to $12.8 \mu \mathrm{g} / \mathrm{m}^{3}$ (MF, 2006) in Miami-Dade County. None of these values exceeded the NAAQS level and concentrations appear to remain relatively constant on average over the decade. Values of the

\footnotetext{
${ }^{6}$ The three-year average of weighted annual average concentration may not exceed this threshold at any communityoriented monitoring site.

${ }^{7}$ The three-year average of the 98th percentile of 24-hour average concentrations may not exceed this threshold at each population-oriented monitoring site.
} 
98th percentile of the 24-hour average ranged from $10.2 \mu \mathrm{g} / \mathrm{m}^{3}$ (Plunkett St, 2009) to $37.6 \mu \mathrm{g} / \mathrm{m}^{3}$ (SW 70th Ave, 2007) in Broward County and from $11 \mu \mathrm{g} / \mathrm{m}^{3}$ (PF site, 2009) to $28.7 \mu \mathrm{g} / \mathrm{m}^{3}$ (MF site, 2007) in Miami-Dade County. A substantial peak in $\mathrm{PM}_{2.5}$ concentrations in Broward County was seen in 2007 at all sites, with the highest value exceeding the NAAQS level, but concentrations declined subsequently. Due to the fluctuations, there is no clear long-term trend; however, calculated county average values were lower in 2009 than 2000.

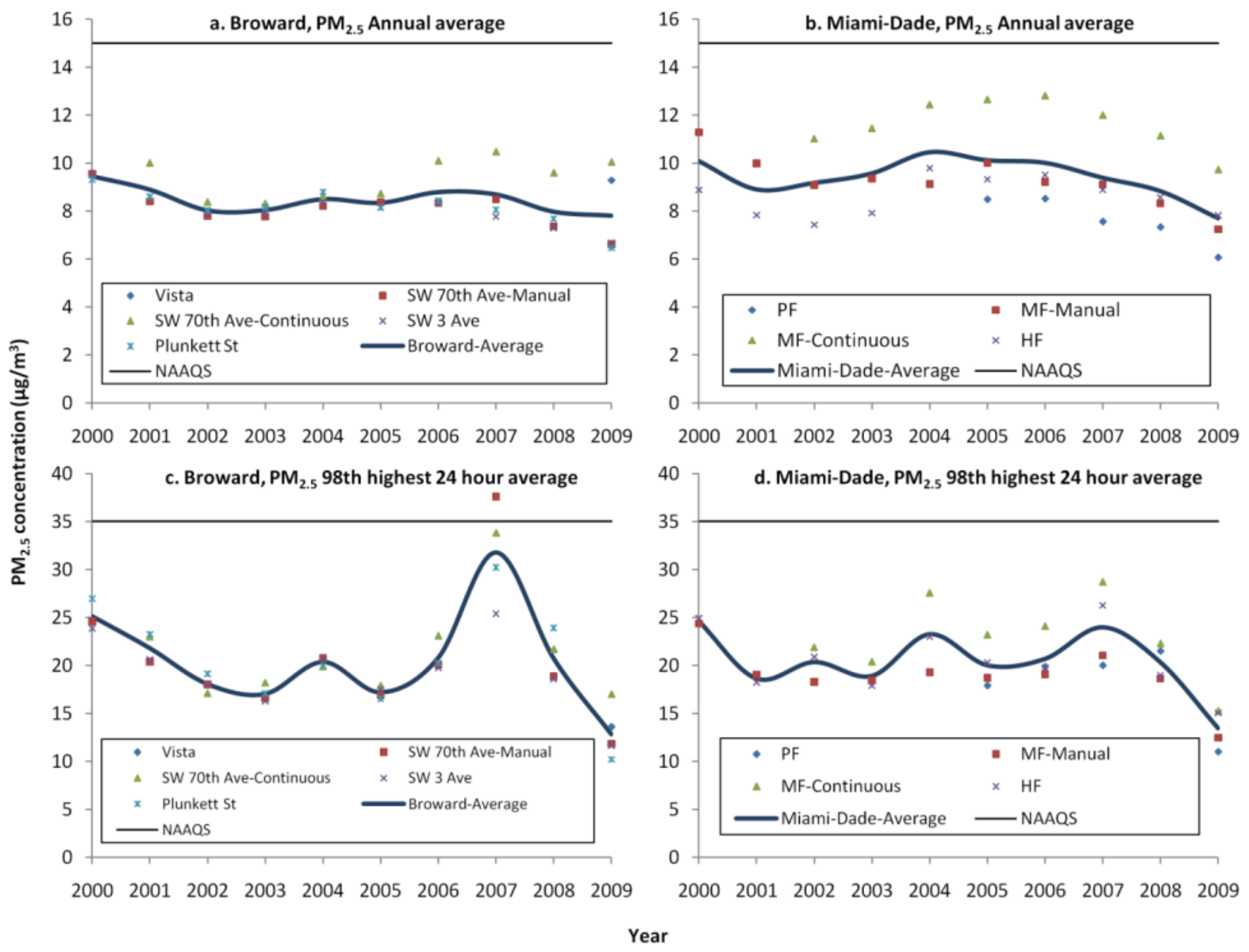

Figure 2-9. Measured $\mathrm{PM}_{2.5}$ concentrations in (a) Broward and (b) Miami-Dade counties.

Subplots $a$ and $b$ provide annual mean values at each monitoring site; $c$ and $d$ provide values of the $98^{\text {th }}$ percentile of the highest 24-hour average concentration. Calculated county averages are shown as solid lines.

\subsubsection{Air Quality Index}

The Air Quality Index (AQI) is a calculated metric of air quality that is based on the measured values of multiple criteria pollutants $\left(\mathrm{O}_{3}, \mathrm{PM}, \mathrm{CO}, \mathrm{SO}_{2}\right.$ and $\left.\mathrm{NO}_{2}\right)$. Its value ranges from 0 to 500 , with higher values considered more hazardous to health. Table 2-5 provides ranges of AQI values and the associated level of health concern. 
Table 2-5. Air Quality Index levels and their interpretation

\begin{tabular}{ccl}
\hline $\begin{array}{c}\text { Air Quality Index } \\
\text { Levels of Health } \\
\text { Concern }\end{array}$ & $\begin{array}{c}\text { Numerical } \\
\text { Value }\end{array}$ & \multicolumn{1}{c}{ Meaning } \\
\hline Good & $0-50$ & $\begin{array}{l}\text { Air quality is considered satisfactory, and air pollution } \\
\text { poses little or no risk. }\end{array}$ \\
\hline Moderate & $51-100$ & $\begin{array}{l}\text { Air quality is acceptable; however, for some pollutants } \\
\text { there may be a moderate health concern for a very small } \\
\text { number of people who are unusually sensitive to air } \\
\text { pollution. }\end{array}$ \\
\hline Sensitive Groups & $101-150$ & $\begin{array}{l}\text { Members of sensitive groups may experience health } \\
\text { effects. The general public is not likely to be affected. }\end{array}$ \\
\hline Unhealthy & $151-200$ & $\begin{array}{l}\text { Everyone may begin to experience health effects; } \\
\text { members of sensitive groups may experience more } \\
\text { serious health effects. }\end{array}$ \\
\hline Very Unhealthy & $201-300$ & $\begin{array}{l}\text { Health alert: everyone may experience more serious } \\
\text { health effects. }\end{array}$ \\
\hline Hazardous & $>300$ & $\begin{array}{l}\text { Health warnings of emergency conditions. The entire } \\
\text { population is more likely to be affected. }\end{array}$ \\
\hline
\end{tabular}

*Source: http://www.airnow.gov

Figure 2-10 shows the annual distributions of the daily Air Quality Index for Broward and MiamiDade counties over the period of study. The highest daily values, categorized as "Unhealthy," were seen in Broward County (two days in 2007 and one day in 2001). Overall in Broward County, approximately 80-90 percent of days are categorized as "Good," 10-20 percent are categorized as "Moderate," and a few days in some years are categorized as "Unhealthy for Sensitive Groups". More days not categorized as "Good" were seen during 2006-2008 than in other years. In Miami-Dade County, a slightly higher number of days (about 85-95\%) were "Good," with no "Unhealthy" days observed. There is no apparent multi-year trend.

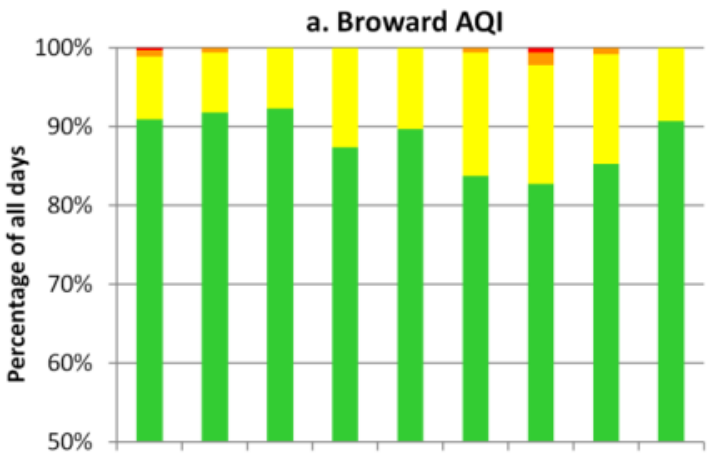

200120022003200420052006200720082009

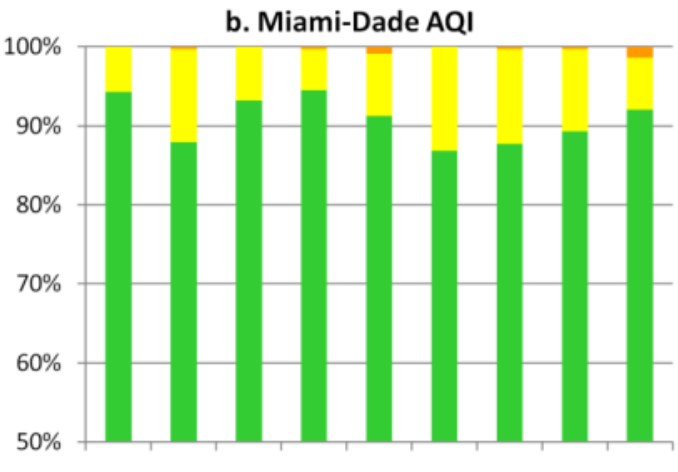

200020012002200320042005200620072008

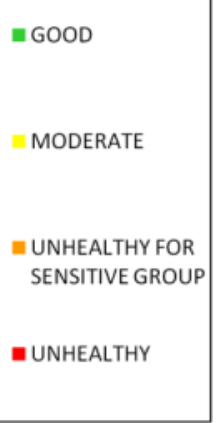

Year

Figure 2-10. Annual distributions in the daily Air Quality Index in (a) Broward and (b) MiamiDade counties. Values are from the local agency reports, which do not consider $\mathrm{SO}_{2}$ and $\mathrm{NO}_{2}$. AQI data from other sources did not provide tabulations over long enough periods for use. Data from 2001 to June 1, 2009 for Broward County and from 2000 to 2008 for Miami-Dade County are reported, based on data availability at the time of the analysis. 


\subsubsection{Organic pollutants}

In addition to criteria pollutants, there are many other air pollutants that are emitted from vehicles and considered harmful to health. Available data are discussed on the volatile organic compound group and on other select pollutants.

\subsubsection{Volatile organic compounds}

VOCs are a variety of gaseous chemicals that are emitted from vehicles, as well as a variety of industrial and natural sources. Exposure to some VOCs may cause adverse health effects ranging from minor irritation to serious effects. However, effects vary between constituents of the group. Hence, VOCs are no longer regulated as a group with NAAQS. Instead, individual chemicals are regulated as hazardous air pollutants (also called air toxics), discussed later. Nonetheless, VOCs are ozone precursors, i.e., they react with nitrogen oxides in the presence of sunlight to form ozone. Therefore, VOC monitoring occurs in support of the ozone NAAQS. As shown in Table 2-6, VOCs are monitored at four stations in Broward County and three stations in Miami-Dade County. However, different compounds were monitored and reported at each station, and some compounds were added or removed each year. No group sums were found. Additionally, some of the reported individual compounds are specifically excluded from the VOC category in the federal regulations (40 CFR 51.100). Hence, no further analyses were performed with the VOC monitoring data. Select air toxics associated with mobile sources were analyzed instead, as discussed below.

Table 2-6. List of VOC monitoring sites and available data period

\begin{tabular}{l|c|c|c}
\hline \multicolumn{1}{c|}{ County } & Site ID & Abbreviation & Data Available \\
\hline Broward & $12-011-1002$ & SW 70th Ave & $2000-2009$ \\
\hline Broward & $12-011-2004$ & SW 3 Ave & $2000-2008$ \\
\hline Broward & $12-011-3002$ & Plunkett St & $2000-2008$ \\
\hline Broward & $12-011-5005$ & Winston & $2000,2002-2009$ \\
\hline Miami-Dade & $12-086-0020$ & NW 36th St & $2002-2005$ \\
\hline Miami-Dade & $12-086-0029$ & Perdue Med & $2002-2005$ \\
\hline Miami-Dade & $12-086-4002$ & Annex & $2002-2003$ \\
\hline
\end{tabular}

\subsubsection{Select mobile source air toxics (benzene, acetaldehyde, and 1,3-butadiene)}

Another group of regulated air pollutants are called hazardous air pollutants. They are not regulated using NAAQS, but rather are regulated based on emissions and technology requirements. A subset of this group that is associated with vehicular sources is called mobile source air toxics. Three of these pollutants - benzene, acetaldehyde, and 1,3-butadiene - were 
selected for analysis here. For these pollutants, the analysis is based on USEPA data, as local agencies do not consistently report on these chemicals.

The monitoring sites in the study area for the selected pollutants are listed in Table 2-7. In Miami-Dade County, no data are available after 2006. In both counties, absorption media or canisters first capture hazardous air pollutants. Gas chromatography, followed by mass spectrometry or flame ionization detection, are used for separation, identification, and quantification. All data are reported as part per billion carbon ( $p p b c)$, which was converted to ppbv for the individual compounds.

Table 2-7. Monitoring sites for the focus pollutants, pollutants monitored at each site, and period of data availability

\begin{tabular}{l|c|c|c|c|c}
\hline \multicolumn{1}{c}{ County } & Site ID & Abbreviation & Benzene & Acetaldehyde & 1,3-Butadiene \\
\hline Broward & $12-011-1002$ & SW 70th Ave & $00-09$ & $05-07$ & $02-09$ \\
\hline Broward & $12-011-2004$ & SW 3 Ave & $00-08$ & $02-03$ & $02-08$ \\
\hline Broward & $12-011-3002$ & Plunkett St & $00-08$ & & $02-08$ \\
\hline Broward & $12-011-5005$ & Winston & $00,02-09$ & & $02-09$ \\
\hline Miami-Dade & $12-086-0020$ & NW 36th St & $02-05$ & & $02-05$ \\
\hline Miami-Dade & $12-086-0029$ & Perdue Med & $02-05$ & & $02-05$ \\
\hline Miami-Dade & $12-086-4002$ & Annex & & $02-03$ & \\
\hline
\end{tabular}

The first mobile source air toxic studied was benzene. Benzene is present in both exhaust and evaporative emissions from motor vehicles. Mobile sources account for approximately threefourths of outdoor emissions (USEPA 2000). Benzene is a known carcinogen. Short-term exposures to benzene are associated with irritation of the skin, eyes, and upper respiratory tract. Chronic exposures are also associated with disorders in the blood and immune system.

Figure 2-11 shows the highest measured 24-hour average and annual benzene concentrations in Broward and Miami-Dade counties. In Broward County, 24-hour values ranged from 0.52 ppbv to 6.3 ppbv (both at the Plunkett site, 2006 and 2003, respectively). In Miami-Dade County, they ranged from 0.58 ppbv (NW 36 Ave, 2005) to 1.3 ppbv (NW 36 Ave, 2002). The annual benzene concentration ranged from $0.18 \mathrm{ppbv}$ (Winston, 2006) to $1.6 \mathrm{ppbv}$ (Plunkett, 2003) in Broward County and 0.26 ppbv (Perdue Med, 2004) to 0.53 ppbv (NW 36 Ave, 2005) in Miami-Dade County. Overall, concentrations were lower in the second half of the decade than the first half. 


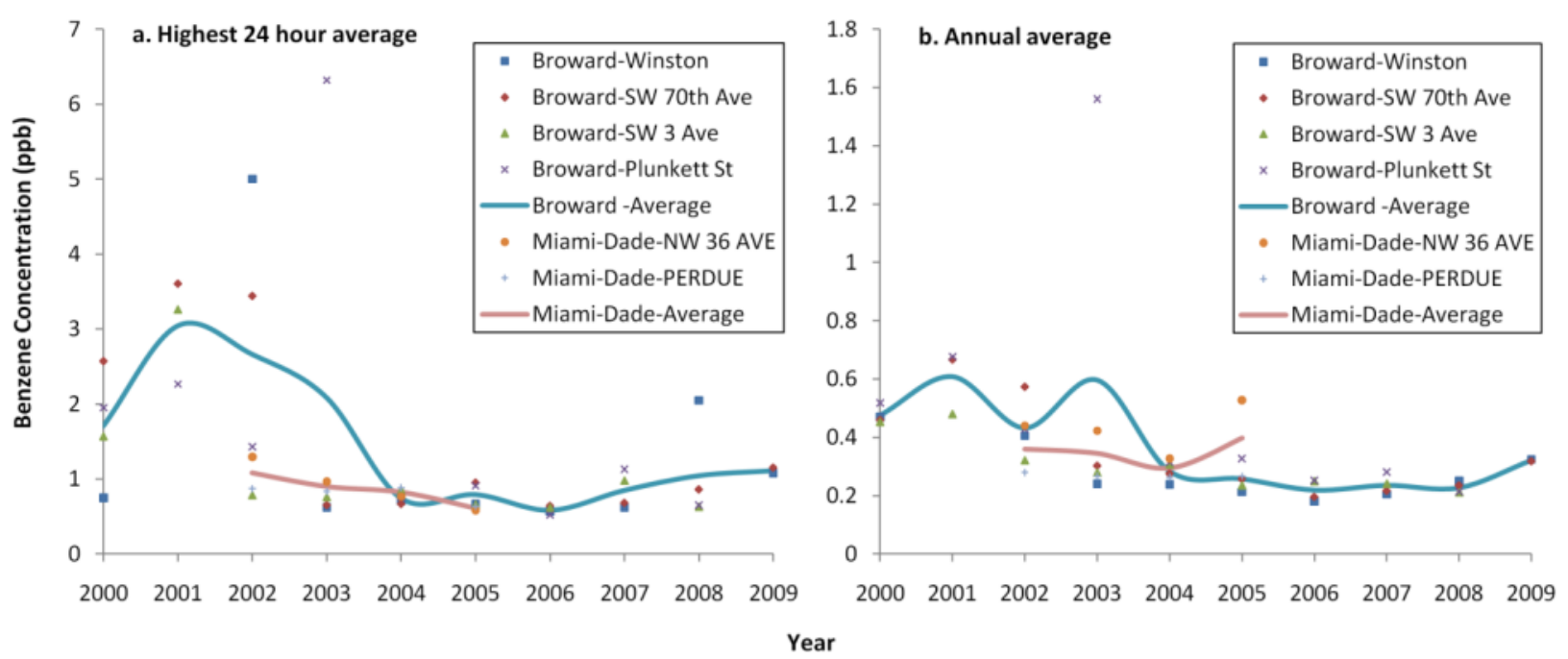

Figure 2-11. Measured benzene concentration in Broward and Miami-Dade counties. Calculated averages of all monitoring sites in a county are shown as solid lines.

Acetaldehyde was the second pollutant studied. It is emitted as a combustion by-product with mobile sources accounting for more than half of inventoried emissions (USEPA, 2000). Shortterm exposures to acetaldehyde may cause irritation of the skin, eyes and respiratory tract. Acetaldehyde is also an animal carcinogen; not enough data are available to classify it as a human carcinogen. Figure 2-12 provides available measured data on acetaldehyde concentrations in the study area. There are few data and values are scattered. The highest values were observed at SW 70th Ave in Broward County in 2006.

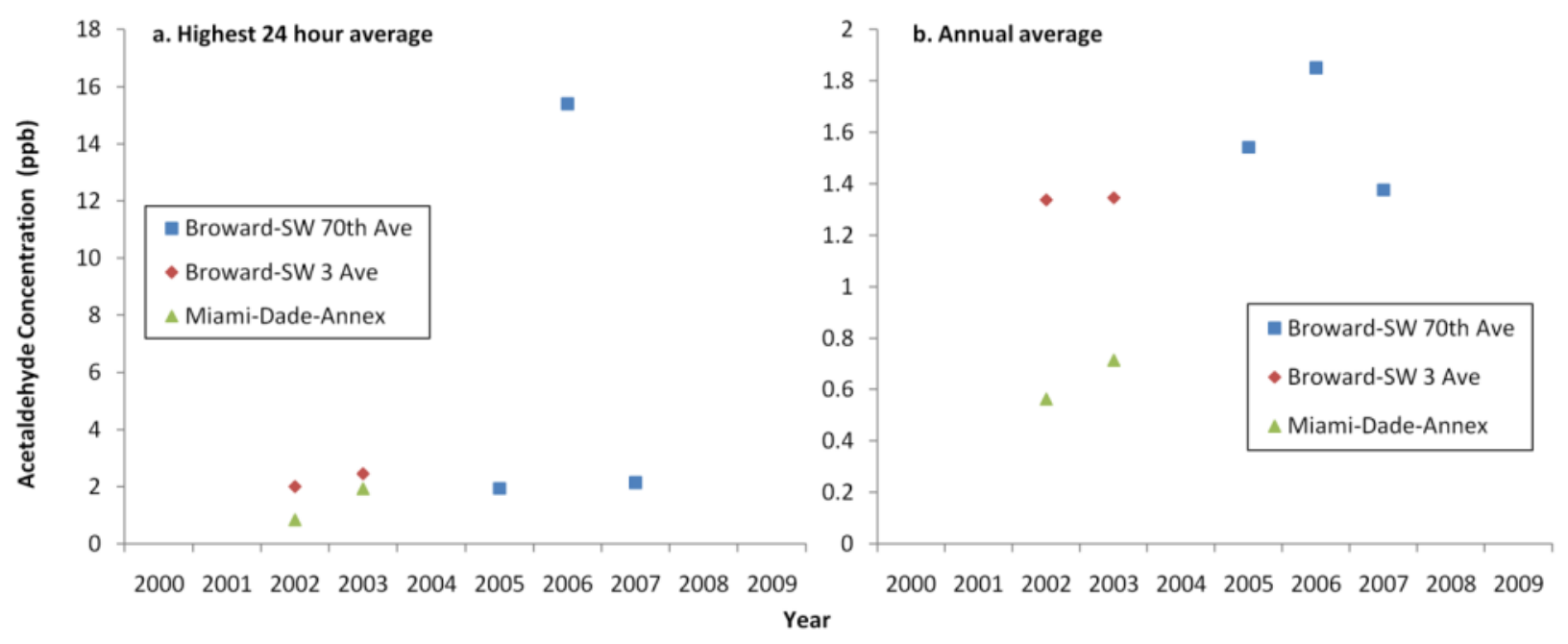

Figure 2-12. Acetaldehyde concentrations in the study area. 
1,3-Butadiene is also present in motor vehicle exhaust, with mobile source contributions accounting for over half of tabulated emissions (USEPA, 2000). It is classified as a known human carcinogen. It also may cause irritation to skin, eyes, and the respiratory tract. Figure 2-13 shows measured 1,3-butadiene concentrations in the study area. As for benzene, 1,3butadiene was monitored only between 2002 and 2005 in Miami-Dade County. The 24-hour average 1,3-butadiene concentration ranged from 0.05 ppbv (SW 70th Ave, 2009) to 1 ppbv (Plunkett, 2003) in Broward County and from 0.2 ppbv (NW 36 Ave and Perdue Med, 2005) to 0.9 ppbv (Perdue Med, 2003) in Miami-Dade County. The annual values ranged from 0.02 ppbv (Winston, 2009) to $0.13 \mathrm{ppbv}$ (Plunkett, 2003) in Broward County and from $0.06 \mathrm{ppbv}$ (Perdue Med, 2002) to 0.11 ppbv (NW 36 Ave, 2005) in Miami-Dade County. An overall downward trend in concentrations is observed over the decade, with a peak in 2003 and 2004, particularly at the Plunkett site.

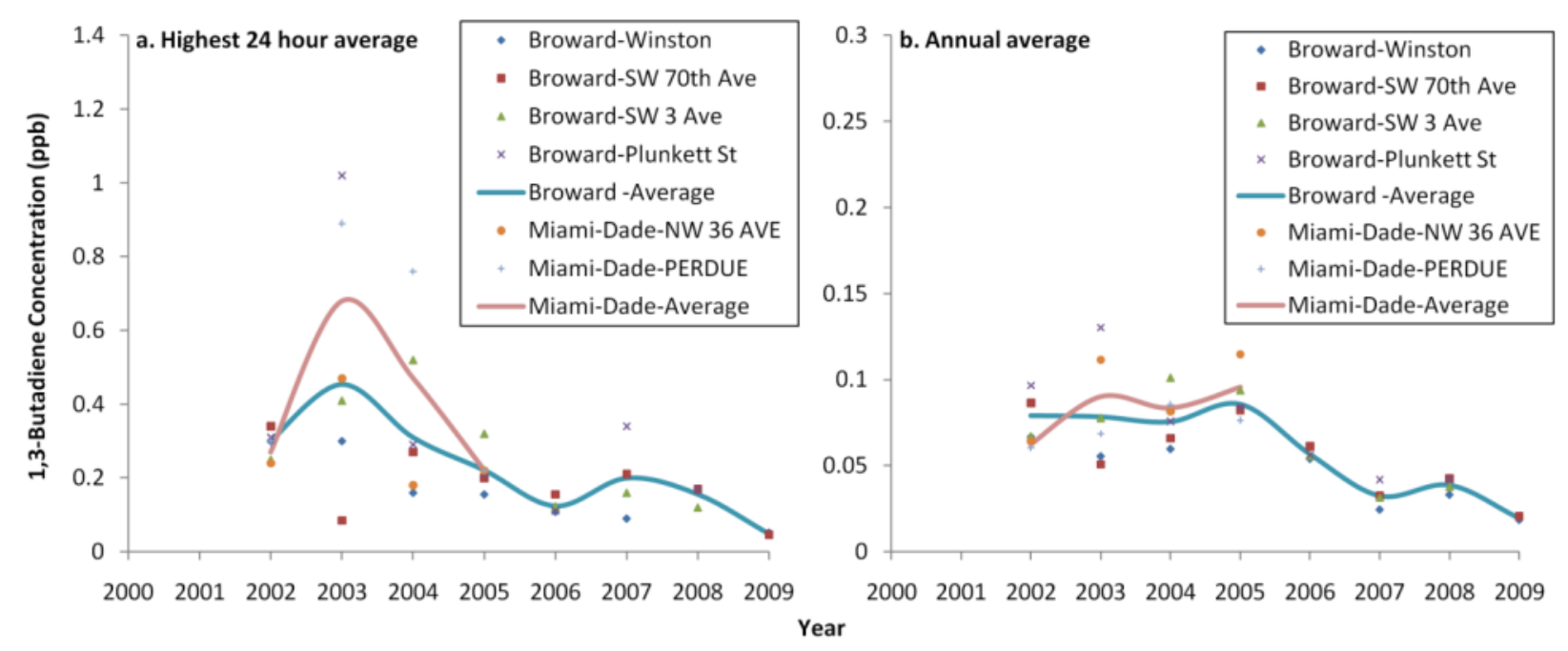

Figure 2-13. 1,3-butadiene concentration in the study area.

\subsection{Summary of baseline air quality and trends in the study area}

Available ambient air monitoring data from 2000 to June 2009 of several focus pollutants, including $\mathrm{CO}, \mathrm{NO}_{2}, \mathrm{PM}_{10}$ and $\mathrm{PM}_{2.5}$, VOCs, and three mobile source air toxics (benzene, acetaldehyde and 1,3-butadiene), were collected and compiled. Of these pollutants, data availability for the VOC category as a group was too limited for further analysis. For each of the other pollutants, individual monitoring site values and county average concentrations for multiple averaging times, including those relevant to the National Ambient Air Quality Standards (NAAQS), were calculated. Multi-year trends in time were plotted and compared with the NAAQS levels. Data on the daily Air Quality Index (AQI) were compiled with the multi-year trend 
in the annual distribution plotted. Finally, pollutant monitoring site locations were mapped relative to the I-95 project corridor to investigate impacts of roadway proximity.

Of the pollutants studied, only ozone and $\mathrm{PM}_{2.5}$ had measured levels at some sites in Broward County near to or slightly exceeding the NAAQS levels. ${ }^{8}$ The other criteria pollutants studied $\left(\mathrm{CO}, \mathrm{NO}_{2}\right.$, and $\left.\mathrm{PM}_{10}\right)$ had measured levels substantially lower than the NAAQS levels. However, a large fluctuation approaching the standard level during 2006-2008 was present in the $\mathrm{PM}_{10}$ measurement data at two sites in Broward County near the I-95. No ambient standard levels are applicable to the mobile source air toxics studied.

Impacts on concentrations of the proximity of monitoring sites to the I-95 roadway also were qualitatively assessed. $\mathrm{CO}, \mathrm{NO}_{2}$, and $\mathrm{PM}_{10}$ all have substantial primary (direct) emissions from sources and mobile sources contribute a large portion of their emissions amounts. Hence, concentrations often are higher near to sources, particularly large roadways. Correspondingly, the highest measured concentrations of these pollutants were observed at sites in close proximity to the I-95 (Annex and Lincoln Park for $\mathrm{CO}$, Annex for $\mathrm{NO}_{2}$, and SW 3 Ave and Plunkett for $\mathrm{PM}_{10}$ ). These monitoring sites may be useful as indicators of the effects of the managed lane project. Since $\mathrm{O}_{3}$ and $\mathrm{PM}_{2.5}$ have substantial contributions to their concentrations from secondary formation (i.e., chemical reactions in the atmosphere of emitted pollutants), the local monitoring site location relative to the any source is not expected to be very important. Additionally, the data do not show higher concentrations at sites in close proximity to the corridor.

Regarding multi-year trends in air quality, no clear trend (in increasing or decreasing concentrations) was seen in the $\mathrm{O}_{3}, \mathrm{PM}_{2.5}$, or $\mathrm{PM}_{10}$ measurement data, though county average values were lower in 2009 than in 2000 for all averaging times except for the maximum 1-hr average ozone concentration. For $\mathrm{CO}$ and $\mathrm{NO}_{2}$, the multi-year trend plots suggest slightly decreasing levels in the study area over the decade. For the mobile source air toxics studied, measurement data suggest lower concentrations of benzene and 1,3-butadiene in the later half of the decade. Data for acetaldehyde are too sparse to discuss trends. Distributions of the AQI suggest that the overall air quality with respect to criteria pollutants is better in Miami-Dade County than in Broward County. Only a few days during the decade in either county were categorized as "Unhealthy for Sensitive Groups," and very few as "Unhealthy" generally (and in Broward County alone).

\footnotetext{
${ }^{8}$ Note that this does not imply regulatory nonattainment with the NAAQS. The criteria for nonattainment involve specific data requirements, multi-year distribution parameters, and other factors. Rather, this is a comparison of the levels measured with those corresponding to the standard.
} 


\section{MOBILE SOURCE EMISSIONS (OBJECTIVE 2): METHODS AND FINDINGS}

As a step toward understanding impacts of the I-95 managed lane project on air quality, it is important to determine the change in mobile source emissions of air pollutants due to the implementation of the corridor project. To do this, a transportation corridor traffic microsimulation model (CORSIM) was selected and applied to simulate corridor traffic flow characteristics (traffic volumes and link speeds). Simulations were performed for scenarios representing conditions prior to the implementation of the managed lane project and after the implementation of Phases $1 \mathrm{~A}$ and $1 \mathrm{~B}$ of the project. Emissions then were calculated using the simulated traffic flow characteristics and emissions factors from the USEPA's MOBILE6.2 emissions factor model. Changes in emissions rates resulting from the managed lane project were analyzed, with a focus and assessing impacts on bus transit emissions. The focus pollutants for emissions calculations were carbon monoxide, nitrogen oxides, $\mathrm{PM}_{10}$, hydrocarbons, and benzene. Detailed information on these methods and the resultant findings are discussed below.

\subsection{Transportation corridor simulation modeling}

This study adopted a Traffic Software Integrated System Corridor-microscopic Simulation software package (generally referred as CORSIM). CORSIM is a traffic simulation model developed by the Federal Highway Administration (FHWA) and models traffic movements in time, with second-by-second resolution. The model assumes that individual vehicles travel based on car-following and lane-changing theories. Based on the car-following theory, a follower vehicle will maintain a desired headway between itself and the in-front vehicle, reacting to changes in speed of that vehicle. The behavior of the vehicle is dependent on how the car that leads it responds to traffic control and other conditions. Thus, the software is capable of simultaneously modeling integrated networks using commonly accepted vehicle and driver behaviors.

CORSIM was selected to simulate the operation performance of the HOT lanes and measure potential changes relevant to vehicle emissions, as it is considered as the most cost-effective option with affordable workloads to build networks. Additionally, model configurations for the I-95 HOT lane implementation were available from FDOT. It should also be noted that CORSIM was recommended by the Committee to Review EPA's Mobile Source Emissions Factor (MOBILE) Model (TRB 2000). Additionally, the Minnesota Department of Transportation has 
applied CORSIM to determine whether the implementation of a managed lane might degrade conditions on general-purpose lanes (GPLs).

\subsubsection{CORSIM model setup for I-95 study corridor}

The I-95 express lane project contains three phases - 1A, 1B, and 2. Phase 1A (northbound on I-95 from I-395 in downtown Miami to the Golden Glades Interchange) was opened in December 2008, and Phase 1B (southbound on I-95 from the Golden Glades Interchange to I395 in downtown Miami) was opened in January 2010. The study area is shown in Figure 3-1a, including the location of the project on I-95 between I-395 and the Golden Glades Interchange.

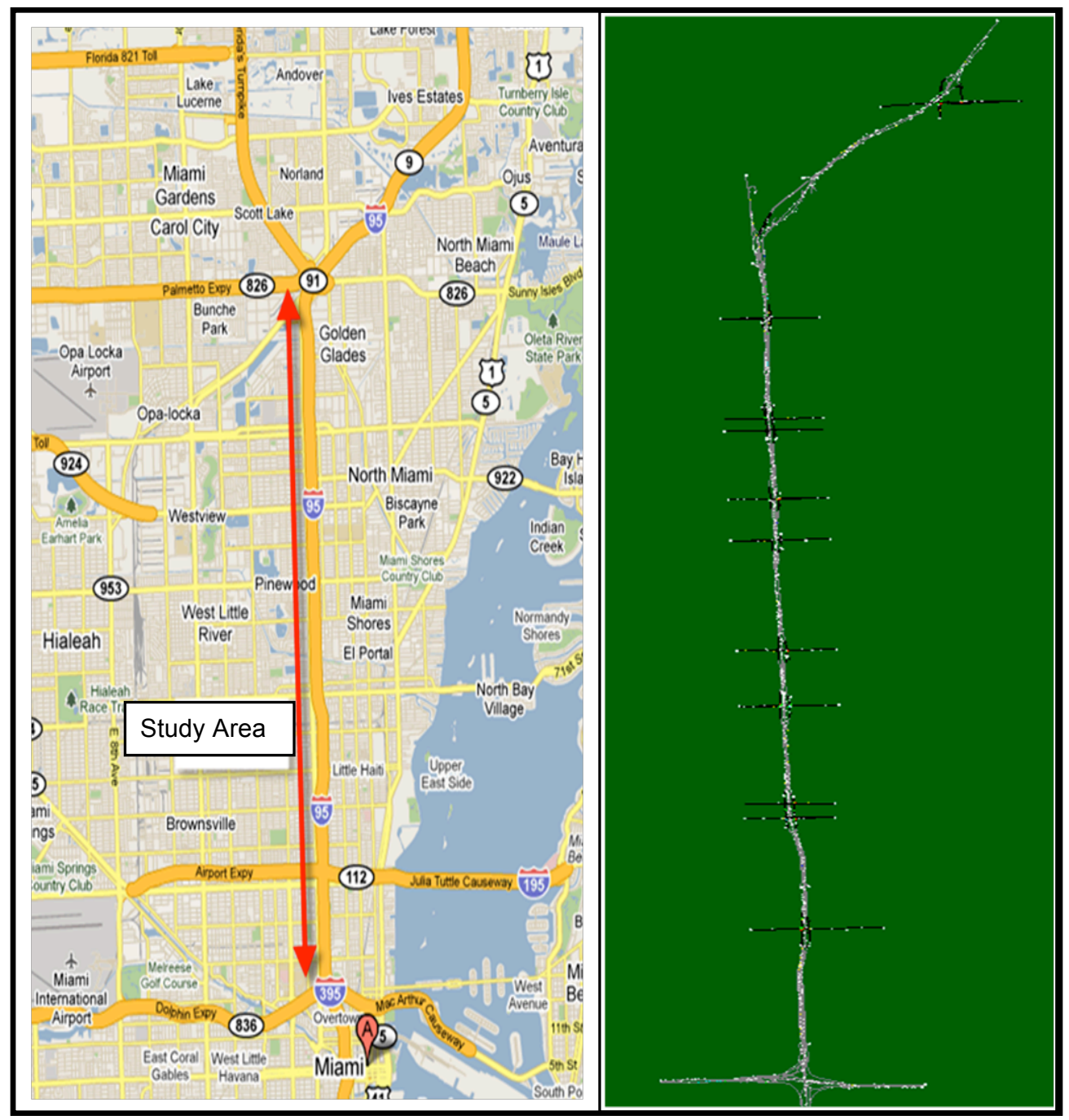

Figure 3-1. I-95 study corridor and corresponding CORSIM network.

CORSIM models for the I-95 express lanes project were obtained from FDOT District 6 and include a configuration representative of conditions prior to the I-95 express lane project, with 
one HOV lane and four GPLs, for both the morning and afternoon peak hours (07:00-09:00 and 15:30-17:30, respectively). This configuration was used as the pre-implementation baseline scenario for this analysis. A configuration representative of the conditions after Phase $1 \mathrm{~A}$ and Phase 1B for both peak-hour ranges also was available, with two HOT lanes and four GPLs. This was adopted as the post-implementation "after" scenario in this analysis. Other than the differences mentioned above, the geometric infrastructure in each configuration is the same. Figure 3-1b shows the basic simulation model for the corridor. The HOV lane was coded with the same links as the GPLs, and the HOT lanes were coded with separate links.

CORSIM volume input data were obtained from the Sunguide Transportation Management Center (TMC) for the year 2007, before the implementation of HOT lanes. The volume data from 2008 cannot be used due to construction at the site. Each model contains eight 15-minute intervals. Total input volumes and mode-share were kept constant in both scenarios. The split of the volumes on the HOT lanes and GPLs was based on the ratio of accurate traffic on two segments from the TMC data.

Regarding buses, the I-95 Express bus (95X) is the only transit service on I-95 between downtown Miami and the Golden Glades Interchange. The bus schedules differ for northbound and southbound lanes during peak hours (7:00 - 9:00, and 15:30 - 17:30). The bus route and schedule was added to the CORSIM models, with volumes shown in Figure 3-2. Buses use only the HOV and HOT lanes, not the GPLs. During morning peak hours, a total of 21 buses travel on the northbound lanes and 31 buses travel on the southbound lanes. During the afternoon peak hours, 29 buses travel northbound, while six buses travel southbound.

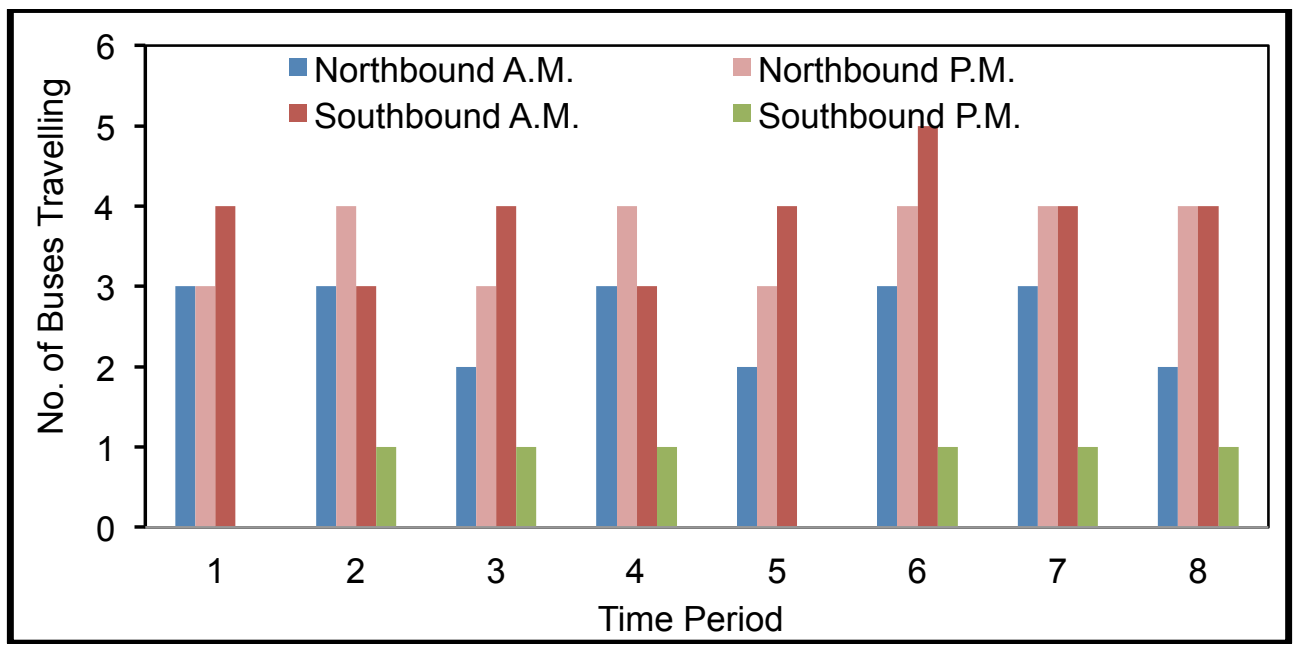

Figure 3-2. Bus volumes for northbound and southbound lanes during each time period. 


\subsubsection{CORSIM Calibration}

Calibration and validation form a crucial element of the simulation task. Because of the stochastic nature of traffic, variations between the model and observed data always are expected, and the onus is upon the model user to establish the desired reliability level and the validation effort required to achieve it. For the baseline scenario, the available model configuration and validation were reviewed and adopted. Since the after scenario models were built prior to the implementation of the project, additional calibration was needed on these. To do this, the research team conducted field data collection by real-time video recording as Phase $1 \mathrm{~A}$ construction was being completed. Four video cameras were installed on a vehicle. Two cameras on the top monitored the front and back geometry and traffic; another two on each side of the vehicle captured the traffic closest to the vehicle. The collected geometric information includes the number of general-purpose lanes and express lanes, locations of sequential entrances and exits, and number of lanes on on-ramps and off-ramps. Those segments that were still under construction (Phase 1B) could not be included in validation efforts. Results confirmed that the after scenario models properly represented the implementation of the I-95 express lanes project.

In addition, the Geoffrey E. Havers (GEH) method was used to calibrate the results. The GEH method is the criteria to calibrate freeway models in the Traffic Analysis Tools Program of the FHWA, which was developed by the Wisconsin Department of Transportation (WDOT 2002; FHWA 2004). For each individual link flow, the acceptable calculated GEH value should be less than 5.0. The GEH statistic is computed as:

$$
\mathrm{GEH}=\left[2(\mathrm{E}-\mathrm{V})^{2} /(\mathrm{E}+\mathrm{V})\right]^{0.5}
$$

where $E$ is the model estimated volume and $V$ is the field count volume. Traffic volume data were obtained from detectors of the Sunguide Transportation Management Center for morning peak hours and afternoon peak hours at 15-minute intervals. Ten locations, shown in Figure 33, were available when comparing the real detector data and CORSIM models. The GEH criteria were calculated for the after scenario model for eight periods in the morning peak hours from 07:00 to 09:00 and eight periods in the afternoon peak hours from 15:30 to 17:30. Based on the calculated GEH values, 98.75 percent of the segments in the morning and 95 percent of the segments in the afternoon meet the accepted calibration target criteria. 


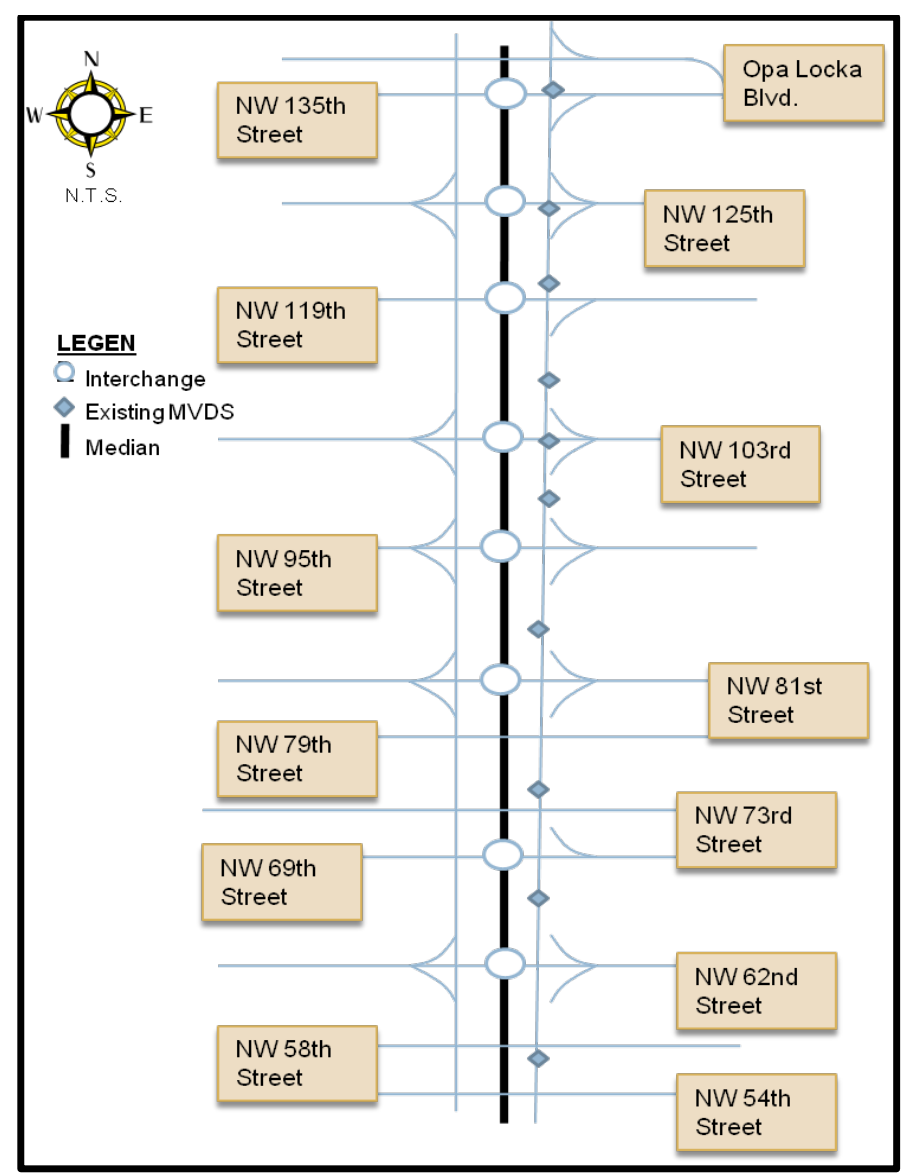

Figure 3-3. Phase 1A-NB 1-95 volume validation sites.

\subsubsection{Discussion of mode share impacts of managed lane implementation}

This project evaluated the changes in emissions due to converting one HOV lane to two HOT lanes on I-95 while four GPLs stayed the same. Since emissions can vary by vehicle type, it is important to understand changes of mode-share due to the lane conversion. HOV lanes are intended to encourage the use of alternate modes of transportation, such as transit, carpool, and vanpool, by providing an exclusive lane with decreased travel times. However, several previous studies have found that HOV lanes in the U.S. are underused due to the poor transit services, the scarcity of potential carpool matches, restricted accesses in some regions to highoccupancy vehicles carrying only two people, and inconvenience related to trip chaining (Kwon and Varaiya 2006; Evans 2009; Burris et al. 2009; Burris and Goel 2010). The concept of using HOT lanes is to increase the use of HOV lanes and provide the unused capacity of the HOV lanes to vehicles with fewer occupants than the HOV threshold. Thus, this capacity also would improve performance of the GPLs through displacement of some single occupancy vehicles (SOV) to HOT lanes by paying a toll. During recent years, HOT lanes have been considered an 
option for increasing the operational efficiency of managed lanes over existing HOV lanes. To determine the likelihood of mode share changes due to the study project, current implemented managed lane facilities in the U.S were examined.

Nine HOT/Express Toll facilities have been completed and eight HOT lanes are under development as of 2010 in the U.S. HOT lane implementations and their findings related to the change of mode-share are summarized in Table 3-1. Nine managed lane facilities, commonly HOT or Express Toll lanes, have been implemented in six states (California, Colorado, Florida, Minnesota, Texas, and Utah). No significant change in mode-share was found. This is consistent with the information from the "Transportation Emission Guidebook" (Dierkers et al. 2002). According the guidebook, about a one percent reduction in automobile use was estimated based on a case study. Based on the limited impact, mode-share was kept constant for both simulation models prior to and after the managed lane implementation.

Table 3-1. Findings of changes of mode-share due to current HOT implementation

\begin{tabular}{|c|c|}
\hline Managed Lane & Change of Mode Share \\
\hline $\begin{array}{l}\text { SR-91 Express } \\
\text { Lanes, Orange } \\
\text { County, CA }\end{array}$ & $\begin{array}{l}\text { - Based on limited bus and commuter rail, it was concluded that } 91 \text { express lanes } \\
\text { did not take patrons from corridor transit service. } \\
\text { - From } 1994 \text { through } 1999 \text {, the counts of PM peak HOV2 vehicles remained } \\
\text { essentially unchanged. }\end{array}$ \\
\hline $\begin{array}{l}\text { l-15 Express } \\
\text { Lanes, San } \\
\text { Diego }\end{array}$ & $\begin{array}{l}\text { - Switching to or from transit riders was not observed. } \\
\text { - Very few carpools were broken up by HOT lanes implementation. }\end{array}$ \\
\hline $\begin{array}{l}\text { Katy and } \\
\text { Northwest, } \\
\text { Houston }\end{array}$ & $\begin{array}{l}\text { - Based on a state survey, responses showed riders loyal to transit mode. } \\
\text { - In the evening peak, only } 1 \% \text { of HOT riders are diverted from HOV modes. }\end{array}$ \\
\hline $\begin{array}{l}\text { I-394 Express } \\
\text { Lanes, } \\
\text { Minneapolis }\end{array}$ & $\begin{array}{l}\text { - Comparing data from } 2004 \text { to } 2005 \text {, no change was found regarding mode } \\
\text { changes of previous transit users. } \\
\text { - No negative effect on carpooling was found due to implementation of MnPASS } \\
\text { HOT lanes. }\end{array}$ \\
\hline $\begin{array}{l}\text { I-25 Express } \\
\text { Lanes, Denver }\end{array}$ & $\begin{array}{l}\text { - No conclusions regarding effects on transit use were made since change in } \\
\text { ridership of concerned routes was very small (<0.5\% over a year). } \\
\text { - Changing rules from HOV to HOT did not have a large impact on most mode } \\
\text { choices. }\end{array}$ \\
\hline $\begin{array}{l}\text { l-15 Express } \\
\text { Lanes, Salt } \\
\text { Lake City }\end{array}$ & - No information or data available regarding mode-share. \\
\hline $\begin{array}{l}\text { SR-167 HOT } \\
\text { Lanes, Seattle }\end{array}$ & - No evidence showed HOT lane impact on transit ridership. \\
\hline $\begin{array}{l}\text { I-95 Express } \\
\text { Lanes, Miami }\end{array}$ & $\begin{array}{l}\text { - Transit mode remained relatively consistent }-3.6 \% \text { in } 2008,3.5 \% \text { in } 2009 \text {. } \\
\text { - Express Lane has limited impact on private auto users with regard to mode share }\end{array}$ \\
\hline
\end{tabular}




\subsubsection{CORSIM Results: Managed lane performance}

Each simulation model was repeated 10 times, and the output data were calculated by taking the average. Performance results are discussed, with a focus on impacts on bus transit.

Average speed results of the pre-implementation (baseline) and post-implementation (after) scenarios in the northbound direction are plotted in Figure 3-4. Results from both scenarios show that average speeds on the managed lanes (HOV/HOT) were slightly higher than on the GPLs. Prior to the HOT lane conversion, the I-95 corridor experienced heavy congestion, with speeds as low as $16 \mathrm{mph}$ on the pre-existing GPLs. Although the average link speeds for both the HOV lane and GPLs were around 40 to $50 \mathrm{mph}$ during morning peak hours, they decreased to 20 to $30 \mathrm{mph}$ for the afternoon peak hours. After implementation of the HOT lanes, speeds increased to 40 to $50 \mathrm{mph}$. This represents a significant increase of travel speeds on I-95 northbound during the afternoon peak hours. Therefore, implementation of HOT lanes relieved congestion on the I-95 corridor, especially for the peak hours. This result is consistent with the previous TMC data. Simulation results also are consistent with the midyear evaluation report on the I-95 corridor (FDOT 2009).

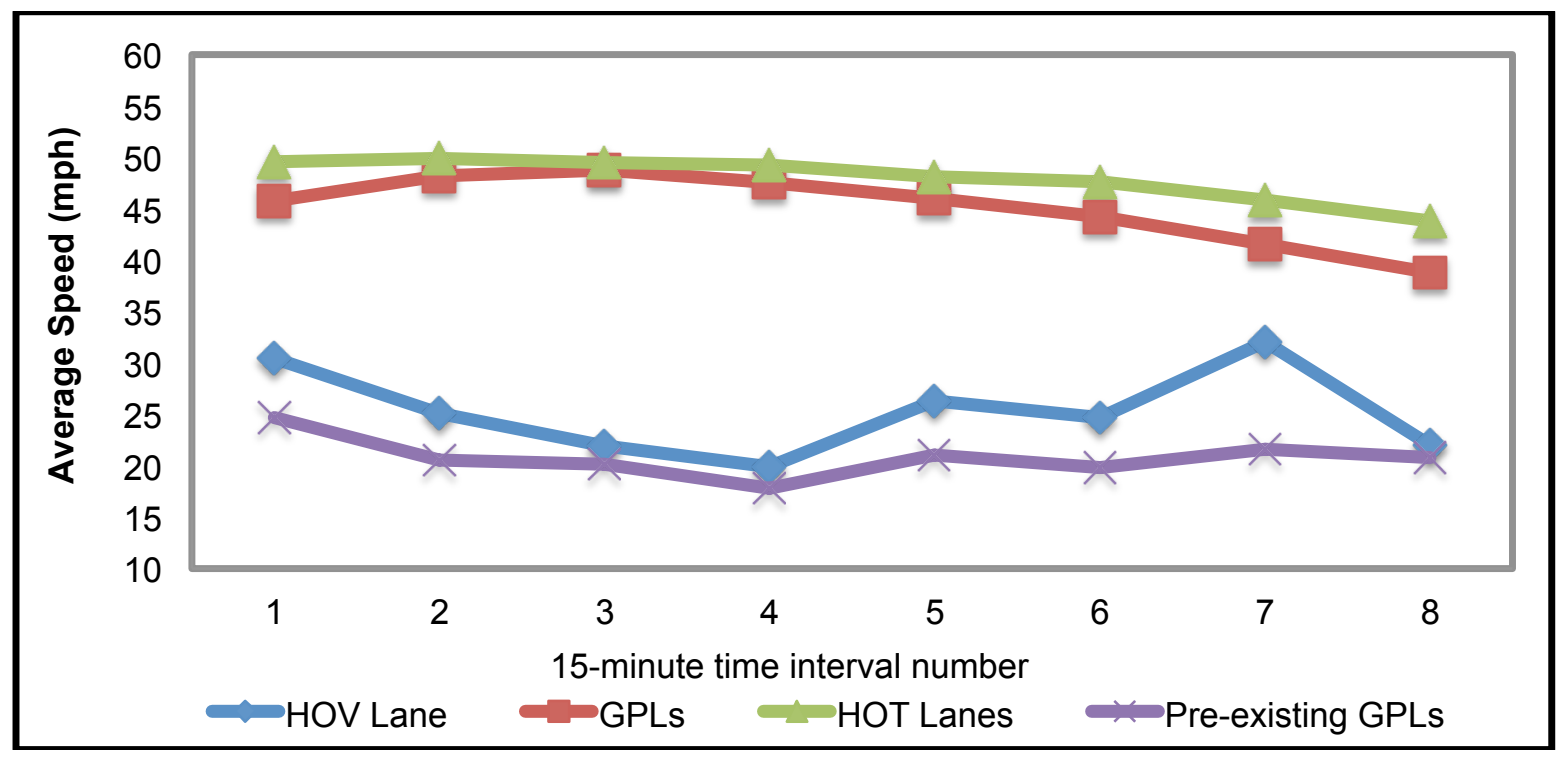

Figure 3-4. Average speeds on managed lanes and GPLs for each time interval during afternoon peak hours (15:30-17:30) for northbound lanes only.

Regarding transit buses, the implementation of HOT lanes relieves congestion and enhances bus speeds. An average of nine minutes savings for each bus traveling northbound during the afternoon peak hours is seen in model results, shown in Figure 3-5. However, for the southbound direction, only two minutes' savings are seen for all the buses on HOT lanes as 
compared to the HOV lane. These results are consistent with the transit evaluation report for 95 Express (FTA 2009), which found that the express lanes on I-95 have a significant impact on the northbound travel times of I-95 Express buses between downtown Miami and the Golden Glades interchanges.

\subsection{Emissions estimation}

To estimate emissions changes resulting from the case study project, simulated results of traffic parameters from the CORSIM transportation model were input into the MOBILE6.2 emissions factor model to obtain emission factors for all vehicles and for buses alone. The generated emissions factors were resolved by roadway link, pollutant, month and year. The emissions factors then were combined with extrapolated annual traffic data to calculate the annual emissions, as discussed below.

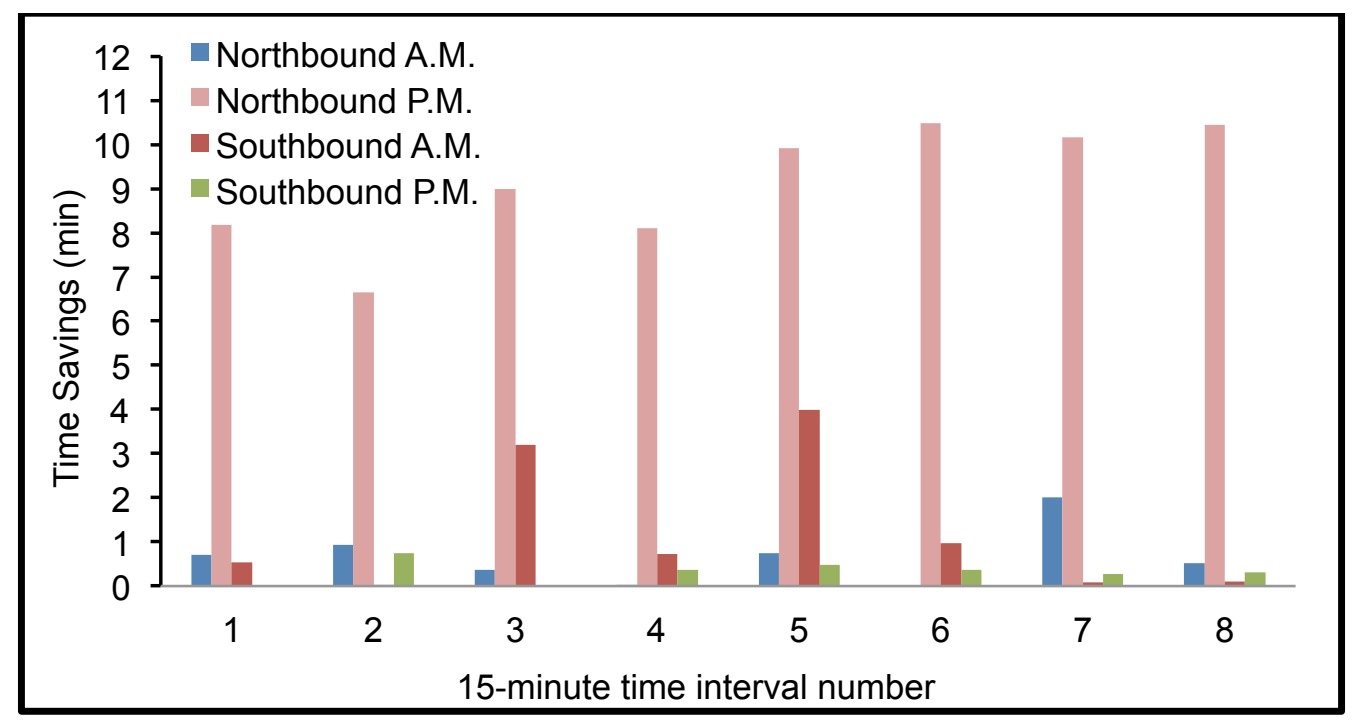

Figure 3-5. Time savings for northbound and southbound lanes during each 15-minute time interval of morning and afternoon peak hours simulated.

\subsubsection{Emission factors}

MOBILE6.2 was used to calculate emissions factors relevant to the corridor project. MOBILE6.2 is an established model for estimating pollutions emitted from on-road vehicles. Several pollutants can be addressed by MOBILE6.2, including hydrocarbons (HC), NOx, CO, PM, and select hazardous air pollutants. MOBILE6.2 has been widely used by federal, state, regional, and local planning agencies and organizations in many applications to evaluate motor vehicle emissions, including for State Implementation Plans (SIPs), National Environmental 
Protection Act (NEPA) analysis, transportation planning and conformity analysis, and environmental impact analysis. ${ }^{9}$

To use results from the CORSIM model for the calculation of emission factors using MOBILE6.2, some processing of the CORSIM results was required. This processing included mapping of the CORSIM vehicle classes to the MOBILE6.2 classes, as the two models have different vehicle classes. The mapping of categories of classes from CORSIM to MOBILE6.2 is shown in Table 3-2 (FHWA 2007; EPA 2001). The vehicle distribution percentages for comparable categories for the before-and-after scenarios also are listed. Note that these were adjusted to include bus counts. For example, buses are assumed to travel only in the HOT lanes, and not in the GPLs in the after scenario. Vehicle type distribution data from the 29 counting sites located on the ramps of I-95 modeling section also were obtained and compared with the vehicle distributions used in CORSIM and they were found to be similar. Distribution percentages from CORSIM then were allocated proportionally to the constituent MOBILE6.2 categories based on the default 2009 vehicle miles traveled (VMT) fraction in MOBILE 6.2 (EPA 2001; EPA 2004), as shown in Table 3-3. Also, CORSIM only includes the freeway facility. Hence, only freeway facilities were modeled with MOBILE6.2, by using VMT distribution input files.

Table 3-2. Mapping of vehicle class categories between CORSIM and MOBILE6.2 model, with vehicle distribution percentages based on CORSIM output

\begin{tabular}{|c|c|c|c|c|c|}
\hline \multirow{3}{*}{$\begin{array}{l}\text { CORSIM } \\
\text { class IDs }\end{array}$} & \multirow{3}{*}{$\begin{array}{l}\text { CORSIM vehicle } \\
\text { descriptions }\end{array}$} & \multirow{3}{*}{$\begin{array}{l}\text { Corresponding } \\
\text { MOBILE6.2 } \\
\text { classes }^{a}\end{array}$} & \multicolumn{3}{|c|}{ Vehicle distribution percentages } \\
\hline & & & \multirow{2}{*}{$\begin{array}{l}\text { Before } \\
\text { scenario, } \\
\text { all lanes }\end{array}$} & \multicolumn{2}{|c|}{ After scenario } \\
\hline & & & & GPLs & HOT lanes \\
\hline $1,2,8,9$ & $\begin{array}{l}\text { Low- and high performance } \\
\text { passenger cars, carpool and } \\
\text { individual occupancy }\end{array}$ & $\begin{array}{l}\text { LDV, LDT1, } \\
\text { LDT2, LDT3 } \\
\text { LDT4 }\end{array}$ & $95.859 \%$ & $96.0 \%$ & $95.5975 \%$ \\
\hline 3 & Single-unit truck & HDV2B - HDV7 & $1.2382 \%$ & $1.24 \%$ & $1.2348 \%$ \\
\hline 4,5 & $\begin{array}{l}\text { Semi-trailer truck with medium } \\
\text { and full loads }\end{array}$ & HDV8A & $2.3965 \%$ & $2.40 \%$ & $2.3899 \%$ \\
\hline 6 & Double-bottom trailer truck & HDV8B & $0.3595 \%$ & $0.36 \%$ & $0.3585 \%$ \\
\hline 7 & Conventional bus & HDBS, HDBT & $0.1469 \%$ & $0.00 \%$ & $0.4192 \%$ \\
\hline
\end{tabular}

${ }^{\mathrm{a}}$ Descriptions of MOBILE6.2 class identifiers are given in Table 3-2. GPLs are general-purpose lanes. HOT lanes are high-occupancy/toll lanes.

In addition to vehicle class mapping, processing of speed data also was required. CORSIM simulates average speeds for 15-minute time intervals on each roadway link for the four rush

\footnotetext{
${ }^{9}$ MOBILE6. 2 currently is being replaced for regulatory analysis with the MOVES model.
} 
hours of a typical weekday. To account for the diurnal variations in speed on each link in MOBILE6.2, external "Speed VMT" files were created for each link using 14 speed bins.

Speeds for hours corresponding to the CORSIM simulation were determined by averaging the 15-minute interval CORSIM link speed output data. Speeds during hours not modeled by CORSIM were assumed to be at the speed limit (55 mph).

Fuel and meteorological parameters used in MOBILE6.2 calculations were extracted from the National Mobile Inventory Model County Database (EPA 2005). Monthly varying fuel parameters for Miami-Dade County were used. Monthly varying meteorological parameters also were used. For 2009, the 20-year (1981-2000) average of hourly temperature and humidity were used due to lack of available data for that year at the time of analysis. Default data were used for other parameters, including the diesel sale fraction distributions among vehicle types.

Table 3-3. MOBILE6.2 vehicle classes and distribution percentages used for emissions calculations

\begin{tabular}{|c|c|c|c|c|c|}
\hline \multirow{2}{*}{$\begin{array}{c}\text { MOBILE6.2 } \\
\text { class ID }\end{array}$} & \multirow{2}{*}{$\begin{array}{c}\text { MOBILE6.2 vehicle class } \\
\text { description }\end{array}$} & \multirow{2}{*}{$\begin{array}{c}\text { Default } \\
2009 \\
\text { distribution }\end{array}$} & \multirow{2}{*}{$\begin{array}{c}\text { Before } \\
\text { scenario } \\
\text { distribution }\end{array}$} & \multicolumn{2}{|c|}{ After scenario } \\
\hline & & & & $\begin{array}{c}\text { GP lane } \\
\text { distribution }\end{array}$ & $\begin{array}{c}\text { HOT lane } \\
\text { distribution }\end{array}$ \\
\hline 1 & $\begin{array}{l}\text { LDV Light-Duty Vehicles } \\
\text { (Passenger Cars) }\end{array}$ & $36.6863 \%$ & $40.2687 \%$ & $40.3279 \%$ & $40.1588 \%$ \\
\hline 2 & LDT1 Light-Duty Trucks 1 & $8.6891 \%$ & $9.5376 \%$ & $9.5516 \%$ & $9.5116 \%$ \\
\hline 3 & LDT2 Light-Duty Trucks 2 & $28.9371 \%$ & $31.7627 \%$ & $31.8095 \%$ & $31.6761 \%$ \\
\hline 4 & LDT3 Light-Duty Trucks 3 & $8.9191 \%$ & $9.7900 \%$ & $9.8044 \%$ & $9.7633 \%$ \\
\hline 5 & LDT4 Light-Duty Trucks 4 & $4.0996 \%$ & $4.4999 \%$ & $4.5065 \%$ & $4.4876 \%$ \\
\hline 6 & $\begin{array}{c}\text { HDV2B Class } 2 b \\
\text { Heavy-Duty Vehicles }\end{array}$ & $3.8896 \%$ & $0.7157 \%$ & $0.7167 \%$ & $0.7137 \%$ \\
\hline 7 & $\begin{array}{c}\text { HDV3 Class } 3 \\
\text { Heavy-Duty Vehicles }\end{array}$ & $0.3800 \%$ & $0.0699 \%$ & $0.0700 \%$ & $0.0697 \%$ \\
\hline 8 & $\begin{array}{c}\text { HDV4 Class } 4 \\
\text { Heavy-Duty Vehicles }\end{array}$ & $0.3200 \%$ & $0.0589 \%$ & $0.0590 \%$ & $0.0587 \%$ \\
\hline 9 & $\begin{array}{c}\text { HDV5 Class } 5 \\
\text { Heavy-Duty Vehicles }\end{array}$ & $0.2400 \%$ & $0.0442 \%$ & $0.0442 \%$ & $0.0440 \%$ \\
\hline 10 & $\begin{array}{c}\text { HDV6 Class } 6 \\
\text { Heavy-Duty Vehicles }\end{array}$ & $0.8699 \%$ & $0.1601 \%$ & $0.1603 \%$ & $0.1596 \%$ \\
\hline 11 & $\begin{array}{c}\text { HDV7 Class } 7 \\
\text { Heavy-Duty Vehicles }\end{array}$ & $1.0299 \%$ & $0.1895 \%$ & $0.1898 \%$ & $0.1890 \%$ \\
\hline 12 & $\begin{array}{l}\text { HDV8A Class 8a } \\
\text { Heavy-Duty Vehicles }\end{array}$ & $1.1199 \%$ & $2.3965 \%$ & $2.4000 \%$ & $2.3899 \%$ \\
\hline 13 & $\begin{array}{l}\text { HDV8B Class } 8 b \\
\text { Heavy-Duty Vehicles }\end{array}$ & $3.9796 \%$ & $0.3595 \%$ & $0.3600 \%$ & $0.3585 \%$ \\
\hline 14 & HDBS School Buses & $0.2000 \%$ & $0.0979 \%$ & $0.0000 \%$ & $0.2795 \%$ \\
\hline 15 & $\begin{array}{l}\text { HDBT Transit and } \\
\text { Urban Buses }\end{array}$ & $0.1000 \%$ & $0.0490 \%$ & $0.0000 \%$ & $0.1397 \%$ \\
\hline 16 & MC Motorcycles & $0.5399 \%$ & $0.0000 \%$ & $0.0000 \%$ & $0.0000 \%$ \\
\hline
\end{tabular}


MOBILE6.2 modeling was performed for the following scenarios: 1) baseline scenario, 2) general-purpose lanes for the after scenario, and 3) HOT lanes for the after scenario. Five pollutants were included: $\mathrm{HC}, \mathrm{CO}, \mathrm{NOx}, \mathrm{PM}_{10}$, and benzene. Evaporative emissions other than running evaporative emissions were omitted because these activities are not modeled by CORSIM. Seven types of particulate emissions were included: exhausted $\mathrm{SO}_{4}$, exhaust lead, organic carbon and elemental carbon from diesel vehicle exhaust, total carbon, and brake-wear and tire-wear particles.

Emissions factors output from MOBILE6.2 were resolved by year, month, pollutant, and link. Emissions factors for buses alone also were obtained to calculate bus emissions. Annual average emission factors for 2009 are listed in Table 3-4 to Table 3-8. Note that it is assumed that there are no buses traveling on the GPLs in the after scenario.

\subsubsection{Daily and annual traffic estimation}

To estimate annualized emissions, traffic information is needed throughout the day and year. Since CORSIM simulates only four rush hours of a typical day, external diurnal and annual profiles were applied, as discussed here.

Diurnal and monthly traffic patterns, shown in Figure 3-6, were derived from 2007 hourly vehicle count data obtained from a traffic monitoring site located on I-95 (site ID: 860331) The count site is approximately five miles from the north end of the section of I-95 modeled by CORSIM. Data for the northbound and southbound lanes were averaged separately to obtain hourly average traffic counts for both directions. Average daily total traffic counts for 12 months also were calculated.
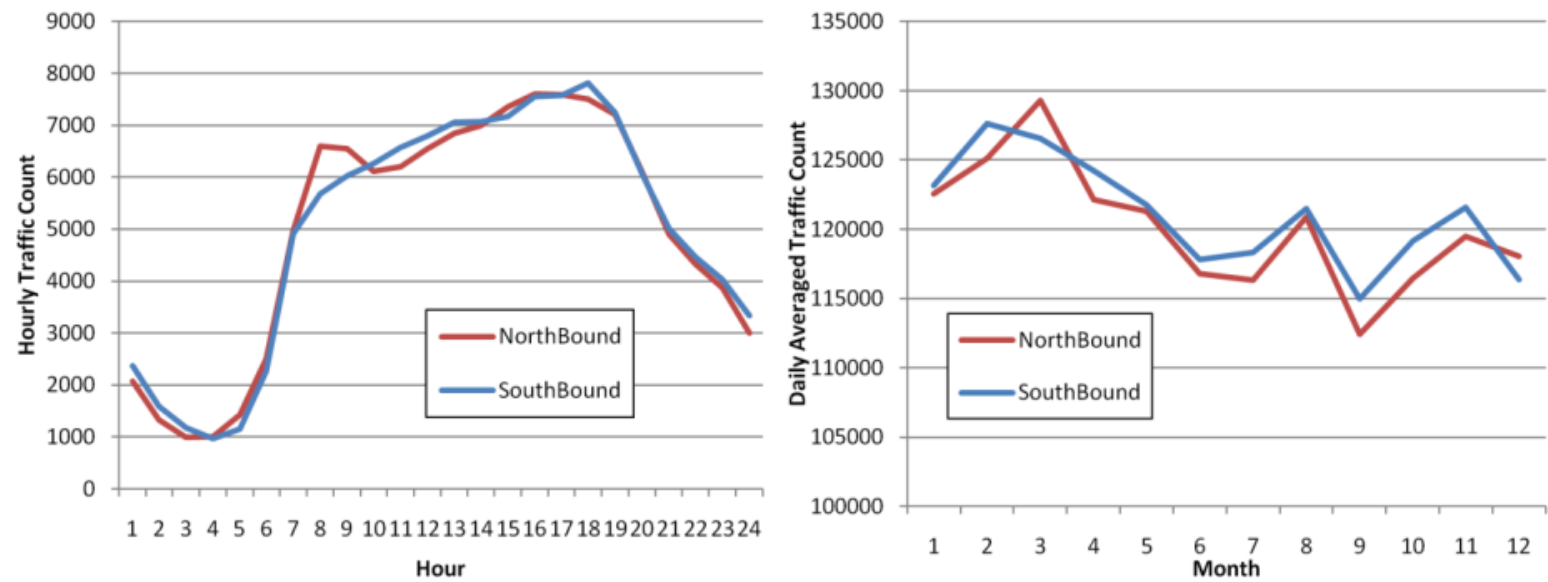

Figure 3-6. Diurnal and monthly traffic count distributions for northbound and southbound lanes. 
Table 3-4. All-vehicle annual average emissions factors (g/mile) for the before scenario

\begin{tabular}{c|c|c|c|c|c}
\hline Pollutant & $\mathbf{2 0 0 5}$ & $\mathbf{2 0 0 6}$ & $\mathbf{2 0 0 7}$ & $\mathbf{2 0 0 8}$ & $\mathbf{2 0 0 9}$ \\
\hline Benzene & 0.0323 & 0.0287 & 0.026 & 0.0228 & 0.0205 \\
\hline $\mathrm{CO}$ & 15.43 & 13.49 & 12.6 & 11.64 & 10.83 \\
\hline $\mathrm{HC}$ & 1.31 & 1.22 & 1.15 & 1.07 & 0.98 \\
\hline $\mathrm{NOx}$ & 1.46 & 1.33 & 1.21 & 1.11 & 1.01 \\
\hline $\mathrm{PM}_{10}$ & 0.0398 & 0.0377 & 0.0361 & 0.0344 & 0.033 \\
\hline
\end{tabular}

Table 3-5. All-vehicle annual average emission factors (g/mile) for after scenario general-purpose lanes

\begin{tabular}{c|c|c|c|c|c}
\hline Pollutant & $\mathbf{2 0 0 5}$ & $\mathbf{2 0 0 6}$ & $\mathbf{2 0 0 7}$ & $\mathbf{2 0 0 8}$ & $\mathbf{2 0 0 9}$ \\
\hline Benzene & 0.0318 & 0.0282 & 0.0256 & 0.0225 & 0.0202 \\
\hline $\mathrm{CO}$ & 15.65 & 13.67 & 12.77 & 11.8 & 10.98 \\
\hline $\mathrm{HC}$ & 1.27 & 1.18 & 1.11 & 1.03 & 0.95 \\
\hline $\mathrm{NOx}$ & 1.45 & 1.32 & 1.2 & 1.1 & 1 \\
\hline $\mathrm{PM}_{10}$ & 0.0388 & 0.0369 & 0.0353 & 0.0337 & 0.0324 \\
\hline
\end{tabular}

Table 3-6. All-vehicle annual average emission factors (g/mile) for after scenario HOT lanes

\begin{tabular}{c|c|c|c|c|c}
\hline Pollutant & $\mathbf{2 0 0 5}$ & $\mathbf{2 0 0 6}$ & $\mathbf{2 0 0 7}$ & $\mathbf{2 0 0 8}$ & $\mathbf{2 0 0 9}$ \\
\hline Benzene & 0.0317 & 0.0281 & 0.0255 & 0.0224 & 0.0201 \\
\hline $\mathrm{CO}$ & 15.63 & 13.65 & 12.75 & 11.77 & 10.95 \\
\hline $\mathrm{HC}$ & 1.26 & 1.17 & 1.1 & 1.03 & 0.95 \\
\hline $\mathrm{NOx}$ & 1.5 & 1.37 & 1.25 & 1.14 & 1.05 \\
\hline $\mathrm{PM}_{10}$ & 0.0415 & 0.0393 & 0.0374 & 0.0356 & 0.0342 \\
\hline
\end{tabular}

Table 3-7. Annual average emissions factors for buses alone for the before scenario ( $\mathrm{g} / \mathrm{mile})$

\begin{tabular}{c|c|c|c|c|c}
\hline Pollutant & $\mathbf{2 0 0 5}$ & $\mathbf{2 0 0 6}$ & $\mathbf{2 0 0 7}$ & $\mathbf{2 0 0 8}$ & $\mathbf{2 0 0 9}$ \\
\hline Benzene & 0.0042 & 0.0036 & 0.0031 & 0.0027 & 0.0024 \\
\hline $\mathrm{CO}$ & 3.19 & 3.01 & 2.74 & 2.42 & 2.14 \\
\hline $\mathrm{HC}$ & 0.39 & 0.34 & 0.29 & 0.25 & 0.22 \\
\hline $\mathrm{NOx}$ & 18.75 & 17.83 & 16.83 & 15.69 & 14.6 \\
\hline $\mathrm{PM}_{10}$ & 0.63 & 0.5 & 0.4 & 0.31 & 0.26 \\
\hline
\end{tabular}

Table 3-8. Annual average emission factors $(\mathrm{g} / \mathrm{mile})$ for buses alone for after scenario HOT lanes

\begin{tabular}{c|c|c|c|c|c}
\hline Pollutant & $\mathbf{2 0 0 5}$ & $\mathbf{2 0 0 6}$ & $\mathbf{2 0 0 7}$ & $\mathbf{2 0 0 8}$ & $\mathbf{2 0 0 9}$ \\
\hline Benzene & 0.0039 & 0.0034 & 0.0029 & 0.0025 & 0.0022 \\
\hline $\mathrm{CO}$ & 2.97 & 2.8 & 2.56 & 2.25 & 1.99 \\
\hline $\mathrm{HC}$ & 0.36 & 0.31 & 0.27 & 0.23 & 0.21 \\
\hline $\mathrm{NOx}$ & 18.97 & 18.04 & 17.02 & 15.88 & 14.77 \\
\hline $\mathrm{PM}_{10}$ & 0.63 & 0.5 & 0.4 & 0.31 & 0.26 \\
\hline
\end{tabular}


Hourly traffic count data also were obtained from 12 counting sites located in Miami-Dade County. After excluding missing and poor quality data, the county average diurnal and monthly profiles were calculated and compared with the profiles calculated based on data site 860331 . As shown in Figure 3-7, the diurnal patterns were very similar, but the monthly patterns were somewhat different. Because it is located on I-95, the diurnal and monthly pattern from site 860331 was considered more representative and was used for further analysis.
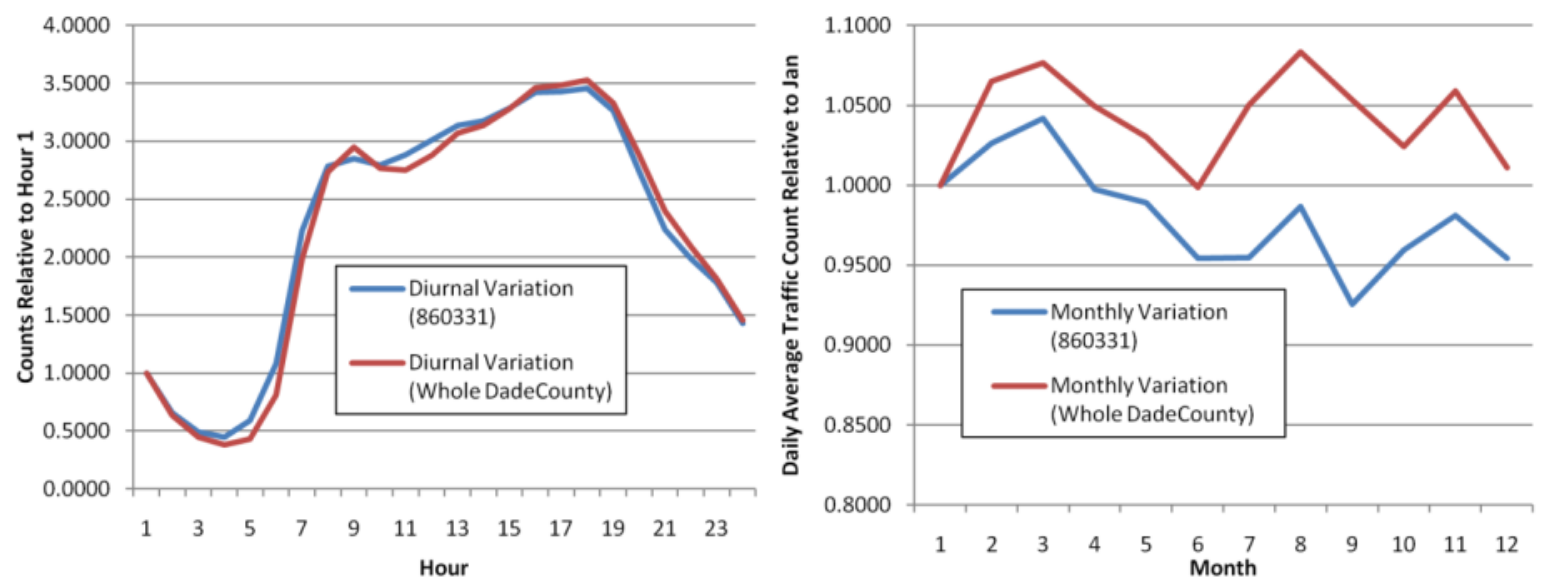

Figure 3-7. Comparison of diurnal and monthly traffic count distributions between site 860331 and the Miami-Dade County average.

A total daily traffic volume for emissions calculations was extrapolated from the CORSIM data by dividing the sum of the CORSIM traffic counts by the fraction of the total measured average daily count represent by the hours in the model, i.e.:

$$
T_{d}=\frac{\sum_{h} t_{h}}{\sum_{h} f_{h}}
$$

where $T_{d}$ is the total daily traffic volume, $t_{h}$ is the CORSIM derived traffic count for hour $h$, and $f_{h}$ is the measurement data derived fraction of the total count for hour $h$. To obtain monthly varying traffic counts, this value was proportionally extrapolated using the monthly distribution from the measurement data.

\subsubsection{Emissions}

Daily emissions for each month were calculated by multiplying the MOBILE6.2 emissions factor for the corresponding month with the roadway link length and the estimated daily traffic counts. Monthly total emissions then were estimated by multiplying the daily emissions for each month with number of days in that month. Monthly total emissions were summed together to get annual total emissions. For the after scenario, emissions from HOT lanes and GPLs were summed to 
obtain the total emissions for the after scenario. Estimated 2009 annual emissions for the five pollutants are shown in Table 3-9.

Figure 3-8 shows a comparison of the relative annual emissions for the five chosen pollutants before and after the HOT lane implementation. As seen in the figure, the HOT lane implementation led to increased total emissions for all pollutants considered except HCs, though increases were small. Emissions from buses alone did, however, decrease.

Table 3-9. Estimated 2009 annual emissions (tons)

\begin{tabular}{c|c|c|c|c}
\hline Pollutants & $\begin{array}{c}\text { Before scenario } \\
\text { total }\end{array}$ & $\begin{array}{c}\text { After scenario } \\
\text { total }\end{array}$ & $\begin{array}{c}\text { Before scenario } \\
\text { buses alone }\end{array}$ & $\begin{array}{c}\text { After scenario } \\
\text { buses alone }\end{array}$ \\
\hline $\mathrm{CO}$ & 6657.19 & 6892.08 & 2.12 & 1.91 \\
\hline $\mathrm{NOx}$ & 623.21 & 640.36 & 14.27 & 14.17 \\
\hline $\mathrm{HC}$ & 604.07 & 595.01 & 0.22 & 0.2 \\
\hline Benzene & 12.58 & 12.65 & 0.0024 & 0.0021 \\
\hline $\mathrm{PM}_{10}$ & 20.28 & 20.69 & 0.25 & 0.24 \\
\hline
\end{tabular}
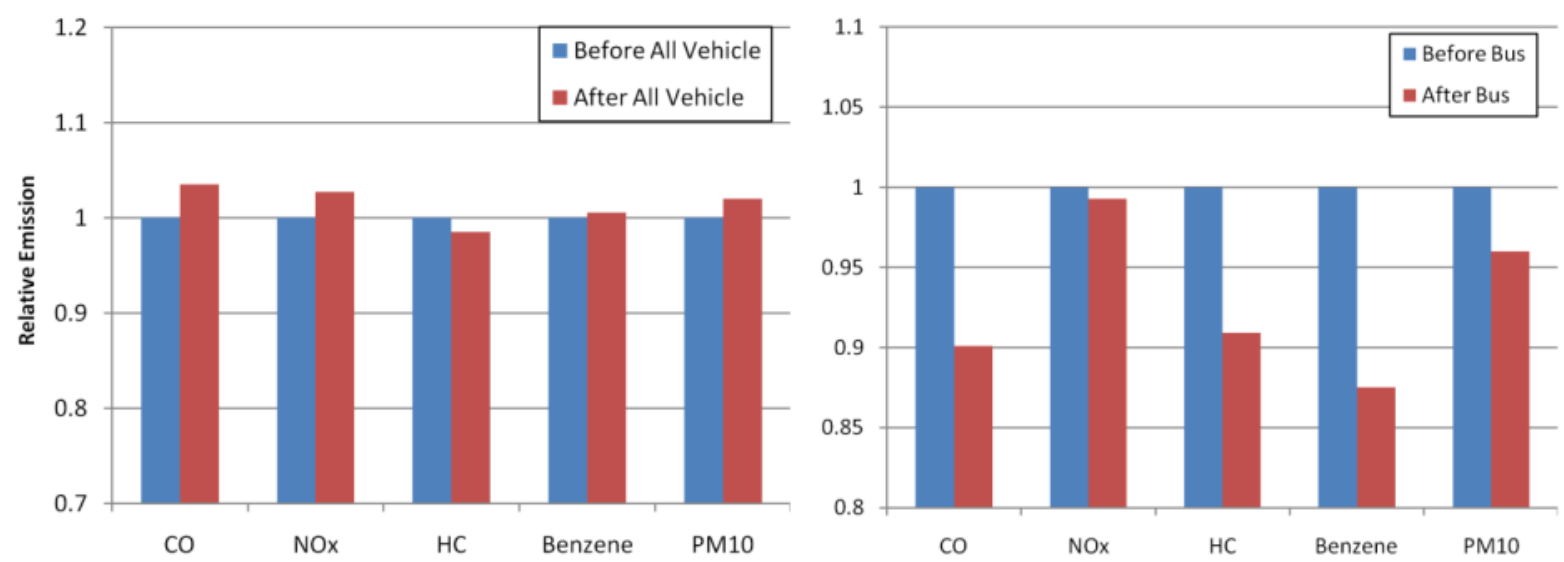

Pollutants

Figure 3-8. Estimated relative emissions before and after managed lane implementation. The before scenario emissions have been set to the reference value of 1 for this comparison.

\subsubsection{Discussion of factors influencing emissions changes}

As seen above, emissions from the corridor for all scenarios increased somewhat for the after scenario. To understand these increases, the parameters influencing emissions were investigated and uncertainties are discussed here.

Two primary constituent parameters can affect estimated emissions: the amount of vehicle miles traveled and emissions factors (mass of pollutant per vehicle mile traveled). If either of these parameters increases independently, emissions will increase. Table 3-10 shows the change in emissions along with the change in each of the constituent factors. Annual miles 
travelled increase by 2 percent, on average. For $\mathrm{CO}, \mathrm{NOx}$, and $\mathrm{PM}_{10}$, the emissions factors increase (on average), consistent with the change in emissions. Conversely, for the HCs the emissions factors decrease (on average), counteracting the increase in miles traveled. For benzene, the emission factors decrease is less, leading to smaller overall increases in emissions.

Table 3-10. Percentage change in 2009 annual emissions and primary parameters contributing to emissions for after vs. before scenario

\begin{tabular}{|c|c|c|c|}
\hline Pollutant & Annual emissions & Emissions factors $^{a}$ & Annual miles traveled ${ }^{a}$ \\
\hline $\mathrm{CO}$ & $3.5 \%$ & $1.2 \%$ & \multirow{5}{*}{$2 \%$} \\
\hline NOx & $2.8 \%$ & $1.3 \%$ & \\
\hline $\mathrm{PM}_{10}$ & $2.0 \%$ & $0.74 \%$ & \\
\hline $\mathrm{HCs}$ & $-1.5 \%$ & $-3.7 \%$ & \\
\hline Benzene & $0.54 \%$ & $-1.7 \%$ & \\
\hline
\end{tabular}

${ }^{a}$ Note that emissions are calculated on a link-by-link basis using disaggregated emissions factors (over $100,000)$, volumes, and link lengths. The values listed here are based on simple averages of individual values to demonstrate overall differences.

\subsubsection{Discussion of emissions uncertainties}

It is useful to consider uncertainty in the emissions, as they are functions of the traffic conditions that may be impacted by project. Therefore, uncertainties in emissions factors and vehicle miles traveled are discussed here.

Emissions factors are functions of vehicle speed and vehicle type. To understand the associated uncertainties, emissions factors output from CORSIM's internal emission factor calculator were considered in comparison to MOBILE6.2 emissions factors. A sensitivity analyses also was performed on impacts of speed on emissions factors.

CORSIM is capable of calculating emissions factors internally for $\mathrm{CO}, \mathrm{NO}_{\mathrm{x}}$ and $\mathrm{HCs}$ for each link and vehicle class type. As a comparison to the MOBILE6.2 emissions, CORSIM emission factors were produced based on the default emissions factor tables in the model. On average, emission factor values output by CORSIM decreased for the after scenario compared with the before scenario. Since this result is the opposite of that found using MOBILE6.2, a comparison of the effects of important traffic conditions was performed. Specifically, sensitivity analyses were performed on the effects of speed using both MOBILE6.2 and CORSIM.

As discussed in Section 3.1.4, travel times on the corridor improved after the implementation of the HOT lanes. Specifically, speeds in the northbound lanes increased from about 20-30 mph to 45-50 mph during the afternoon rush hours. Since emission factors are a function of speed, this can impact emissions. Sensitivity analysis with speed varying in both MOBILE6.2 and CORSIM indicate different impacts of speed on the emissions factors for the different models. 
In MOBILE6.2, the change in speed had little impact on the emissions factors for $\mathrm{CO}$ and $\mathrm{NO}_{\mathrm{x}}$, as shown in Figure 3-9a, due to the shape of the emission factor curve. However, for the CORSIM emission factors, shown in Figure 3-9b, emission factor values consistently decrease as speed increase over the range of speed improvements found here. This leads to a difference in the direction of the emission results. Since MOBILE6.2 emissions factors have been reviewed extensively, it is expected that their dependence on speed is more representative. However, this difference leads to an uncertainty in the emissions results.

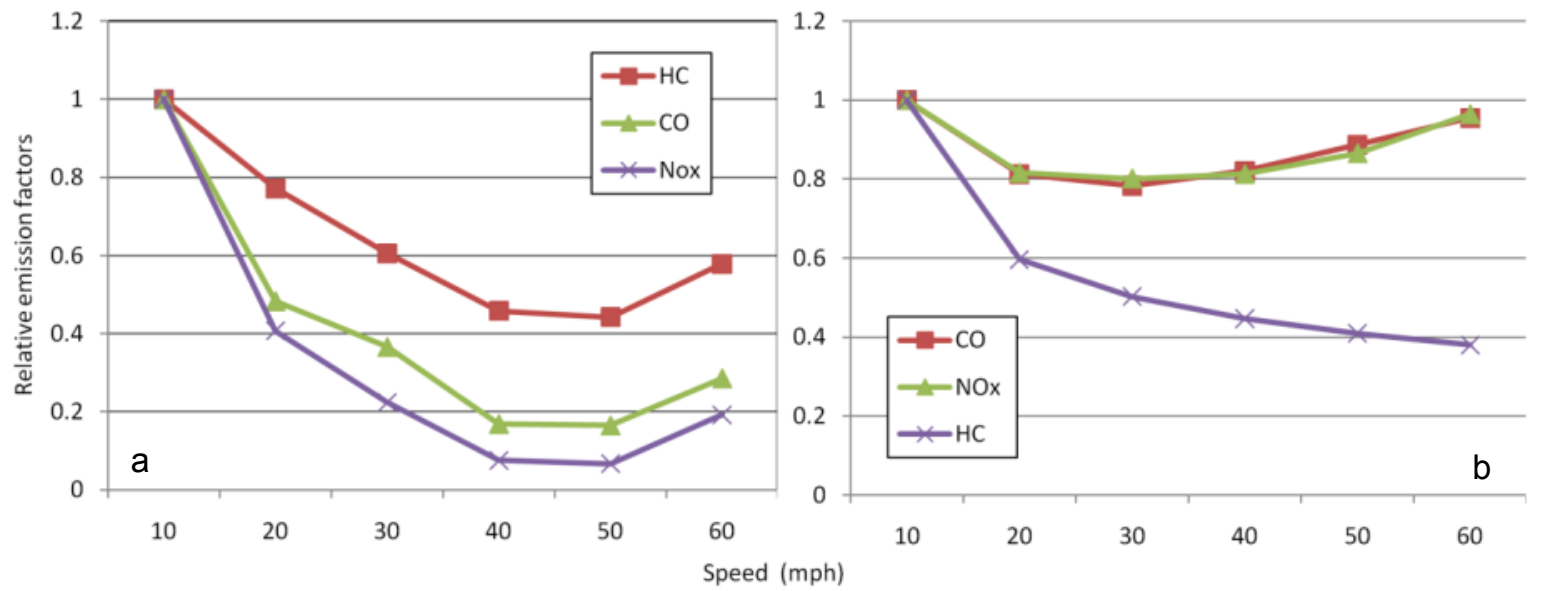

Figure 3-9. Relative emission factors for all vehicles from (a) CORSIM and (b) MOBILE6.2. Values are relative to value at $10 \mathrm{mph}$.

Vehicle type distribution also can affect emission factors. For the MOBILE6.2 estimation, average corridor vehicle distributions were used for all vehicles except buses to calculate emissions factors. (Buses were allocated only to the HOV and HOT lanes). In CORSIM, vehicle distributions can change temporally in each lane. If vehicles with higher emissions rates (e.g., trucks) are traveling in a manner different from other vehicles (i.e., on poorer-performing lanes) such that their speeds are significantly different from other vehicles, this could result in some error in emissions factor generation using an average corridor vehicle distribution. However, speed improvements seen in model results did not significantly affect the MOBILE6.2 emissions factors; hence, this is not expected to have a big impact. Additionally, although improvements in emissions for buses were found here, their contribution to the overall vehicle distribution is small enough that changes in their emissions do not have a significant impact on overall emissions changes.

The age of the fleet can affect emissions factors, as newer vehicles often have new technologies that reduce emissions. A large portion of the fleet in the study area consists of rental cars, which are replaced relatively quickly. Additionally, buses in Broward County also 
are replaced more quickly than in many areas. Therefore, emissions estimated using default fleet age characteristics may overestimate emissions for the study area (both before and after implementation of the managed lanes.)

In addition to emissions factors, uncertainties in estimated vehicle miles traveled can impact emissions. Although input vehicle volumes to CORSIM were kept constant between the baseline scenario and after scenario modeling, CORSIM is a stochastic model. This resulted in an increase in the total vehicle count during peak hours for the after scenario by 3.1 percent for the northbound direction and 1.9 percent for southbound direction. Increases in link vehicle volumes resulted in increases in estimated vehicle miles traveled. Increased VMT results in increased estimated emissions for the after scenario relative to the baseline case. More important, VMT on the corridor may change due to improvements in the corridor speed performance, as more vehicles will choose to use the corridor rather than surface streets. This effect could not be considered here, as vehicle volumes entering the corridor are an input parameter to corridor models like CORSIM. A model of the entire surrounding transportation network would be required to consider this impact. However, overall effects on emissions could be balanced due to decreases in emissions on other roadways.

\subsection{Summary of emissions calculations and results}

To calculate emissions changes associated with HOT lane implementation, transportation corridor micro-simulation modeling and emissions estimation were performed. CORSIM was selected as the transportation model and was used to simulate traffic conditions before the implementation of the HOT lane on I-95 (baseline scenario) and after the implementation of Phases $1 \mathrm{~A}$ and 1B of the project (after scenario). Results of the micro-simulation modeling indicate that the average speeds on the corridor were improved and congestion was reduced after HOT lane implementation. With regard to transit, bus travel times were improved.

Traffic condition and infrastructure data from CORSIM then were used to generate MOBILE6.2 emissions factors and to calculate emissions changes associated with the HOT lane implementation. Total estimated annual emissions of $\mathrm{CO}, \mathrm{NOx}, \mathrm{PM}_{10}$, and benzene showed small increases after the implementation of the HOT lanes, while HCs showed decreases. CO showed the highest percentage increase of 3.5 percent, while $\mathrm{HC}$ emissions decreased by 1.5 percent. Regarding transit specifically, emissions from buses decreased after the implementation of the HOT lane. The overall increased emissions for criteria pollutants were found to be due to modeled increases in corridor vehicle volumes and emissions factors. 
However, it should be noted that there is significant uncertainty in estimated vehicle volume changes. Overall, the magnitude of the emissions changes is small, with substantial uncertainty. 


\section{AIR QUALITY EFFECTS (OBJECTIVE 3): METHODS AND FINDINGS}

To investigate the impacts of the I-95 HOT lane project on air quality, changes in air pollutant concentrations due project implementation were estimated. Specifically, an atmospheric dispersion model was selected and used to simulated pollutant concentrations in the study area.

\subsection{Dispersion modeling methods}

\subsubsection{Review and selection of dispersion models}

Several atmospheric dispersion modeling systems were reviewed as candidate models for this work, including CALINE (3 and 4), CAL3QHC and CAL3QHCR, AERMOD, CALPUFF, and HYROAD. Characteristics of each model and previous performance for roadway modeling studies are discussed.

CALINE (3 and 4) are the third and the fourth generation steady-state Gaussian line source dispersion models developed by the California Department of Transportation. Both models can be used in uncomplicated terrains (Jungers et al. 2006). CALINE3 was designed to model inert pollutant concentrations within 150 meters of a roadway under free-flow conditions. Idling emission at intersections are not represented in the model. Up to 20 roadway links and 20 receptors can be used into CALINE3 (Benson 1979). CALINE4 extended the modeling distance to 500 meters and employed a mixing zone concept to characterize pollutant dispersion very close to roadways. Simple modeling options for intersections, street canyons, and parking facilities also have been incorporated into CALINE4 (Benson 1989). CALINE4 has the ability to model pollutants emitted from vehicle acceleration and deceleration; however, the algorithm does no fully represent current vehicle technology (Carr et al. 2007). CALINE3 and CALINE4 have been used to model roadway emissions for many years because they are very easy to use and have low computational requirements. Previous studies using CALINE (Marmur and Mamane 2003; Levitin et al. 2005; Jones et al. 1998) have show good performance, and modeling results have been evaluated (Jungers et al. 2006; Benson 1992). Limitations of CALINE 3 and 4 include the limited number of sources and receptors allowed, the small allowable size of modeling domain, and source elevation limitation to below 30 feet. The performance of both models is poor under low wind conditions (less than one $\mathrm{m} / \mathrm{s}$ ) (Benson 1992). Additionally, as steady-state models, they cannot capture fast varying atmospheric patterns.

CAL3QHC and CAL3QHCR are models based on CALINE3 with an added queuing algorithm at signalized intersections. CAL3QHCR additionally includes processing of meteorological data for 
a whole year, a complete mixing height algorithm, representation of variable traffic, and added concentration averaging algorithms (Eckhoff et al. 1995). Because these models are based on CALINE3, they also can be used to model inert pollutant concentration near roadways. However, they are also limited in the representation of the height of sources and very low wind speed conditions (Eckhoff et al. 1995). Additionally, the traffic delay and capacity data within the model are based on 1985 data, which may not be applicable for current conditions (Carr et al. 2007). The performance of these models is somewhat mixed in a number of studies. Some studies have obtained favorable results under open area and moderate traffic flow conditions (Abdul-Wahab 2004, Kho et al. 2007; Cain and Welch 2004). However, other evaluation studies have found the performance to be poor (Chen et al. 2008).

AERMOD is a steady-state Gaussian plume model developed by the USEPA and the American Metrological Society. It was designed to replace the ISCST3 model and is recommended by the EPA as a preferred model for dispersion modeling of inert pollutants under short range (up to 50 $\mathrm{km}$ ) and steady-state conditions (Jungers et al. 2006). AERMOD has several input data processors, including a meteorological data processor (AERMET), a terrain data processor (AERMAP), and a surface characteristics processor (AERSURFACE). AERSCREEN, a screening version of AERMOD, also is built into the model. In modeling scenarios involving terrain interaction and building downwash, BPIPPRIME is also available. AERMOD has the ability to model a combination of point, area, and volume sources under all terrain conditions, and it incorporates some state-of-the-science features such as a building wake algorithm (PRIME). An updated planetary boundary layer turbulence parameterization also enables the treatment of elevated sources and complex terrain. AERMOD is considered an accurate dispersion model for regulatory purposes (Jungers et al. 2006) and has been used in mobile source pollutant dispersion modeling in numerous studies (e.g., Radonjic et al. 2003; Cook et al. 2008; Wang et al. 2009; Venkatram et al. 2009). Comparison between AERMOD modeling results and monitoring results in these studies showed good agreement, generally within a factor of 2. Roadways are represented as area sources in these studies, with the length-towidth ratio kept below 10 in most studies. Comparison between AERMOD and ISCST3, a widely used historical dispersion model, also showed improved performance. However, for long-range pollutant transport and non-steady conditions, the CALPUFF model is recommended (Jungers et al. 2006).

CALPUFF is a non-steady state Lagrangian puff model. Although the model is privately owned and maintained, the USEPA recommends using CALPUFF for long-range pollutant transport 
and non-steady atmosphere patterns. Compared with other models discussed here, CALPUFF incorporates many enhanced features, including transport over water, coastal interaction, puff splitting, slug (elongated puff) transport, and wind shear effects. Because it is a non-steady state model, it is able to handle spatial and temporal varying metrological conditions (Scire et al. 2000). CALPUFF also has the ability to model simple chemical reaction mechanisms. CALPUFF has many pre- and post- processors, including CALMET, a meteorological preprocessor that provides hourly three-dimensional wind and temperature fields, and CALPOST, a post-processor for analysis of concentration. CALPUFF requires much more input data than the other models discussed here. Studies that have used CALPUFF for roadway modeling show mixed results. Modeled concentrations have been found to be within a factor of 2 of the monitored concentrations for some studies (Radonjic et al. 2003; Cohen 2004; Song et al. 2006), while results from other studies are less favorable (Hatzopoulou 2008). Due to the complexity of the model, more evaluation is needed in near field cases (Brode et al. 2008). HYROAD is an integrated model that includes a traffic module, an emissions module, and a dispersion module. The dispersion algorithm is based on CALPUFF (Carr et al. 2007). HYROAD was designed to predict hourly CO concentrations near intersections (up to 500 meters), but also can be used for other inert pollutants. The puff algorithms in HYROAD also include several features specifically designed for roadways, such as vehicle-induced flows, vehicle wake effects, and enhanced vertical dispersion over roadways. The traffic module in HYROAD is based on NETSIM (a part of the CORSIM model), which simulates individual vehicle drive patterns, including accelerations and decelerations. In the emissions module, MOBILE5 or MOBILE6 emission factors can be applied. Emission factors do not account for acceleration or deceleration rates, but are based on calculated average speeds on roadway links (Carr et al. 2002). Up to 60 receptors and 50 roadway links can be represented in HYROAD (Carr et al. 2002). According to Carr et al. (2007), HYROAD has shown better performance when compared with CAL3QHC. Limitations include the small spatial extent of the dispersion representation (less than 500 meters) and the limited focus on intersections. Additionally, HYROAD is a relatively new model, with few evaluation studies.

The focus of the current study is to investigate impacts of the managed lane project on air quality in the case study area. Therefore, a model capable of representing concentrations over a large area is needed. Several of the models reviewed here, including CALINE 3 and 4, CAL3QHC (and R), and HYROAD cannot represent concentrations over the study area domain. CALPUFF is a promising model for this type of analysis due to its enhanced features and ability 
to represent non-steady conditions. However, it is data and computationally intense, and the enhanced features likely are not necessary for understanding average conditions sought here. Additionally, it has not been adequately evaluated for near-field conditions. Therefore, AERMOD was chosen for this work due to its wide use and performance in air quality modeling of roadway emissions, its capabilities for modeling larger domains, and its lower computational and data requirements relative to CALPUFF.

\subsubsection{AERMOD dispersion simulations}

To determine impacts of the 1-95 managed lane project on air quality in the study area, AERMOD simulations were performed for both the baseline scenario and after scenario cases discussed previously. Several types of input data and processing were required. These include calculation of emissions sources, selection and processing of appropriate meteorological data, configuration of the receptor grid, and selection of appropriate dispersion parameters. Methods used are discussed below.

Pollutant emissions from the case study I-95 roadway section modeled by CORSIM were represented, as shown in Figure 4-1. The coordinates of all roadway link nodes were obtained from the CORSIM configuration and converted to UTM coordinates. Roadway links were input into AERMOD as area sources. Each roadway link was expanded to a rectangle, whose width was calculated using the number of lanes times the width of each lane. The length was set as the link length. A maximum aspect ratio of 10 was applied to each source (EPA 2004b), with links subdivided when necessary. The emission rates of each source for each pollutant modeled in the AERMOD simulation were set to vary by season and hour of the day. For each season, the daily emissions values discussed in Chapter 3 in the constituent months were averaged to obtain the average daily emissions for the season. The daily profile then was used to allocate the calculated daily emissions to each hour of the day.

For meteorological data, five years (2005-2009) of data from the Miami International Airport station were used to represent conditions in the study area. Surface monitoring data on temperatures, winds and cloud cover were retrieved from the Integrated Surface Hourly Database through the National Climatic Data Center (ftp://ftp.ncdc.noaa.gov/pub/data/noaa). Upper air sounding data on pressure, temperature, relative humidity, and upper-level winds were collected from NOAA/ESRL Radiosonde Database (http://www.esrl.noaa.gov/raobs/). The data were processed by AERMET to produce hourly resolved meteorological fields. 


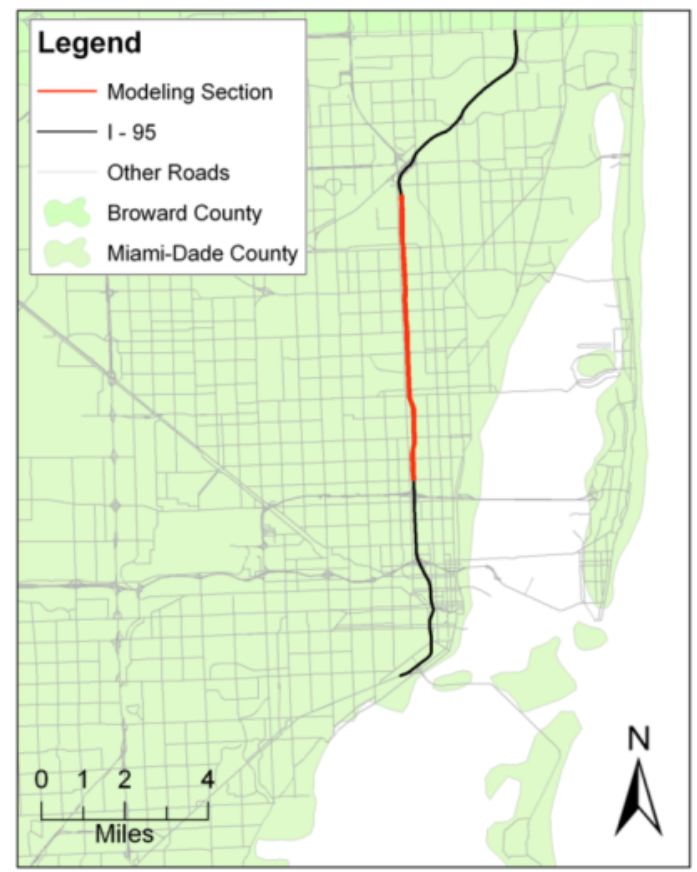

Figure 4-1. Section of I-95 modeled.

Necessary modeling parameters include the initial vertical dispersion parameter and surface characteristics. The initial vertical dispersion parameter was used to account for the initial mixing of the pollutants during emissions (EPA 1995), which can be important in situations where pollutants are mechanically generated, such as vehicle emissions (EPA 2004). A value of 2 was used consistent with previous literature (Venkatram et al. 2009). Surface characteristics such as noontime albedo, Bowen ratio, and surface roughness length were used to estimate boundary layer turbulence. The range of the three parameters and the values selected are shown in Table 4-1 (EPA 1999; EPA 2004; Paine 1987). In consideration of the sub tropical climate characteristics in Broward and Miami-Dade counties, a summer value of albedo and Bowen ratio were applied.

Table 4-1. Surface characteristic parameters

\begin{tabular}{l|l|l}
\hline Surface characteristics & \multicolumn{1}{|c}{ Range } & \multicolumn{1}{c}{ Value used } \\
\hline Albedo & 0.1 (thick forests) - 0.65 (fresh snow) & 0.16 (summer) \\
\hline Bowen ratio & 0.1 (over water) - 10.0 (desert) & 1 (summer) \\
\hline Surface roughness length & $0.01 \mathrm{~m}$ (calm water) - $1 \mathrm{~m}$ (forest or urban area) & 1 (urban) \\
\hline
\end{tabular}

The receptor grid provides the locations at which concentrations are calculated by AERMOD. It was chosen to cover Broward County and the northern part of Miami-Dade County, as shown in Figure 4-2. To characterize the pollution concentration near I-95, the receptor network was 
denser near to the roadway and less dense farther away. Maximum resolution was $100 \mathrm{~m}$ and minimum resolution was $5 \mathrm{~km}$.

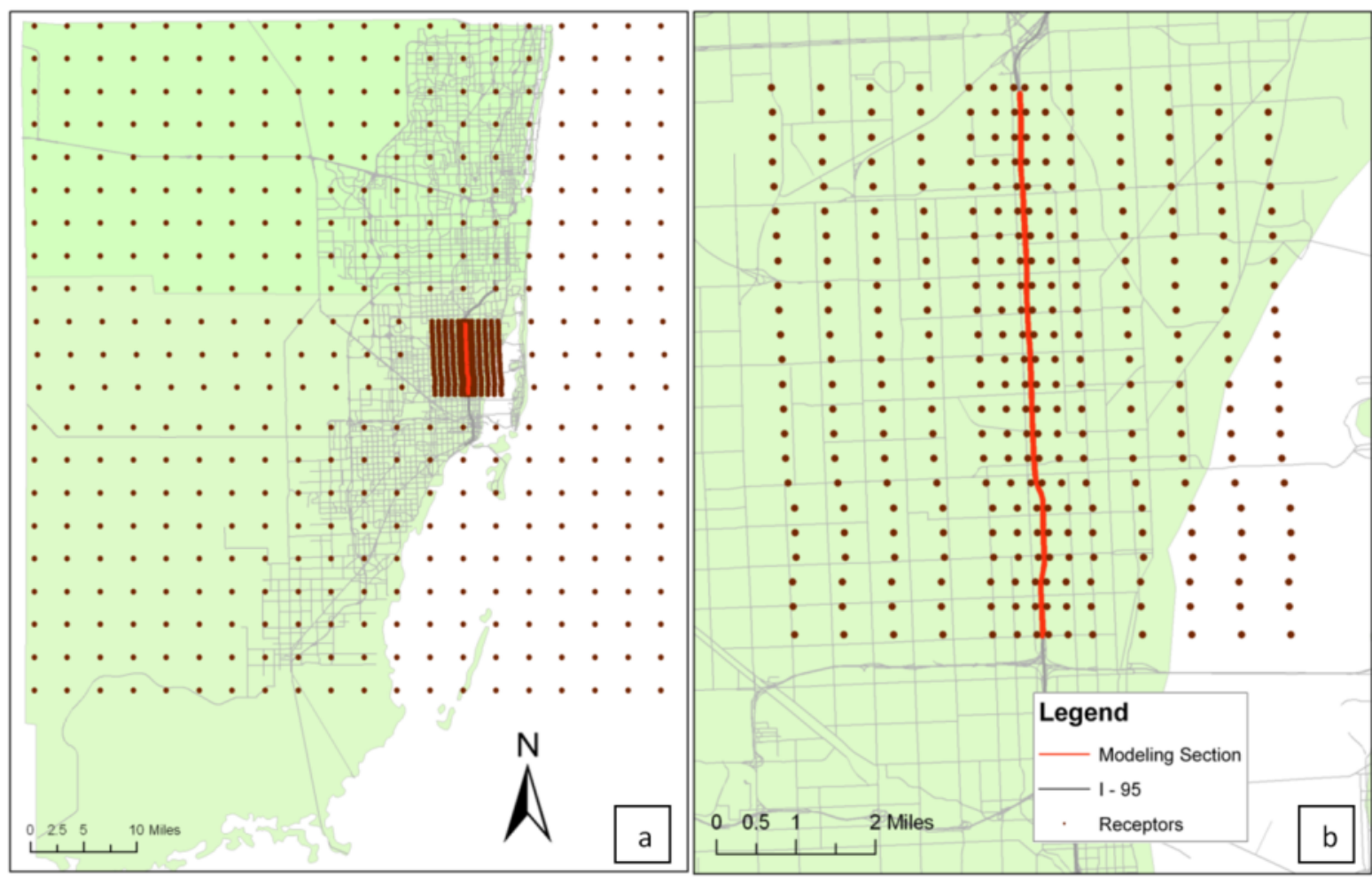

Figure 4-2. Receptor grid. Subplot a provides an overview of the receptors in the entire modeling domain, and $\mathrm{b}$ provides the network near the $1-95$ project section.

Once pre-processing and parameter selection were complete, AERMOD simulations were performed for each of the five years of meteorological data for both baseline and after scenario emissions. Concentrations of nitrogen oxides, carbon monoxide, and benzene were estimated. Specifically, the first and second highest one-hour average and eight-hour average concentrations, as well as annual average concentrations at each receptor location, were calculated and extracted from the model output. Differences between concentrations for the baseline and after scenario were also calculated. Results were interpolated and mapped using ArcGIS for analysis.

\subsection{Results: Estimated pollutant concentrations}

Table 4-2 and 4-3 provide a summary of estimated concentration ranges for the baseline and after scenarios for each pollutant. All estimated $\mathrm{CO}$ concentrations are well below regulatory standard levels. No standard level for $\mathrm{NO}_{\mathrm{x}}$ exists; however, in comparison to the $\mathrm{NO}_{2}$ standard level, most modeled levels are low, but the highest modeled one-hour average $\mathrm{NO}_{\mathrm{x}}$ values are of the same magnitude as the $\mathrm{NO}_{2}$ standard level. It should be noted that the percentage of 
$\mathrm{NO}_{\mathrm{x}}$ that is $\mathrm{NO}_{2}$ varies significantly; hence, this comparison does not imply that $\mathrm{NO}_{2}$ levels exceed the standard level. No comparable standard for benzene is available. An example modeled spatial distribution of pollutant concentrations is provided in Figure 4-3. The highest concentrations were found near to I-95 with decreasing concentration as distance to the roadway increased. Figure 4-4 provides the trend of domain-averaged concentrations for each meteorological year modeled. Concentrations generally decreased from 2005 to 2008, with higher concentrations again in 2009 for all pollutants. Increases in 2009 may be due to the large number of low wind speed hours in 2009.

Table 4-2. Range in modeled concentration in study area for each pollutant due to emissions from focus I-95 section before implementation of HOT lane project

\begin{tabular}{|c|c|c|c|c|c|c|}
\hline \multirow[t]{2}{*}{ Pollutant } & \multirow[t]{2}{*}{ NAAQS levels } & \multicolumn{2}{|c|}{$\begin{array}{c}\text { One-hour average }{ }^{a} \\
\left(\mu \mathrm{g} / \mathrm{m}^{3}\right)\end{array}$} & \multicolumn{2}{|c|}{$\begin{array}{c}\text { Eight-hour average }{ }^{a} \\
\left(\mu \mathrm{g} / \mathrm{m}^{3}\right)\end{array}$} & \multirow{2}{*}{$\begin{array}{c}\text { Annual } \\
\text { average } \\
\left(\mu g / m^{3}\right)\end{array}$} \\
\hline & & $1^{\text {st }}$ & $2^{\text {nd }}$ & $1^{\text {st }}$ & $2^{n d}$ & \\
\hline $\mathrm{CO}$ & $\begin{array}{l}10,000(8-\mathrm{hr}) \\
40,000(1-\mathrm{hr})\end{array}$ & $15-6,100$ & $10-4,800$ & $3-2,100$ & $2-1,900$ & $0.04-200$ \\
\hline $\mathrm{NO}_{\mathrm{x}}$ & Not applicable $^{b}$ & $1.5-440$ & $1-350$ & $0.3-170$ & $0.2-160$ & $0.004-19$ \\
\hline Benzene & Not applicable & $0.03-9.4$ & $0.03-8.1$ & $0.005-3.9$ & $0.004-3.4$ & $0.00008-0.4$ \\
\hline
\end{tabular}

${ }^{\mathrm{a}} 1^{\text {st }}$ and $2^{\text {nd }}$ refer to highest and second highest values, respectively, at receptor location over the five years of meteorological data. ${ }^{b}$ Standards do exist for $\mathrm{NO}_{2}$. Assuming standard ambient temperature and pressure, they are 100 and $188 \mu \mathrm{g} / \mathrm{m}^{3}$ for annual average and one-hour average, respectively.

Table 4-3. Range in modeled concentration in study area for each pollutant due to emissions from focus I-95 section after implementation of Phase 1A and 1B of HOT lane project

\begin{tabular}{|c|c|c|c|c|c|c|}
\hline \multirow[t]{2}{*}{ Pollutant } & \multirow[t]{2}{*}{ NAAQS levels } & \multicolumn{2}{|c|}{$\begin{array}{c}\text { One-hour average }{ }^{a} \\
\left(\mu \mathrm{g} / \mathrm{m}^{3}\right)\end{array}$} & \multicolumn{2}{|c|}{$\begin{array}{c}\text { Eight-hour average }{ }^{a} \\
\left(\mu g / m^{3}\right)\end{array}$} & \multirow{2}{*}{$\begin{array}{c}\text { Annual } \\
\text { average } \\
\left(\mu \mathrm{g} / \mathrm{m}^{3}\right)\end{array}$} \\
\hline & & $1^{\text {st }}$ & $2^{n d}$ & $1^{\text {st }}$ & $2^{n d}$ & \\
\hline $\mathrm{CO}$ & $\begin{array}{l}10,000 \text { (8-hr) } \\
40,000(1-\mathrm{hr})\end{array}$ & $15-6200$ & $10-4900$ & $3-2,100$ & $2-2,000$ & $0.05-230$ \\
\hline NOx & Not applicable & $1.5-450$ & $1-350$ & $0.3-168$ & $0.2-160$ & $0.004-19$ \\
\hline Benzene & Not applicable & $0.03-9.3$ & $0.02-7.7$ & $0.005-3.7$ & $0.004-3.4$ & $0.00008-0.4$ \\
\hline
\end{tabular}

${ }^{\mathrm{a}} 1^{\text {st }}$ and $2^{\text {nd }}$ refer to highest and second highest values, respectively, at receptor location over the five years of meteorological data. 


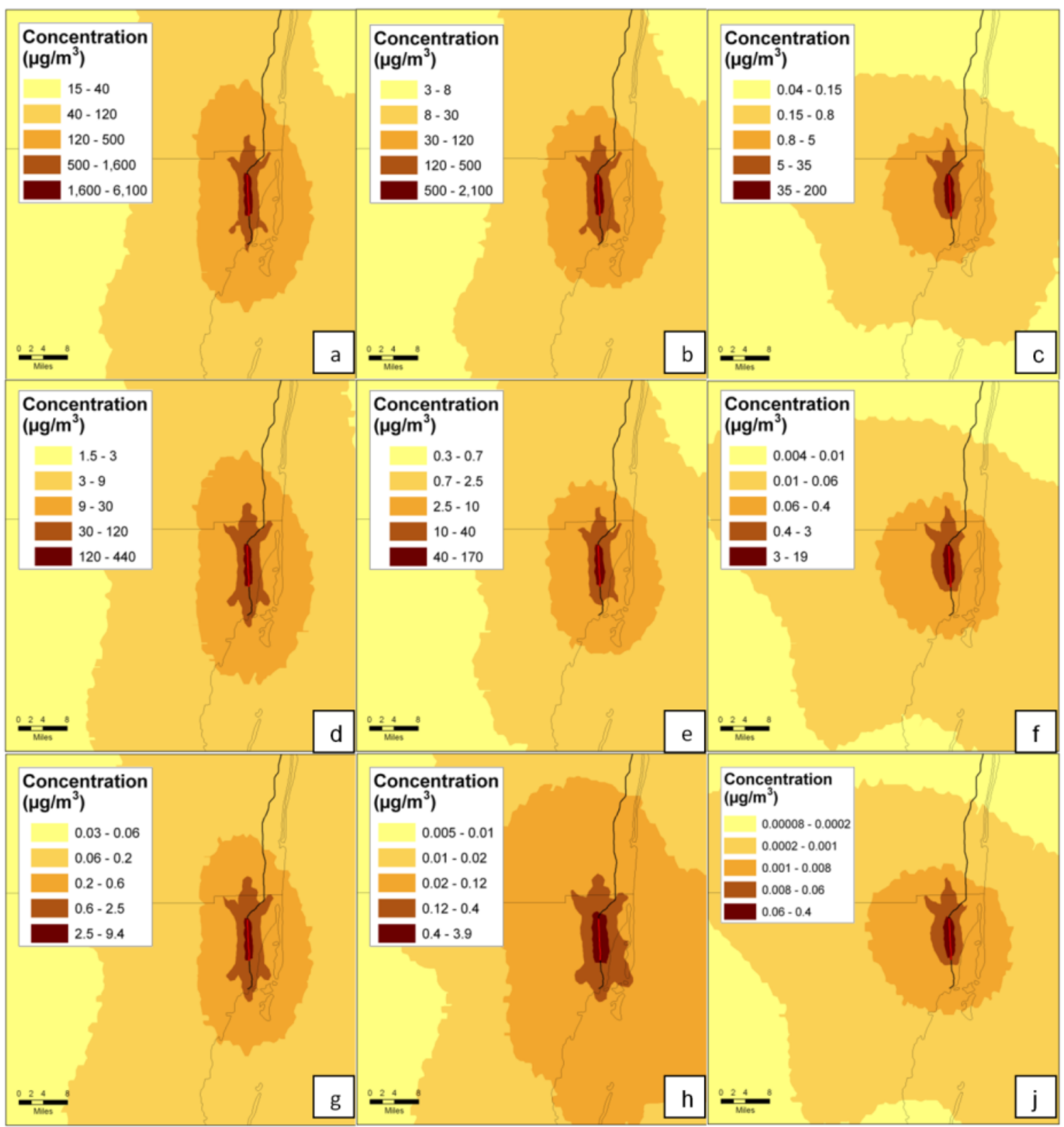

Figure 4-3. Modeled pollutant concentrations in study area due to emissions from focus I95 section prior to the implementation of HOT lanes project. Subplots a - $c$ are for $\mathrm{CO}, \mathrm{d}-\mathrm{f}$ are for NOx, and $\mathrm{g}-\mathrm{i}$ are for benzene. Concentration averaging times plotted are highest one-hour average (a, $d, g)$, highest eight-hour average (b,e, h), and annual average (c, f, i) over the five-year meteorological study period. 


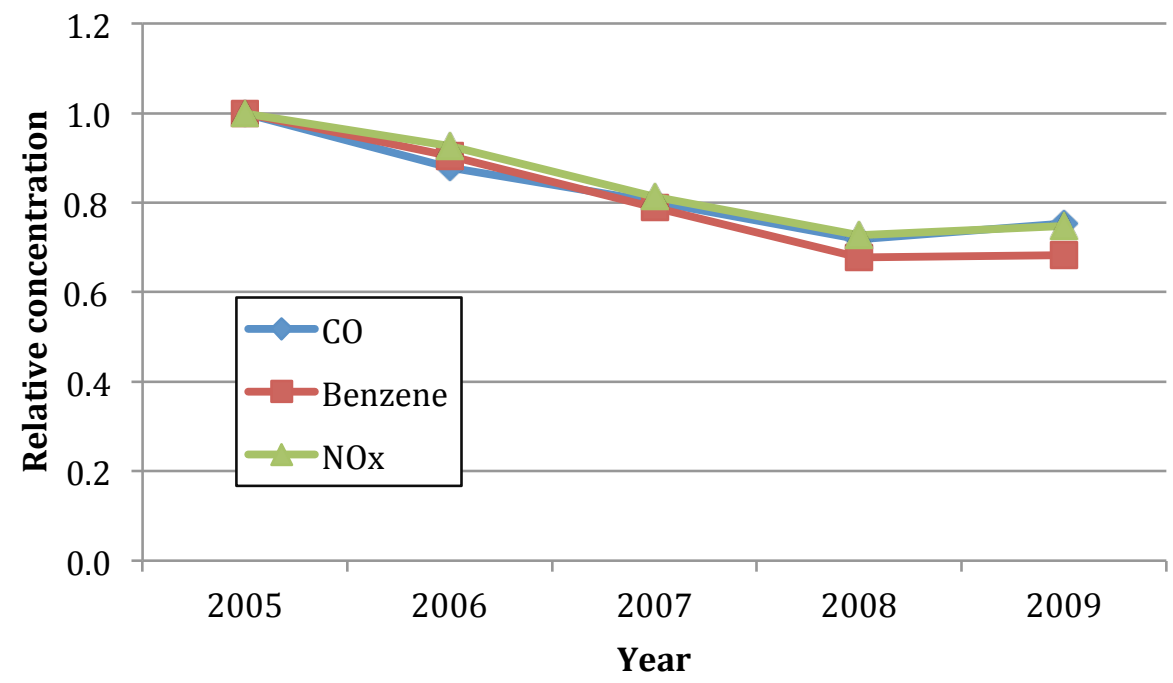

Figure 4-4. Domain average concentrations of the three pollutants from 2005 to 2009. Concentration shown is for baseline scenario. Due to wide range of concentration values, all values have been adjusted relative to values in 2005 to illustrate trend.

As an evaluation, the modeling results of carbon monoxide at the Annex monitoring site, which is located in close proximity to I-95, were compared with measured concentrations. The comparison is shown in Table 4-4. For the highest one-hour CO concentration, the modeled values are close to the measured values. However, the highest eight-hour modeled concentrations are substantially less than the measured concentration. These results are consistent as short-term averages (such as the one-hour) are expected to respond to high rush hour mobile source emissions nearby, leading to close approximation by the model. However, for longer averaging times (such as the eight-hour), the contribution of other sources in the county, not modeled here, likely becomes important. Hence, longer-term averages are expected to show lower concentrations for the modeled versus measured data. No evaluation for NOx and benzene could be performed due to lack of appropriate monitoring data.

Table 4-4. Comparison between modeled and measured highest one-hour $\mathrm{CO}$ concentration $\left(1^{\text {st }} 1 \mathrm{~h}\right)$ and highest eight-hour $\mathrm{CO}$ concentration $\left(1^{\text {st }} 8 \mathrm{~h}\right)$ at Annex monitoring site.

\begin{tabular}{l|c|c|c|c|c|c|c|c}
\hline & \multicolumn{2}{|c|}{$2005\left(\mu \mathrm{g} / \mathrm{m}^{3}\right)$} & \multicolumn{2}{c}{$2006\left(\mu \mathrm{g} / \mathrm{m}^{3}\right)$} & \multicolumn{2}{c}{$2007\left(\mu \mathrm{m} / \mathrm{m}^{3}\right)$} & \multicolumn{2}{c}{$2008\left(\mu \mathrm{g} / \mathrm{m}^{3}\right)$} \\
\cline { 2 - 9 } & Measured & Modeled & Measured & Modeled & Measured & Modeled & Measured & Modeled \\
\hline 1st 1h & 725 & 627 & 575 & 581 & 437 & 478 & 322 & 378 \\
\hline 1st 8h & 288 & 137 & 230 & 150 & 242 & 99 & 242 & 106 \\
\hline
\end{tabular}

To determine impacts on modeled concentrations of the implementation of the HOT lane project, concentrations for the after scenario were modeled and compared with baseline scenario concentrations. Absolute differences (after - baseline) averaged over the spatial 
domain are provided in Table 4-5. Example difference distributions are shown in Figure 4-5 through Figure 4-7. For all $\mathrm{CO}$ and NOx for the averaging times studied, modeled domain average concentrations increased slightly after the managed lane implementation versus before implementation. For benzene, the sign of the difference in domain average concentrations depends on the averaging time considered. Difference plots also indicate that differences are positive (higher for the after scenario) throughout most of the study domain. However, small negative differences were observed north of the focus I-95 section for all pollutants. An analysis of the vehicle miles traveled on the corridor indicates that these decreases are due to the spatial distribution of VMT. In the after scenario, the north section of the corridor experienced lower traffic volumes (and, hence, lower emissions). Overall, all difference were very small, representing less than 3 percent of the baseline scenario concentrations for all receptors.

Table 4-5 Domain-average ${ }^{\text {a }}$ differences in modeled pollutant concentrations for each pollutant due to implementation of HOT lane project.

Positive values indicate increases for after scenario, while negative values indicate decreases.

\begin{tabular}{l|c|c|c}
\hline Pollutant & $\begin{array}{c}\text { Highest } \\
\text { one-hour average } \\
\left(\mu \mathrm{g} / \mathrm{m}^{3}\right)\end{array}$ & $\begin{array}{c}\text { Highest } \\
\text { eight-hour average } \\
\left(\mu \mathrm{g} / \mathrm{m}^{3}\right)\end{array}$ & $\begin{array}{c}\text { Annual average } \\
\left(\mu \mathrm{g} / \mathrm{m}^{3}\right)\end{array}$ \\
\hline $\mathrm{CO}$ & 18 & 4.9 & 3.1 \\
\hline $\mathrm{NOx}$ & 1.1 & 0.27 & 0.033 \\
\hline Benzene & 0.0006 & -0.0013 & 0.0001 \\
\hline
\end{tabular}

${ }^{a}$ Simple domain average of concentration at all receptors in domain. Since receptor network is denser near roadway, concentrations near roadway carry heavier weight in average.
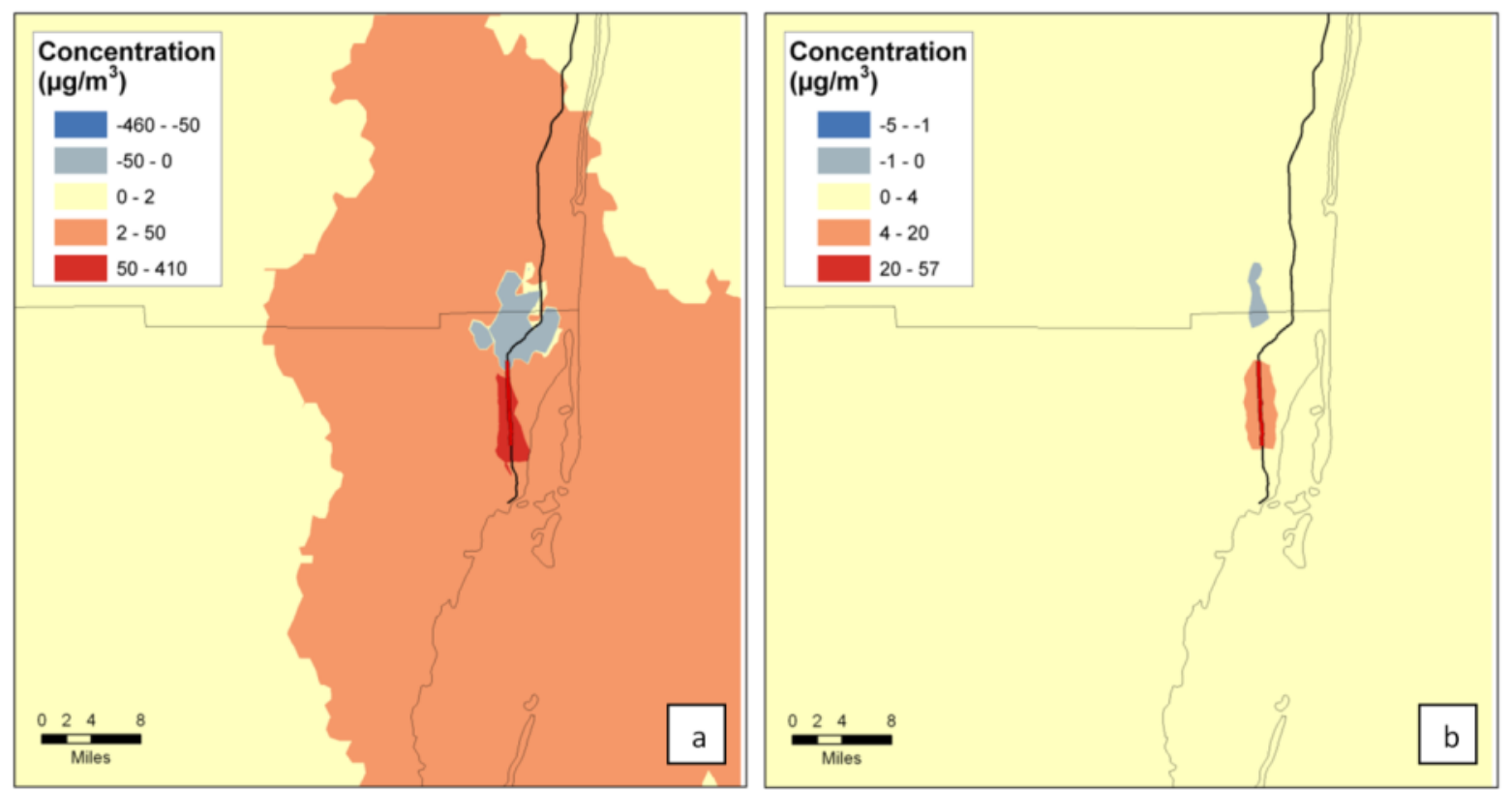

Figure 4-5. Estimated changes in carbon monoxide concentrations due to implementation of HOT lane project. Plots are interpolated from absolute differences at each receptor site for after scenario vs. baseline scenario. Subplot a provides change in highest one-hour average concentration, while subplot $b$ provides change in five-year average annual benzene concentration. 

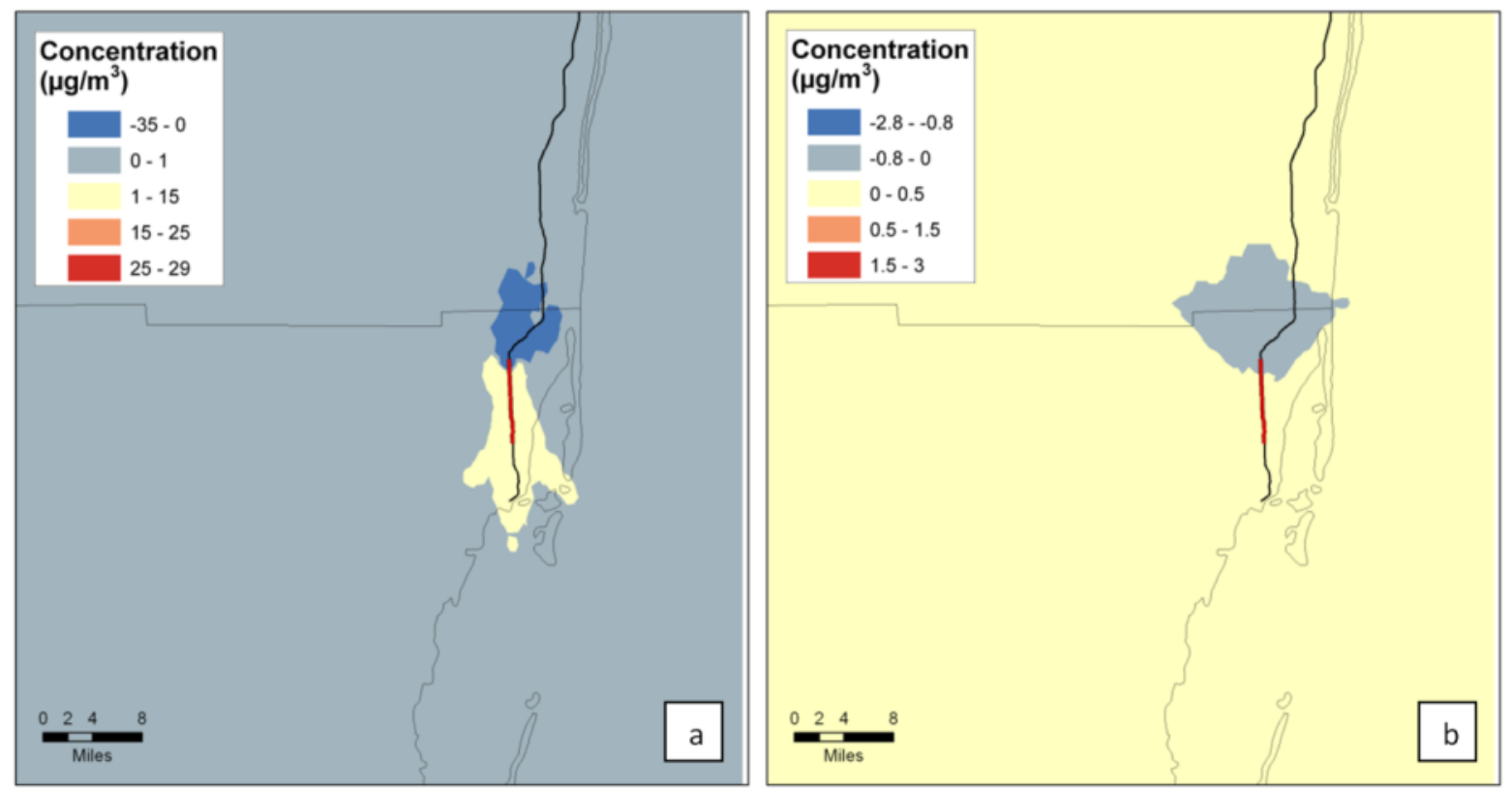

Figure 4-6. Estimated change in nitrogen oxides concentrations due to implementation of HOT

lane project. Plots are interpolated from absolute differences at each receptor site for after scenario vs. baseline scenario. Subplot a provides change in highest one-hour average concentration, while subplot b provides change in five-year average annual nitrogen oxides concentration.

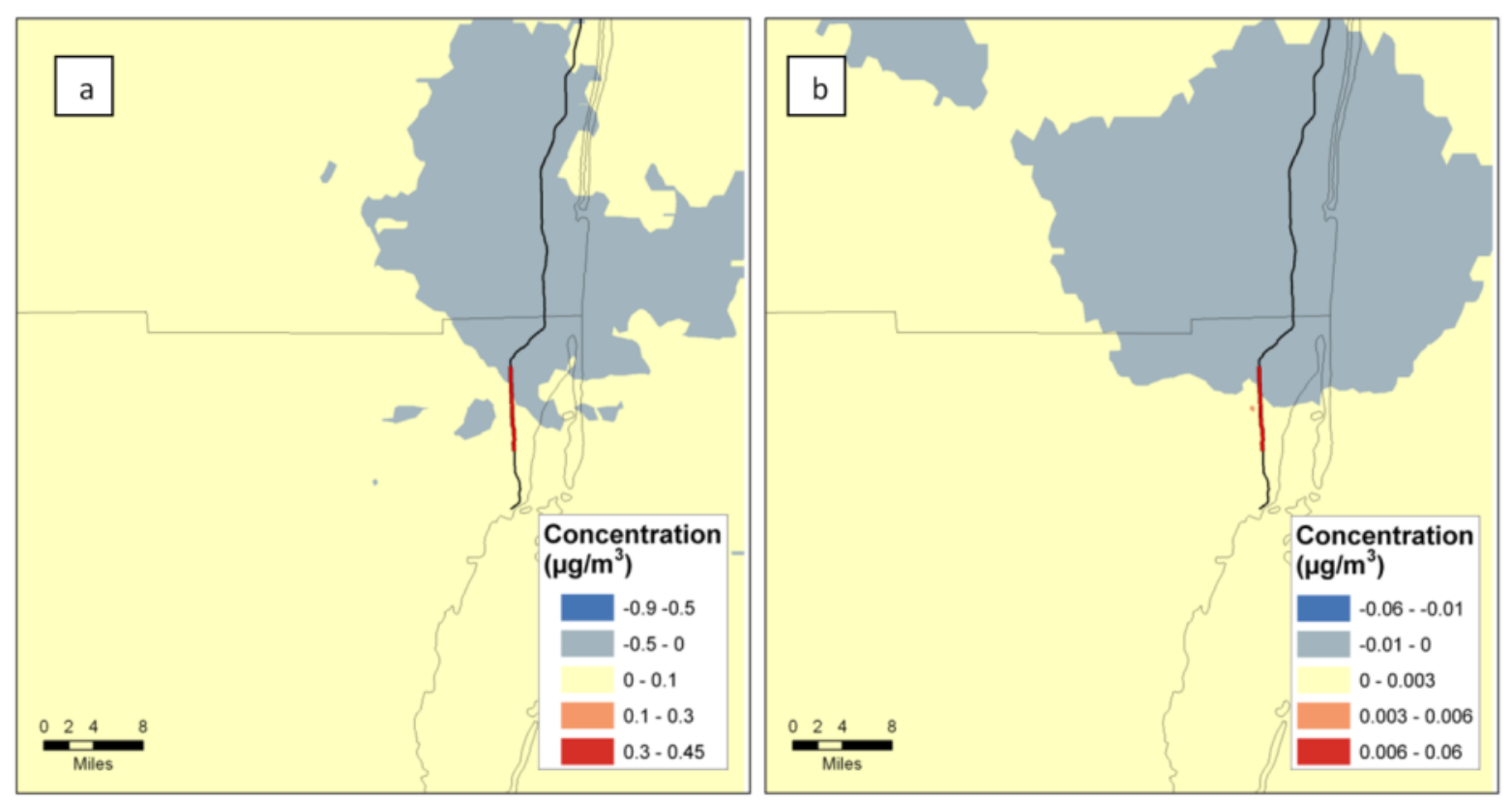

Figure 4-7. Estimated change in benzene concentrations due to implementation of HOT lane project. Plots are interpolated from absolute differences at each receptor site for after scenario vs. baseline scenario. Subplot a provides change in highest one-hour average concentration, while subplot b provides change in five-year average annual benzene concentration. 


\subsection{Summary and discussion of air quality results}

The AERMOD Gaussian dispersion model was selected and used to estimate pollutant concentrations in the study area due to emissions from the case study I-95 corridor.

Concentrations of carbon monoxide, nitrogen oxides, and benzene were estimated. AERMOD simulations were performed using emissions for the baseline scenario (before the implementation of HOT lanes on the corridor) and for the after scenario (after the implementation of Phases $1 \mathrm{~A}$ and $1 \mathrm{~B}$ of the HOT lane project). All modeled concentrations of $\mathrm{CO}$ were substantially lower than the comparable regulatory standard level. (No directly comparable standard exist for $\mathrm{NO}_{\mathrm{x}}$ or benzene.) As expected, concentrations near the emissions corridor were substantially higher than farther from the corridor. On average and throughout most of the study spatial domain, higher concentrations of $\mathrm{CO}$ and $\mathrm{NO}_{x}$ were estimated after HOT lane implementation, though the magnitude of the increase is small. Although concentrations of benzene also increased slightly in part of the study domain, a large area had decreasing concentrations. For all pollutants, concentrations near the north end of the corridor decreased due to a change in the spatial distribution of vehicle volumes. Overall, all concentrations differences between the after and baseline scenarios were small. 


\section{INTEGRATED DISCUSSION AND SUMMARY}

\subsection{Impact of the I-95 HOT lanes project on bus transit}

Corridor simulation results suggest improvement in corridor speeds after implementation of the HOT lanes, particularly in the northbound lanes during the afternoon peak hours. This reduction in congestion led to improved travel times for buses. It is expected that improved bus travel times could improve the perception and use of transit on the corridor.

\subsection{Impacts of the I-95 HOT lanes project on air quality}

The total annual estimated emissions of $\mathrm{CO}, \mathrm{NO}_{\mathrm{x}}, \mathrm{PM}_{10}$, and benzene showed slight increases after the implementation of the managed lane project. Emissions of HCs showed a slight decrease. Emissions changes were quite small, with the highest total emissions change for CO of 3.5 percent. For buses alone, total emissions decreased significantly after the implementation of the HOT lanes. Further analysis suggests that the link traffic volumes in the CORSIM modeling were slightly higher in the after scenario compared to the baseline scenario, contributing to the emissions change. Speed improvements on the corridor did not result in decreased overall MOBILE6.2 emissions factors. Emissions factors decreased on average for $\mathrm{HCs}$ and benzene only. Uncertainties regarding volume changes associated with HOT lane implementation, coupled with the small magnitude of estimated changes in emissions, suggest important uncertainties in the overall impacts of the project on emissions.

Consistent with the emissions results, modeled concentrations of $\mathrm{CO}$ and NOx showed slight increases after the HOT lane implementation throughout much of the study area. The benzene concentrations results are more mixed. The highest concentration differences were found close to the I-95 corridor for the shortest averaging times. Concentration to the north of the corridor deceased for all pollutant due to changes in the emissions distribution. Compared to the magnitude of the overall concentration values, the change in air quality due to the implementation of the management lane project is quite small.

\subsection{Implications for impacts of managed lane projects}

A purpose of managed lane projects is to encourage vehicle sharing and reduce congestion by applying access restrictions to certain lanes. Upon successful implementation, increases are expected for the average speed on the roadway and the percentage of high occupancy vehicles (and transit ridership) in the fleet. The results here are consistent with increases in roadway performance regarding speed, with concomitant improvements in transit bus travel times. 
Regarding air quality impacts, the increase of average speed on the roadways may lead to the reduction of mobile source emissions for some pollutants, but not all of them (USEPA 2002; Granell et al. 2004; Tang et al. 2004). Emissions of benzene, volatile organic compounds and particulate matter have shown a negative relationship with increasing average speed. Thus, reduction in congestion may lead to emission reduction for these pollutants. The correlations between speed and the emissions for other pollutants, such as carbon monoxide, are more complicated; the estimated all-vehicle average $\mathrm{CO}$ emission rate exhibited a minimum in the range of speeds found on the corridor studied here, resulting in increases on either side of that minimum. Regarding vehicle distributions, if vehicle sharing and transit ridership increase significantly due to the implementation of the managed lane project, the total VMT could decrease and the reduction of mobile source emissions could occur. However, significant mode change has not yet been observed substantially in many managed lane projects across the U.S. (discussed in Chapter 3); hence, these benefits are still unclear. More work is needed to understand mode share impacts.

\subsection{Issues with combining transportation modeling and air pollution methods}

Since transportation models and air quality models were developed out of separate disciplines for different purposes, their combination requires translation. For the purposes of air quality modeling, transportation modeling provides traffic information such as vehicle temporal behavior (e.g., speeds and vehicle flow rates) and characteristics (vehicle types) necessary for emissions estimation. Two issues were identified during the translation between CORSIM and MOBILE6.2/AERMOD. First, vehicle classification methods are different between the transportation simulation model and the emission estimation model. Better mapping of vehicle class distributions between models would be helpful for the emission estimation. Additionally, the time scales traditionally relevant to each type of study are distinct. CORSIM simulated traffic during rush hours. This is not sufficient for long-term air quality modeling purposes, which requires allocation of this short time scale data to the annual time scale. The extrapolation required introduces uncertainties in the emissions and concentration estimation.

\subsection{Final Summary}

The air quality and bus transit performance impacts of a case study managed lane project were studied. The case study project involved the implementation of HOT lanes on a corridor of I-95 near Miami. Conditions after Phase 1B of the project were compared to conditions prior to project implementation. Methods from the transportation and air pollution fields were combined to investigate impacts. Specifically, air quality monitoring data were collected from multiple 
agencies to analyze the baseline and temporal trends in air quality in Broward and Miami-Dade counties. Using corridor micro-simulation transportation modeling with CORSIM, traffic conditions before and after the implementation of the HOT lanes project were simulated. Corridor performance, with a particular focus on transit bus speeds and travel time, were analyzed. Using traffic data from the CORSIM simulation results and MOBILE6.2 emission factor estimation, emissions of $\mathrm{CO}, \mathrm{NO}_{x}, \mathrm{PM}_{10} \mathrm{HC}$, and benzene before and after the implementation of the HOT lane project were calculated. Dispersion modeling using AERMOD was performed for select pollutants to investigate the air quality impact of the managed lane project.

Air quality monitoring data were collected from reports and databases of relevant local to federal agencies. Monitoring data from 2000 through June 2009 of $\mathrm{O}_{3}, \mathrm{NO}_{2}, \mathrm{CO}, \mathrm{PM}_{2.5}$ and $\mathrm{PM}_{10}$, VOCs, and selected air toxics in Broward and Miami-Dade counties were compiled. Concentrations of pollutants other than $\mathrm{O}_{3}$ and $\mathrm{PM}_{2.5}$ were well below the comparable NAAQS levels. The highest measured concentrations of the latter two pollutants approached or slightly exceeded the standard levels at some monitors. Over the decade, an apparent decreasing trend in concentrations was observed for $\mathrm{CO}, \mathrm{NO}_{2}$, benzene, and 1,3-butadiene, while no apparent trends were observed for other pollutants.

Emissions from the study corridor of primary pollutants associated with vehicle sources (CO, $\mathrm{NOx}, \mathrm{PM}_{10}, \mathrm{HCs}$, and benzene) before and after the implementation of the managed lane project were calculated. Results of the corridor traffic simulations show improvements in the speed performance of the corridor, particularly in the northbound lanes during afternoon peak hours. Bus travel times, in particular, were reduced. Comparison of emissions before and after implementation of the HOT lane project indicates small increases in total emissions of all pollutants studied except HCs after the implementation of the project. However, differences are small with important uncertainties.

Concentrations of three select pollutants (CO, NOx, and benzene) resulting from corridor emission before and after the HOT lane implementation were estimated using AERMOD dispersion modeling. Differences in concentrations were small overall but indicate increases in the concentration throughout much of the study domain, with a small area of decreases near the north end of the study corridor. Concentrations and differences were largest near the I-95 corridor. Impacts for benzene were more mixed, with a large area of the domain experiencing decreased concentrations. Overall, results suggest relatively small impacts of the HOT lane project on air quality for this case study. 
Finally, methods for assessing air quality impacts of managed lane projects were developed and demonstrated here. Although useful and necessary for understanding general trends in air quality in the study area, available monitoring data did not clearly show an apparent signature of the managed lane project. In future work, comparative statistical analysis of time series data at select monitoring sites may be useful in attributing the trends found here. Conversely, the combination of corridor transportation modeling with air pollution modeling allowed estimation of highly-resolved spatial distributions of pollutant concentrations due the managed lane implementation. This approach likely would be useful for additional case studies under varying conditions, necessary for generalizability. Important sources of uncertainties in understanding and modeling air quality impacts of managed lane projects also were identified. Specifically, improvements in methods are needed for 1) estimation of network level impacts on vehicle volume redistribution, 2) emissions factor model representation of speed effects, and 3) tools for effectively translating between transportation and air pollution models. Nonetheless, the results found and methods demonstrated provide an important step towards understanding the impacts of managed lanes and other corridor-level projects on air quality. 


\section{REFERENCES}

Abdul-Wahab, S. A. 2004. An application and evaluation of the cal3qhc model for predicting carbon monoxide concentrations from motor vehicles ear a roadway intersection in Muscat, Oman. Environmental Management 34(3): 372-382.

Benson, P. E. 1979. CALINE3 - A versatile dispersion model for predicting air pollutant levels near highways and arterial streets. Office of Transportation Laboratory, California Department of Transportation.

Benson, P. E. 1989. CALINE4 - A dispersion model for predicting air pollutant concentrations near roadways. Division of New Technology and Research, California Department of Transportation.

Benson, P. E. 1992. A review of the development and application of the CALINE3 and CALINE4 models. Atmospheric Environment 26B-3, 379-390.

Brode, R. W., and B. Anderson. 2008. Technical Issues related to CALPUFF near-field applications. U.S. Environmental Protection Agency.

Burris, W. M., H. D. Ungemah, M. Mahlawat, and S. M. Pannu. 2009. Investigating the impact of tolls on high-occupancy-vehicle lanes using managed lanes. Transportation Research Record 2099: 113-122.

Burris, W. M., and R. Goel. 2010. Mode choice due to HOV to HOT conversions. Presented at 89th Transportation Research Board Annual Meeting, Washington D.C.

Cain, C. J., and S. Welch. 2004. Cal3qhcr modeling analysis for Missoula, Montana, redesignation to carbon monoxide NAAQS attainment. Retrieved from: http://www.co.missoula.mt.us/airquality/AirProgramProjects/CORedesignation/pdfs/Broo ksSouthRussellModelling.pdf.

Carr, E. L., R. G. Johnson, and R. G. Ireson. 2002. User's guide to Hyroad - The Hybrid Roadway Intersection Model. Systems Applications International, Inc., and KLD Associates, Inc.

Carr, E. L., D. A. Ernst, A. Rosenbaum, G. Glass, and S. Hartley. 2007. Analyzing, documenting, and communicating the impacts of mobile source air toxic emissions in the NEPA process. ICF International.

Chen, H., S. Bai, D. Eisinger, D. Niemeier, and M. Claggett. 2008. Modeling uncertainties and near-road PM2.5: A comparison of CALINE4, CAL3QHC and AERMOD. Retrieved from: http://aqp.engr.ucdavis.edu/Documents/2008-Chen-Dispersion-Model-Report-PMfinal.pdf.

Cohen, J., R. Cook, C. R. Bailey, and E. Carr. 2004. Relationship between motor vehicle emissions of hazardous pollutants, roadway proximity, and ambient concentrations in Portland, Oregon. Environmental Modeling and Software 20: 7-12.

Committee to Review EPA's Mobile Source Emissions Factor (MOBILE) Model. 2000. Modeling mobile-source emissions. Board on Environmental Studies and Toxicology, Transportation Research Board, National Research Council.

Cook, R., V. Isakov, J. S. Touma, W. Benjey, J. Thurman, E. Kinnee, and D. Ensley. 2008. Resolving local-scale emissions for modeling air quality near roadways. Journal of the Air \& Waste Management Association 58: 451-461.

Dierkers, G., E. Silsbe, S. Stott, S. Winkelman, and M. Wubben. 2002. CCAP transportation emissions guidebook - Part one: Land use, transit \& travel demand management. Center for Clean Air Policy. Retrieved from: http://www.ccap.org/images/guidebook/ CCAP_Transportation_Guidebook_Part1.pdf

Dowling, R., R. Ireson, A. Skābardonis, D. Gillen, and P. Stopher. 2005. Predicting Air Quality Effects of Traffic Flow Improvements. NCHRP Report 535. Washington D.C.: Transportation Research Board. 
Eckhoff, P. A., and T. N. Braverman. 1995. CAL3QHCR user's guide. office of air quality planning and standards. U.S. Environmental Protection Agency.

Evans J. J. 2009, Exploring travel preferences of transit and shared ride users in a proposed HOV to HOT conversion. Cambridge Systematic, Inc., TRB Planning Applications Conference, Houston, Texas.

Federal Highway Administration. 2003. FHWA guide for HOT lane development, FHWA-OP-030009, http://www.its.dot.gov/JPODOCS/REPTS_TE/13668.html, accessed March 3th, 2010.

Federal Highway Administration. 2007. Traffic analysis toolbox volume IV: Guidelines for applying CORSIM microsimulation modeling software. Retrieved from: http://ops.fhwa.dot.gov/trafficanalysistools/tat_vol4/vol4_guidelines.pdf.

Federal Transit Administration. 2009. Miami Urban Partnership Agreement (UPA) project phase $1 \mathrm{~A}$ - Transit evaluation report.

Florida Department of Environmental Protection. 2009. Broward County 2009 air monitor site. Retrieved from: http://www.dep.state.fl.us/air/FLAQS.

Florida Department of Transportation. 2009. Final 95 Express midyear report: Project status for Urban Partnership Agreement.

Georgia Transportation Partner Public Relations. 2010. Case study: California's SR 91 express lanes - First private, congestion-priced toll lanes reduce trip times in congested southern California. Retrieved from:

http://www.georgiatransportationpartners.com/case_study_sr91etl_lanes.pdf.

Godish, T. 2004. Air Quality - 4th Edition. Lewis Publishers.

Hatzopoulou, M. 2008. An integrated multi-model approach for predicting the impact of household travel on urban air quality and simulating population exposure. Department of Civil Engineering, University of Toronto.

Hinds, W. C. 1999. AerosolTechnology: Properties, Behavior, and Measurement of Airborne Particles. Second Edition. John Wiley \& Sons, Inc.

Jones, G., N. Gonzalez-Flesca, R. S. Sokhi, T. McDonald, and M. Ma. 1998. Measurement and interpretation of concentrations of urban atmospheric organic compounds. Environmental Monitoring and Assessment 52: 107-121.

Jungers, B. D., D. Niemeier, T. Kear, and D. Eisinger. 2006. A survey of air quality dispersion models for project level conformity analysis. Retrieved from: http://aqp.engr.ucdavis.edu/Documents/Dispersion-Model-Report-Fnl.pdf.

Kho, F. W. L., P. L. Law, S. H. Ibrahim, and J. Sentian. 2007. Carbon monoxide levels along roadway. Journal of Environmental Science and Technology 4(1): 27-34.

Kwon J., and P. Varaiya. 2006. Effectiveness of California's High Occupancy Vehicle (HOV) System. University of California, Berkeley. Retrieved from: http://paleale.eecs.berkeley.edu/ varaiya/papers_ps.dir/HOV_summitv6

Levitin, J., J. Harkonen, J. Kukkonen, and J. Nikmo. 2005. Evaluation of the CALINE4 and CARFMI models against measurements near a major road. Atmospheric Environment 39: 4439-4452.

Marmur A., and Y. Mamane. 2003. Comparison and evaluation of several mobile-source and line-source models in Israel. Transportation Research Part D: Transport and Environment 8(4): 249-265.

National Research Council. 2004. Air quality management in the United States. National Academies Press, Washington, D.C.

Nesamani S. K., L. Chu, G. M. McNally, and R. Jayakrishnan. 2006. Estimation of vehicle emissions by capturing traffic variations. Presented 86th TRB Annual Meeting, Washington, D.C. 
New Zealand Ministry for the Environment. 2000. Health effects of five common air contaminants and recommended protective ranges. Retrieved from: http://www.mfe.govt.nz/publications/air/5-common-air-oct00.pdf.

Orange County Transportation Authority. 2009. SR-91 Express Lanes in Orange County, California. Retrieved from: http://www.91expresslanes.com.

Paine, R. J. 1987. User's guide to the CTDM Meteorological Preprocessor (METPRO) Program. EPA-600/8-88-004, U.S. Environmental Protection Agency, Research Triangle Park, North Carolina.

Replogle, M. 1995. Appendix E. Minority statement. In Expanding Metropolitan Highways. Implications for Air Quality and Energy Use. Washington, D.C.: National Academy Press.

Radonjic, Z., D. B. Chambers, and J. Kirkaldy. 2003. Modelling line sources (roads) using CAL3QHCR, ISCST3, AERMOD and CALPUFF. Richmond Hill, Ontario, Canada: SENES Consultants Limited.

San Diego Area Transportation Partners. 2009. I-15 express lanes in San Diego, California. Retrieved from: http://fastrak.511sd.com.

Scire, J. S., D. G. Strimaitis, and R. J. Yamartino. 2000. A user's guide for the CALPUFF dispersion model (version 5). Earth Tech, Inc.

Sheng, W. W., X. Tang, Z. H. Fan, X. Wu, P. J. Lioy, and P. G. Georgopoulos. 2009. Modeling of personal exposures to ambient air toxics in Camden, New Jersey: An evaluation study. Journal of the Air \& Waste Management Association 59: 733-746.

Song, Y., M.Zhang, and X. Cai. 2006. PM10 modeling of Beijing in the winter. Atmospheric Environment 40-22: 4126-4136.

Sullivan, E. 2000. Continuation study to evaluate the impacts of SR-91 value-priced express lanes: Final report, 2000, Prepared for California State Department of Transportation, San Luis Obispo, California.

Transportation Research Board. 1995. Expanding Metropolitan Highways. Implications for Air Quality and Energy Use. Washington D.C.: National Academy Press.

Turner-Fairbank Highway Research Center. 2004. Traffic analysis toolbox volume III: Guidelines for applying traffic microsimulation modeling software. Federal Highway Administration, U.S. Department of Transportation.

University of Florida. 2008 CORSIM reference manual. McTrans.

U.S. Environmental Protection Agency. 1995. Industrial Source Complex (ISC3) Dispersion Model User's Guide - Volumes I and II. U.S. Environmental Protection Agency, Research Triangle Park, North Carolina.

U.S. Environmental Protection Agency. 1995. User's guide to CAL3QHC Version 2.0: A modeling methodology for predicting pollutant concentrations near roadway intersections. Office of Air Quality Planning and Standards.

U.S. Environmental Protection Agency. 1999. Compendium of methods for the determination of toxic organic compounds in ambient air - Second edition. Retrieved from: http://www.epa.gov/ttnamti1/files/ambient/airtox/tocomp99.pdf

U.S. Environmental Protection Agency. 1999. Meteorological Processor for Regulatory Models (MPRM) user's guide. U.S. Environmental Protection Agency, Research Triangle Park, North Carolina.

U.S. Environmental Protection Agency. 2001. Fleet characterization data for MOBILE6:

Development and use of age distributions, average annual mileage accumulation rates, and projected vehicle counts for use in MOBILE6. Retrieved from:

http://www.epa.gov/OMS/models/mobile6/r01047.pdf 
U.S. Environmental Protection Agency. 2004a. Technical guidance on the use of MOBILE6.2 for emission inventory preparation. Retrieved from:

http://www.epa.gov/otaq/models/mobile6/420r04013.pdf

U.S. Environmental Protection Agency. 2004b. User's guide for the AMS/EPA Regulatory Model - AERMOD. U.S. Environmental Protection Agency, Research Triangle Park, North Carolina.

U.S. Environmental Protection Agency. 2005a. EPA's National Inventory Model (NMIM), a consolidated emissions modeling system for MOBILE6 and NONROAD. Retrieved from: http://epa.gov/otaq/models/nmim/420r05024.pdf

U.S. Environmental Protection Agency. 2005b. Revision to the guideline on air quality models: Adoption of a preferred general purpose (flat and complex terrain) dispersion model and other revisions - Final rule.

Venkatram, A., V. Isakov, R. Seila, and R. Baldauf. 2009. Modeling the impacts of traffic emissions on air toxics concentrations near roadways. Atmospheric Environment 43: 3191-3199.

Wisconsin Department of Transportation, District 2. 2002. Freeway system operational assessment, paramics calibration and validation guidelines (draft), technical report I-33. 


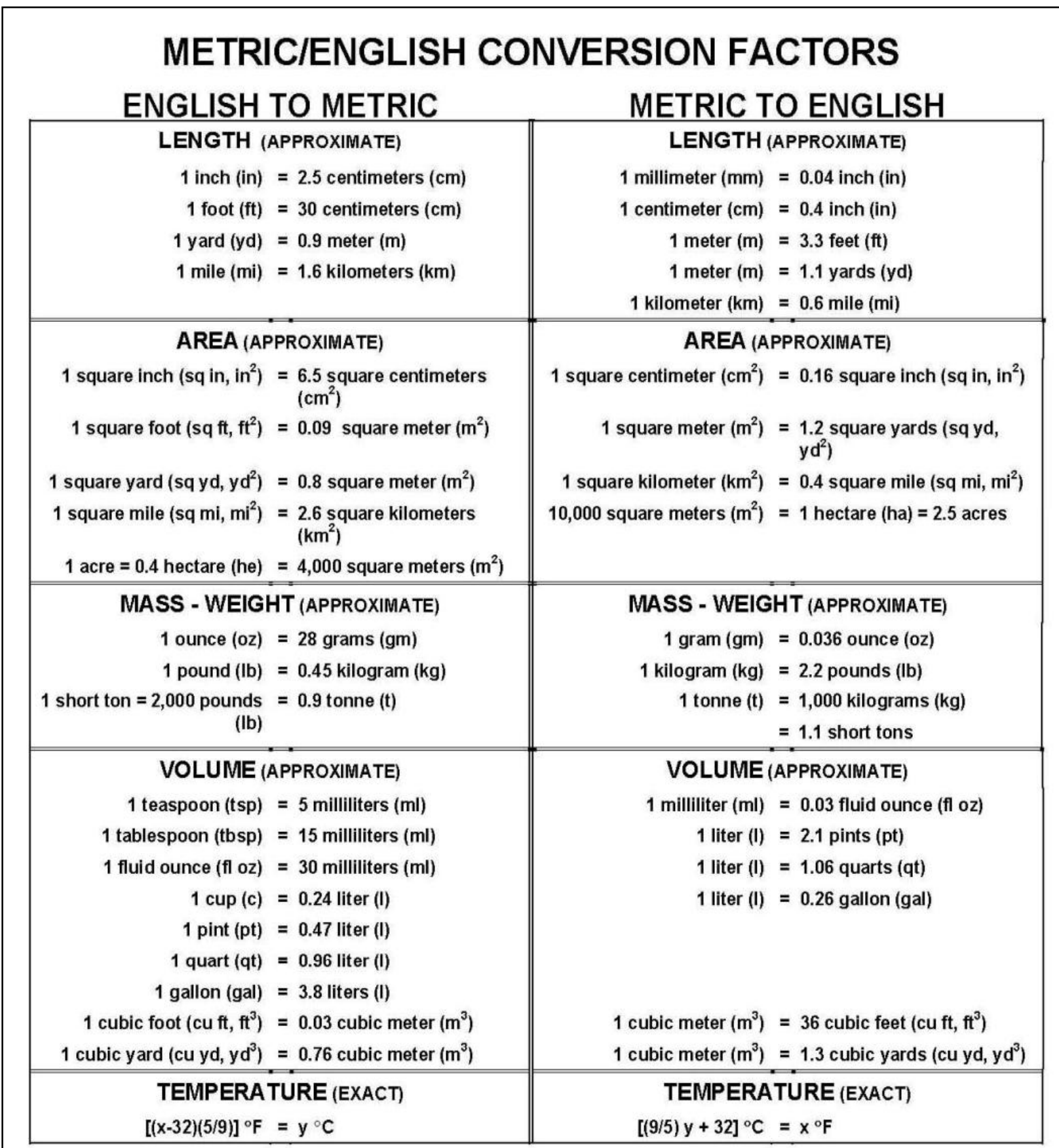

\section{QUICK INCH - CENTIMETER LENGTH CONVERSION}

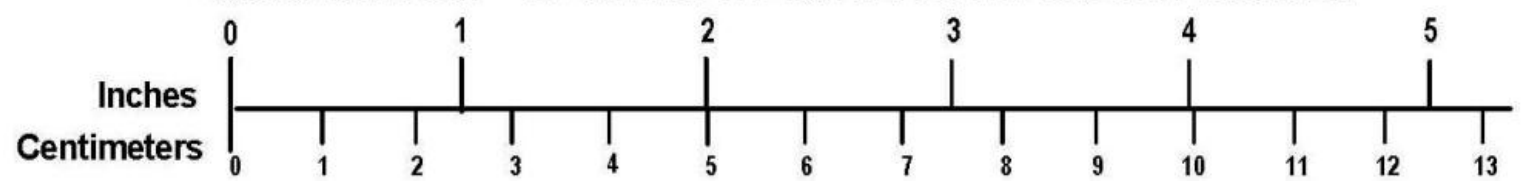

\section{QUICK FAHRENHEIT - CELSIUS TEMPERATURE CONVERSION}

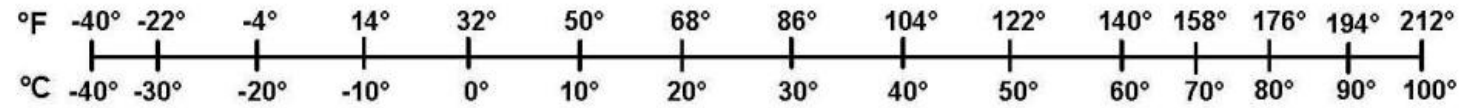

For more exact and or other conversion factors, see NIST Miscellaneous Publication 286, Units of Weights and Measures. Price \$2.50 SD Catalog No. C13 10286 